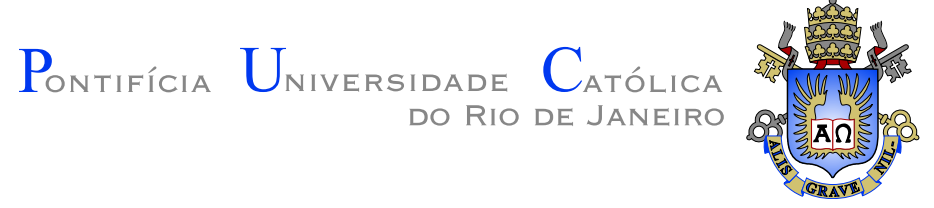

André de Souza Moreira

\title{
Engenharia Reversa em Modelos CAD Utilizando Descritores de Forma e Máquina de Vetores de Suporte
}

Dissertação apresentada como requisito parcial para obtenção do grau de Mestre pelo Programa de Pósgraduação em Informática do Departamento de Informática da PUC-Rio

Orientador: Prof. Marcelo Gattass 


\title{
André de Souza Moreira
}

\section{Engenharia Reversa em Modelos CAD Utilizando Descritores de Forma e Máquina de Vetores de Suporte}

\begin{abstract}
Dissertação apresentada como requisito parcial para obtenção do grau de Mestre pelo Programa de Pósgraduação em Informática do Departamento de Informática do Centro Técnico Científico da PUC-Rio. Aprovada pela Comissão Examinadora abaixo assinada.
\end{abstract}

Prof. Marcelo Gattass

Orientador

Departamento de Informática — PUC-Rio

Prof. Anselmo Cardoso de Paiva

Departamento de Informática — UFMA

Prof. Cristina Nader Vasconcelos Departamento de Informática - UFF

Prof. Waldemar Celes Filho Departamento de Informática - PUC-Rio

Prof. José Eugenio Leal Coordenador Setorial do Centro Técnico Científico PUC-Rio 
Todos os direitos reservados. É proibida a reprodução total ou parcial do trabalho sem autorização da universidade, do autor e do orientador.

\section{André de Souza Moreira}

Graduou-se no curso de Bacharelado em Ciência da Computação pela Universidade Federal do Maranhão em 15 de maio de 2013.

Ficha Catalográfica

Moreira, André de Souza

Engenharia Reversa em Modelos CAD Utilizando Descritores de Forma e Máquina de Vetores de Suporte / André de Souza Moreira; orientador: Prof. Marcelo Gattass. - Rio de Janeiro : PUC-Rio, Departamento de Informática, 2015.

v., 72 f: il. ; 29,7 cm

1. Dissertação (mestrado) - Pontifícia Universidade Católica do Rio de Janeiro, Departamento de Informática.

Inclui referências bibliográficas.

1. Informática - Tese. 2. Engenharia Reversa. 3. Modelos CAD. 4. Máquinas de Vetores de Suporte. 5. Descritores de Forma. I. Gattass, Marcelo. II. Pontifícia Universidade Católica do Rio de Janeiro. Departamento de Informática. III. Título. 


\section{Agradecimentos}

Gostaria de expressar os meus mais profundos agradecimentos:

Ao meu orientador, professor Marcelo Gattass, cuja paciência e conhecimento foram motivações importantes em todo o meu mestrado.

Ao professor Anselmo Cardoso de Paiva, pelo incentivo e por toda a atenção concedida, apesar da distância.

À minha família, especialmente meus pais, Raimundo e Bernadete, pelo estímulo, apoio incondicional e carinho.

À querida Patrícia Carrion, pelo companheirismo, compreensão e suporte.

À todos os meus amigos do CAE-Tecgraf, em especial aos do grupo Environ, pelo compartilhamento do conhecimento e experiências ao longo dos anos, assim como pela inspiração que originou a realização deste trabalho.

Ao CNPq, à PUC-Rio e ao Tecgraf, pelo auxílios concedidos, sem os quais este trabalho não poderia ser realizado. 


\section{Resumo}

Moreira, André de Souza; Gattass, Marcelo. Engenharia Reversa em Modelos CAD Utilizando Descritores de Forma e Máquina de Vetores de Suporte. Rio de Janeiro, 2015. 72p. Dissertação de Mestrado - Departamento de Informática, Pontifícia Universidade Católica do Rio de Janeiro.

Modelos CAD 3D têm desempenhado um importante papel no gerenciamento de projetos de engenharia. Em vários desses modelos é perceptível a presença de diversos objetos com representações implícitas sendo representados por malhas triangulares. Ainda que apropriada para o rendering, a utilização de malhas triangulares traz consigo algumas desvantagens, como a ambiguidade em objetos pouco discretizados. A engenharia reversa visa a reconstrução dessa representação discreta em sua representação contínua original. Neste trabalho, propomos uma metodologia para a reconstrução de geometrias em modelos CAD utilizando Support Vector Machines e Descritores de Forma.

\section{Palavras-chave}

Engenharia Reversa; Modelos CAD; Máquinas de Vetores de Suporte; Descritores de Forma; 


\section{Abstract}

Moreira, André de Souza; Gattass, Marcelo (advisor). Reverse Engineering for CAD Models Using Shape Descriptors and Support Vector Machine. Rio de Janeiro, 2015. 72p. MSc Dissertation Departamento de Informática, Pontifícia Universidade Católica do Rio de Janeiro.

3D CAD Models have played an important role in engineering projects' management. It is noticeable in many of these files the presence of several objects with implicit representation that end up being represented as triangular meshes. Although suitable for rendering, the triangular mesh representation brings some drawbacks, such as the ambiguity in objects with low discretization rate. The reverse engineering aims to reconstruct this discrete representation to its original continuous representation. In this work, we propose a novel methodology for geometry reconstruction in CAD models using Support Vector Machines and Shape Descriptors.

\section{Keywords}

Reverse Engineering; CAD Models; Support Vector Machines; Shape Descriptors; 


\section{Sumário}

1 Introdução $\quad 8$

1.1 Motivação $\quad 8$

1.2 Objetivos 11

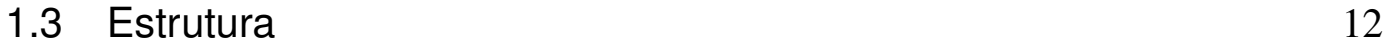

2 Trabalhos Relacionados $\quad 13$

3 Fundamentação Teórica $\quad 18$

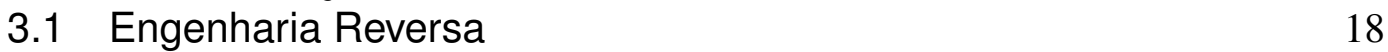

$\begin{array}{ll}3.2 & \text { Descritor de Forma } \\ 3.3 & 21\end{array}$

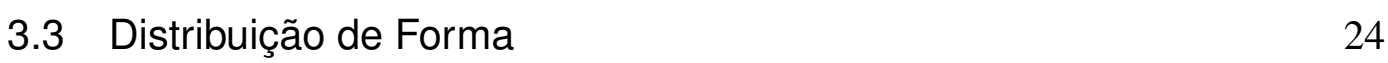

$\begin{array}{ll}3.4 \text { Curvatura } & 27\end{array}$

3.5 Aprendizagem de Máquina 29

4 Metodologia Proposta $\quad \mathbf{4 0}$

4.1 Classificação 40

4.2 Validação 49

4.3 Reconstrução $\quad 52$

5 Resultados Obtidos $\quad \mathbf{5 5}$

6 Conclusões e Trabalhos Futuros $\quad 67$

$\begin{array}{lr}\text { Referências Bibliográficas } & 69\end{array}$ 


\section{Introdução}

\section{1 Motivação}

A computação gráfica tem desempenhado papel fundamental na representação de objetos do mundo real, com a finalidade de guiar e dar suporte a atividades a serem realizadas. $\mathrm{Na}$ engenharia, por exemplo, a automação de projetos tem feito uso de ferramentas computacionais em processos que tem como base o uso de modelos CAD (Computer-Aided Design). Essa automação visa um maior nível de gestão de informação e de integração de disciplinas, que possibilitam um melhor planejamento das atividades, bem como redução de custos e cumprimento de tarefas dentro do prazo planejado (Koo e Fischer, 2000) e (Hartmann et al., 2008).

Grande parte dos modelos computacionais empregados nessas atividades apresentam alto grau de detalhes, com o propósito de representar com máxima fidelidade determinado cenário do mundo real (Figura 1.1). Ainda que os recursos computacionais tenham crescido significativamente nos últimos anos, a complexidade desses modelos resulta em desafios para o uso dos mesmos em ferramentas computacionais, tais como o armazenamento, a transmissão em rede de computadores e a própria visualização dos modelos.

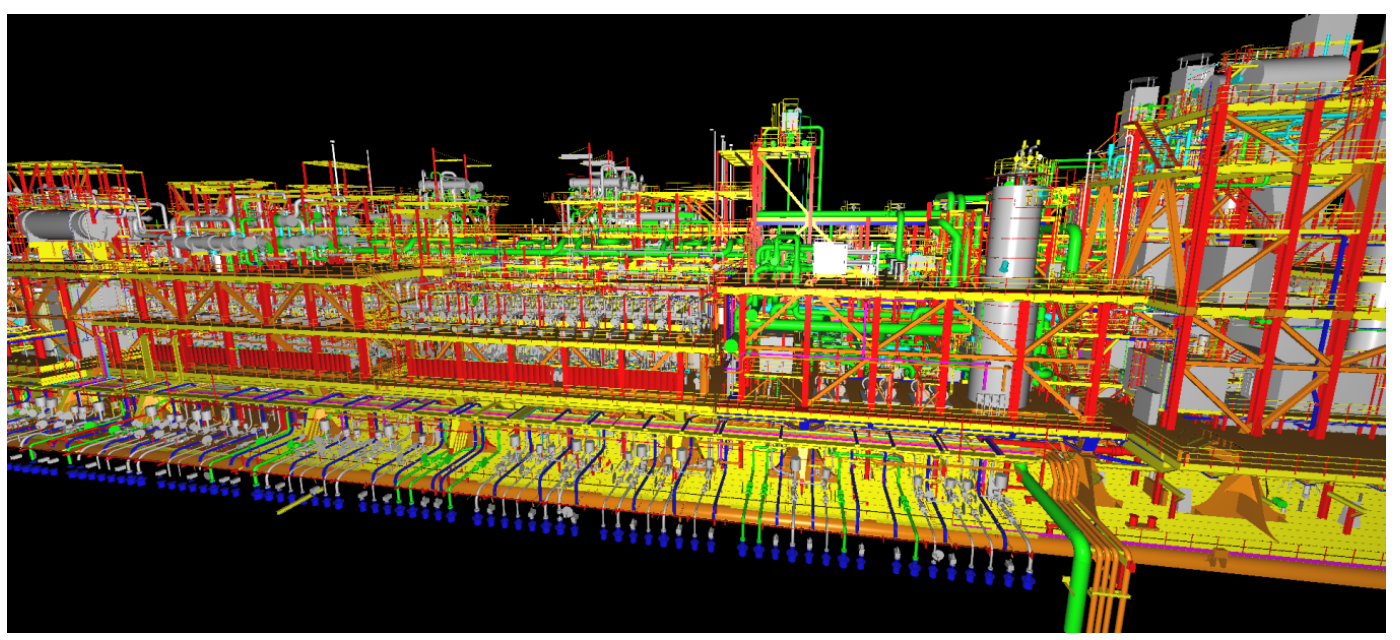

Figura 1.1: Modelo CAD de uma plataforma de petróleo composto por 35.183 .629 triângulos. 
As ferramentas utilizadas na criação de modelos CAD fazem uso de uma representação interna própria, porém, quando os modelos são exportados, grande parte dos objetos são discretizados em malhas triangulares. Outras ferramentas fazem o uso de uma abordagem híbrida, exportando partes do modelo como um conjunto de sólidos paramétricos e as demais partes como malhas de triângulo. Nesse processo de discretização, a representação original contínua do modelo é perdida, configurando-se um problema crítico em algumas atividades de engenharia. Nestas, a utilização da representação contínua proporciona a obtenção de resultados numéricos mais precisos, além de requerer menos tempo para que os resultados numéricos sejam obtidos.

Uma dessas atividades corresponde à manutenção da pintura da superfície de equipamentos. Em geral, as tintas utilizadas no processo de pintura desses equipamentos apresentam propriedades químicas especiais, aumentando assim o custo de mercado desses produtos. Assim sendo, é fundamental planejar corretamente a quantidade de material a ser gasto nessa operação para que não ocorram prejuízos. A representação contínua da superfície desses equipamentos possibilita a obtenção da área a ser pintada com maior precisão numérica e com menor custo computacional, uma vez que esta pode ser obtido de forma analítica. Em contrapartida, com a representação em malhas triangulares o mesmo resultado é obtido com o somatório da área de todos os triângulos que representam a superfície do equipamento.

Outra vantagem apresentada pela representação paramétrica decorre do fato dela ser mais compacta que a representação por malhas triangulares. Isso porque ela requer apenas um identificador do tipo do sólido e seus respectivos atributos, viabilizando assim o armazenamento e a transferência desses modelos. Técnicas de simplificação de malhas têm sido bastante exploradas para atingir o mesmo objetivo, contudo tais métodos acabam por degradar e suprimir informações relevantes, podendo gerar efeitos colaterais indesejáveis aos processos que utilizam tais informações. Mesmo técnicas específicas de simplificação de malha para modelos CAD nem sempre preservam todas as informações relevantes (Figura 1.2).

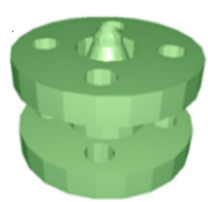

(a)

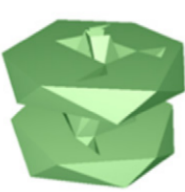

(b)

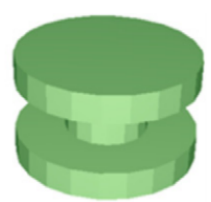

(c)

Figura 1.2: Resultados obtidos por técnicas de simplificação de malhas. (a) Malha de modelo CAD original; (b) Simplificação obtida por método tradicional de simplificação de malha; (c) Simplificação obtida por método específico para modelos CAD. (Gao et al., 2010) 
Em se tratando exclusivamente da visualização desses modelos, o uso da representação implícita também possibilita a renderização de todas as primitivas utilizando apenas uma única malha em memória de vídeo. Um grid regular por exemplo (Figura 1.3), pode ser deformado por meio da utilização das equações paramétricas de cada um dos sólidos. Devido à necessidade de se ter apenas uma única malha para a renderização de todos os objetos com representação implícita, o consumo da memória de vídeo é reduzido e o uso de rotinas custosas para transferência de dados da malha à placa de vídeo é minimizado.

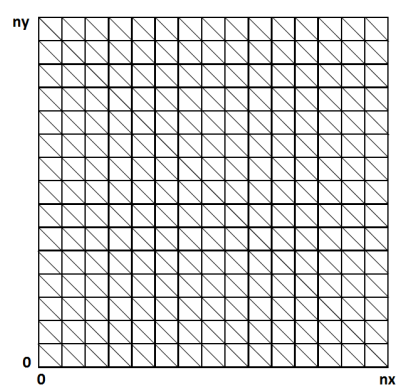

(a)

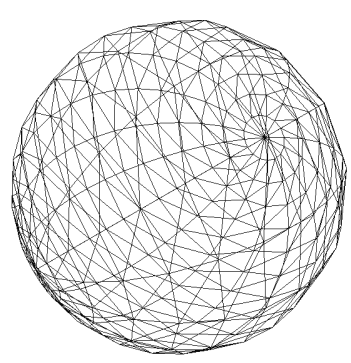

(b)

Figura 1.3: Resultado da aplicação da equação paramétrica da esfera em um grid regular. (a) Grid base usado para todas as primitivas; (b) Esfera resultante após o uso da equação paramétrica da esfera em a.

Todos esses fatores motivam a busca por novas abordagens em engenharia reversa, ou seja, técnicas que sejam capazes de extrair uma representação contínua a partir de uma representação discreta das superfícies de objetos. Alguns exemplos destes trabalhos são discutidos no próximo capítulo. Uma característica comumente observada em modelos CAD é que os mesmos apresentam em sua constituição um número significativo de sólidos geométricos bem definidos, tais como caixas, esferas, cilindros, entre outros. De acordo com (Hakala et al., 1981) e (Requicha e Voelcker, 1982), cerca de $95 \%$ dos objetos industriais podem ser descritos pela composição de planos, cones, esferas, cilindros e secções de torus, como pode ser observado na (Figura 1.4). 


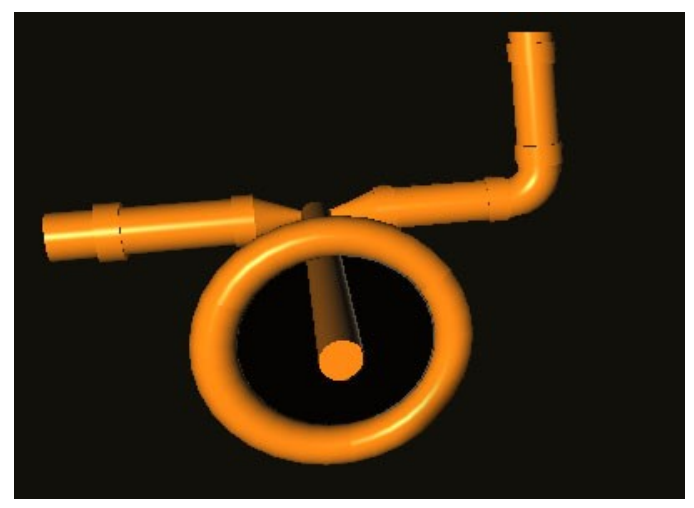

Figura 1.4: Exemplo de equipamento obtido em um modelo CAD constituído pela união de diversos sólidos geométricos, entre eles: torus circular, cilindro e cone.

Este trabalho apresenta uma metodologia de engenharia reversa para modelos CAD utilizando descritores de forma e aprendizagem de máquina. Para fins de validação, foram realizados testes em cenários controlados e também em modelos CAD reais. Os resultados obtidos nos casos controlados indicam a ausência de falsos positivos, enquanto que a técnica aplicada em modelos CAD reais proporcionou uma redução do tamanho do arquivo de aproximadamente $65 \%$. Além desses fatores, outra grande contribuição deste trabalho reside na invariância à configuração da malha dos objetos, diferente das técnicas já existentes, onde a triangulação da malha dos objetos influencia diretamente nos resultados obtidos.

\section{2}

\section{Objetivos}

\subsection{1 \\ Objetivos Gerais}

Este trabalho visa a elaboração de uma metodologia de engenharia reversa para a extração da representação paramétrica de objetos que estão representados como malhas de triângulos em modelos CAD. Este trabalho considera sólidos paramétricos como sendo os que podem ser descritos por um identificador de classe do sólido e seus atributos intrísecos, como o raio no caso da esfera. As classes de sólidos abordadas são: esfera, tronco de cone, cilindro, tronco de pirâmide, esferoide oblato e caixa (paralelepípedo reto). Tais procedimentos serão utilizados em modelos CAD de plataformas e refinarias de petróleo, a fim de reduzir o tamanho da representação dos objetos presentes nestes modelos.

\section{2 .2}




\section{Objetivos Específicos}

Uma desvantagem das técnicas já existentes de engenharia reversa consiste na sensibilidade à triangulação da malha. Portanto, a técnica aqui apresentada busca utilizar procedimentos que não dependam da configuração da malha. Para tanto, é feita uma avaliação do uso de descritores de forma que atendam esta característica. A classificação dos vetores de característica é realizada através das Máquinas de Vetores de Suporte.

Espera-se, desse modo, obter um classificador genérico o suficiente para a obtenção de resultados com boa taxa de acurácia, mesmo quando submetidas novas instâncias de objetos. Contudo, a formulação das Máquinas de Vetores de Suporte considera problemas que envolvem a classificação de duas classes. Logo, também é necessário avaliar as generalizações das Máquinas de Vetores de Suporte para problemas multiclasses. É desejável, por fim, minimizar a ocorrência de resultados errôneos, em especial os falsos positivos de sólidos paramétricos, uma vez que estes resultados mudam a superfície dos sólidos avaliados.

Está fora do escopo deste trabalho a elaboração e utilização de técnicas de segmentação, visto que este tópico por si só representa uma vasta área de pesquisa, além de que grande parte dos modelos CAD já dispõem de suas primitivas segmentadas.

\section{3 \\ Estrutura}

Os próximos capítulos estão organizados da seguinte forma: no Capítulo 2, são apresentados os trabalhos relacionados acerca de engenharia reversa em modelos CAD. Neste, são abordados os pontos positivos e negativos de cada um desses modelos. No Capítulo 3, são discutidos os principais fundamentos teóricos envolvidos na elaboração deste trabalho. É feita uma apresentação das técnicas de engenharia reversa e dos desafios existentes, além de ser apresentado um detalhamento sobre descritores de forma - possibilitando, assim, a discussão da adoção de métodos capazes de caracterizar cada uma das formas de modo unívoco. Ainda neste capítulo, as Máquinas de Vetores de Suporte são introduzidas, bem como a generalização dessa técnica para problemas multiclasses. O Capítulo 4 detalha precisamente cada uma das etapas da técnica de engenharia reversa proposta e, no 5, são apresentados os resultados obtidos com a metodologia. No Capítulo 6 , são feitas as considerações finais acerca dos objetivos esperados, os resultados obtidos e propostas de melhorias. 


\section{2 \\ Trabalhos Relacionados}

Há diversos trabalhos realizados a respeito de métodos de engenharia reversa, devido à vasta utilização destes em várias áreas de pesquisas. Entre elas, podemos citar: reconstrução de superfícies, simplificação de geometria, shape matching e shape retrieval, entre outras. Além disso, as etapas de engenharia reversa muitas vezes têm interesse em comum com outros tópicos de pesquisa. Por exemplo, a formulação de um framework de busca em uma base de sólidos 3D em muito se assemelha à fase de classificação de um processo de engenharia reversa.

Em (Benko et al., 2002) é utilizada a coplanaridade entre triângulos vizinhos como critério para a segmentação das malhas. Para cada uma dessas malhas é feito um ajuste da superfície com um plano. Caso não seja possível realizar o ajuste do plano utilizando um limiar de erro, então o ajuste é realizado novamente com primitivas geométricas mais complexas, tais como: cilindro, esfera, entre outros. Assim, o autor não realiza uma classificação direta, mas sim testa todas as possibilidades de sólidos para ver qual se adequa melhor. Essa abordagem é propensa a erros na classificação dos sólidos devido a possibilidade de representações ambíguas (Figura 2.1).

Em (Toledo et al., 2008) é feito um estudo sobre dois métodos para a recuperação de superfícies implícitas (cilindro, torus e cone) a partir de um modelo CAD: um método numérico e outro por meio de abordagem topológica. O método numérico consiste no ajuste de superfícies quádricas através de mínimos quadrados, para a obtenção de uma superfície quádrica parametrizada por dez coeficientes. Nesta etapa também são utilizadas as normais dos vértices, afim de eliminar resultados ambíguos (Figura 2.1). A segunda etapa consiste em classificar o tipo de quádrica obtida na etapa anterior avaliando os coeficientes obtidos dessa quádrica. Tal classificação é realizada de acordo com invariantes geométricos das mesmas (Cai et al., 1996). Por último, tem-se a reconstrução da superfície de entrada, isto é, a aquisição dos parâmetros que definem o sólido classificado na etapa anterior. Cada classe de sólido possui uma abordagem diferente nessa etapa final: o cilindro, por exemplo, consiste na identificação de dois pontos extremos e o raio do cilindro. 

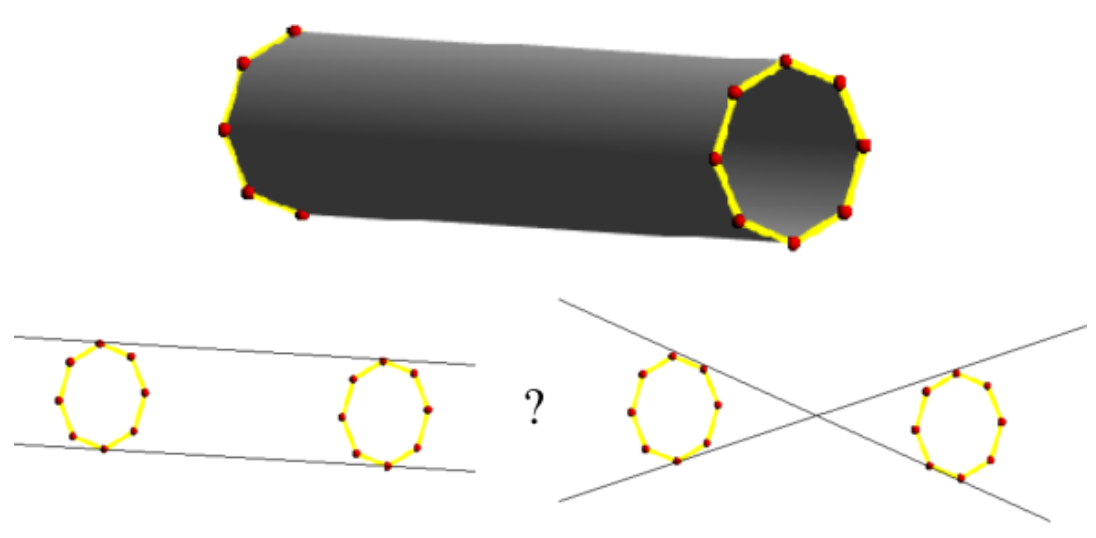

Figura 2.1: Topo: cilindro original composto por 16 vértices. Ambiguidade entre cilindro ou cone no processo de ajuste da superfície decorrente da pouca representatividade dos 16 vértices. (Toledo et al., 2008)

Contudo, a forte dependência das normais dos vértices no processo de ajuste da quádrica faz com que esta etapa falhe quando essas normais não estão devidamente configuradas. Tal ocorrência é bastante comum em regiões de transição de uma classe de sólido para outra, visto que, em geral, as normais dos vértices nessas regiões são obtidas pela média aritmética das normais das faces vizinhas. Como pode ser visto na Figura 2.2, os vértices compartilhados pelo torus e o cilindro não apresentam a normal perpendicular à direção principal do cilindro.

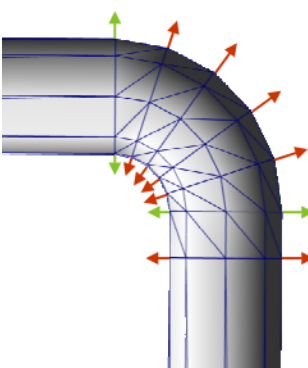

(a)

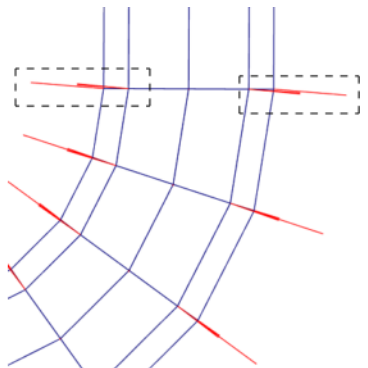

(b)

Figura 2.2: Problema na estimativa das normais em regiões de transição. Em 2.2(a) as normais em verde são compartilhadas entre cilindro e torus. A ampliação desta região, em 2.2(b), demonstra a não perpendicularidade destas normais com o eixo principal do cilindro (Toledo et al., 2008).

A abordagem topológica faz uma análise da malha de triângulos a fim contornar os problemas enfrentados na abordagem numérica. A ideia básica deste método consiste em encontrar regiões circulares regulares e na análise de suas conectividades. Inicialmente, é realizada uma série de reparos na malha de entrada, tendo como propósito a eliminação de triângulos isolados, degenerados, triângulos repetidos, entre outros. Cada classe de sólido é inferida de um modo peculiar. No caso particular do cilindro, o mesmo é obtido quando é encontrado uma 
sequência de regiões anelares consecutivas com o mesmo raio. Nessa circunstância, a reconstrução é direta, visto que o raio do cilindro é igual ao raio dos anéis, e a altura dá-se pela distância entre o primeiro e o último anel encontrado. Contudo, a abordagem topológica demonstra-se extremamente dependente da triangulação da malha, como pode ser visto na Figura 2.3. Para que a abordagem topológica produza bons resultados, é necessário que as arestas da malha formem círculos regulares, uma vez que esta abordagem baseia-se na procura destes círculos.

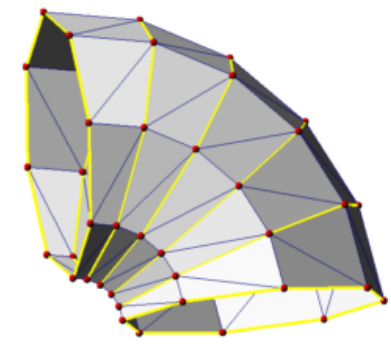

(a)

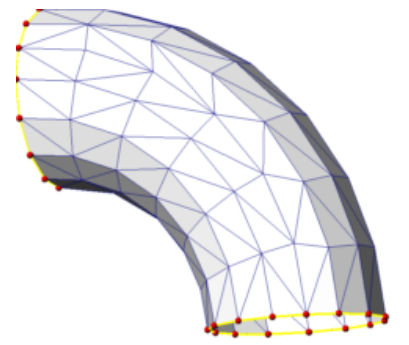

(b)

Figura 2.3: Dependência da abordagem topológica à triangulação da malha. A triangulação da malha em 2.3(a) forma os círculos necessários na abordagem topológica. Diferentemente, em 2.3(b) a ausência de círculos regulares não permite a aquisição de bons resultados (Toledo et al., 2008).

Em (Bénière et al., 2011), a segmentação e detecção de planos, esferas, cones e cilindro de malhas de modelos CAD são realizadas com base nas curvaturas principais das superfícies, $K_{m}$ in e $K_{m} a x$, assim como as suas respectivas direções Dir $r_{m} i n$ e $D i r_{m} a x$. As características das curvaturas principais de cada tipo de sólido podem ser vistas na Tabela 2.1 .

Tabela 2.1: Descrição dos atributos de curvatura por tipo de sólido.

\begin{tabular}{ccccc}
\hline & $\boldsymbol{K}_{\boldsymbol{m i n}}$ & $\boldsymbol{K}_{\boldsymbol{m a x}}$ & Dir $_{\text {min }}$ & Dir $_{\text {max }}$ \\
\hline Plano & 0 & 0 & Não definida & Não definida \\
Esfera & $1 /$ raio & $1 /$ raio & Não definida & Não definida \\
Cilindro & 0 & $1 /$ raio & Geratriz & Não definida \\
Cone & $1 /$ raio & 0 & Não definida & Geratriz \\
\hline
\end{tabular}

A segmentação é realizada pelo agrupamento em submalhas de vértices vizinhos que apresentam a mesma característica de curvatura. Cada submalha é relacionada a um tipo de primitiva de acordo com as características de curvatura listadas na Tabela 2.1. Por fim, a reconstrução das primitivas é obtida com a utilização de mínimos quadrados, fazendo uso da equação característica de cada primitiva e assim obtendo os parâmetros associados. A curvatura também é utilizada nesta etapa como validação dos atributos extraídos. 
Todavia, esta metodologia não se demonstra eficiente em superfícies pouco discretizadas e em malhas esparsas (Figura 2.4), uma vez que neste caso o valor de curvatura é pouco preciso. Tal ocorrência deve-se ao fato da baixa densidade na vizinhança de cada vértice. Desse modo, os vértices vizinhos que pertencem a outra classe de sólido acabam por interferir no resultado de curvatura obtido. O autor sugere para esses casos, a utilização de um algoritmo de segmentação, a fim de retirar a interferência dessas regiões vizinhas.

(a)

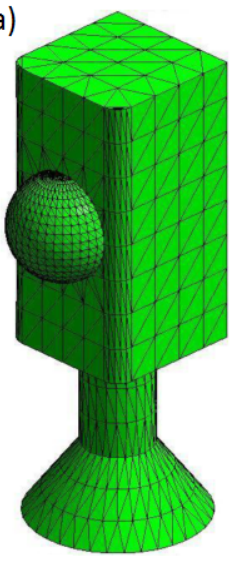

(b)

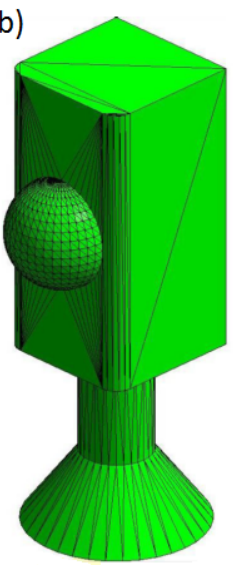

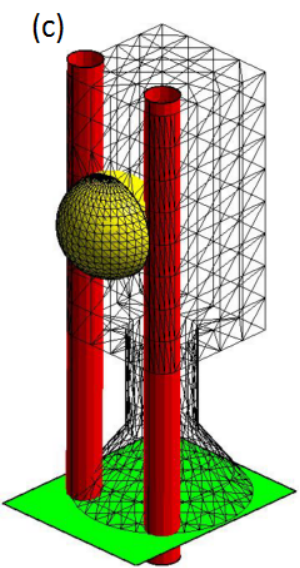

(d)

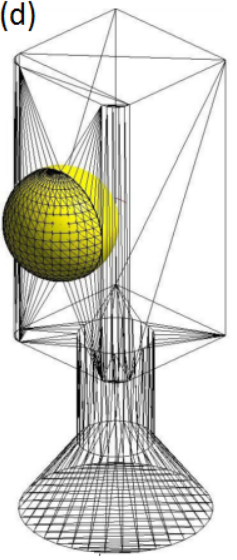

Figura 2.4: Desempenho da técnica baseada em curvatura (Bénière et al., 2011). (a) Malha com 1.712 triângulos; (b) Malha com 1.034 triângulos esparsos; (c) Primitivas extraídas de a; (d) Primitivas extraídas de b.

Similarmente, (Böhm e Brenner, 2000) e (Lavva et al., 2008) utilizam a curvatura para a segmentação e classificação de malhas. Um triângulo inicial é escolhido no processo de segmentação. A partir desse triângulo, os triângulos vizinhos com as mesmas características de curvatura são agrupados. Para cada uma das submalhas obtidas, um tipo de sólido é associado. Essa associação é realizada com base no espaço bidimensional $H K$, onde $H$ corresponde à curvatura média e $K$ à curvatura gaussiana. Alguns sólidos como plano e esfera são representados por apenas um ponto no espaço $H K$, enquanto outros possuem uma assinatura com diferentes formas. Por exemplo, as curvaturas médias e gaussianas de um torus estão sobre uma linha neste espaço (Figura 2.5). Esses trabalhos também dependem do conhecimento prévio da configuração da malha para a obtenção de valores $H$ e $K$ confiáveis. O resultado obtido pode ser pouco preciso caso seja utilizada uma pequena vizinhança em uma malha esparsa. Por outro lado, a utilização de uma região maior poderá resultar em valores imprecisos nas regiões próximas das bordas. 


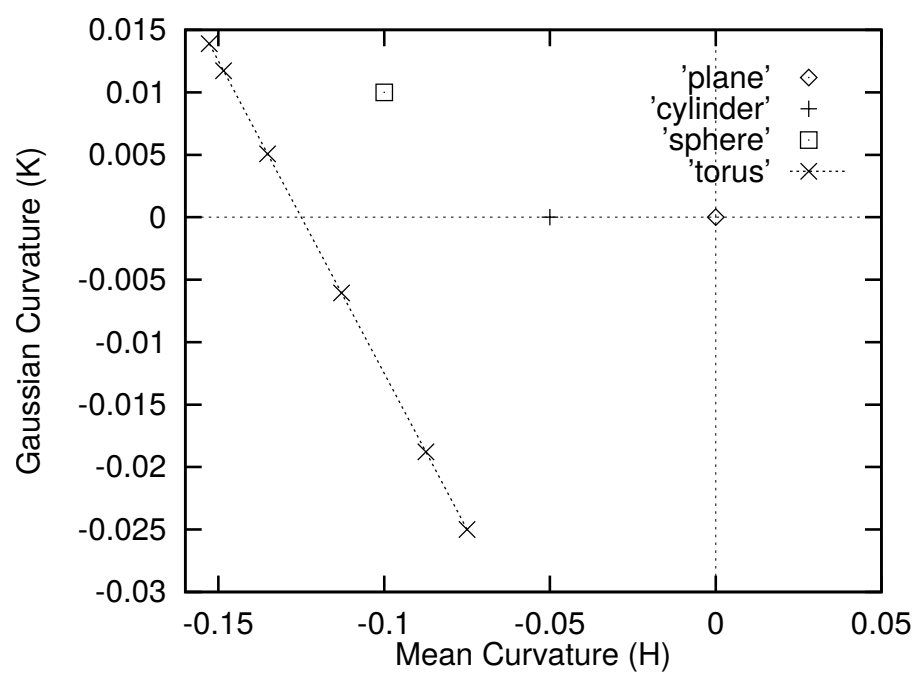

Figura 2.5: Espaço $H K$ de plano, cilindro, esfera e torus (Böhm e Brenner, 2000).

Os trabalhos realizados nesta área limitam-se a três ou, no máximo, quatro classes de sólidos diferentes, enquanto que nos modelos CAD são utilizados um número bem maior de tipos de sólidos. Além disso, as técnicas apresentadas possuem uma forte sensibilidade à triangulação da malha. Essa dependência faz com que muitas vezes estas técnicas possam ser utilizadas somente em domínios específicos e com conhecimento prévio da base de dados. Por fim, apesar de conceitualmente as técnicas de engenharia reversa serem divididas em etapas bem definidas (Varady et al., 1997), as técnicas aqui descritas realizam procedimentos que acabam por acoplar todas as etapas em uma única fase. Por exemplo, a abordagem que busca regiões anelares na superfície utiliza essa mesma abordagem tanto para segmentar, classificar e extrair atributos. Dessa forma, as limitações presentes na técnica não podem ser facilmente trabalhadas sem interferirem diretamente nas etapas posteriores.

Percebe-se então a necessidade de novas abordagens de engenharia reversa que superem os problemas apontados acima. Desse modo, busca-se estabelecer uma metodologia de engenharia reversa com etapas fracamente acopladas. Além disso, a introdução da engenharia reversa para novas classes de sólidos traria consigo o benefício de abranger um número maior de objetos dos modelos CAD. Outro desafio consiste na elaboração de técnicas capazes de produzir bons resultados mesmo em domínios desconhecidos ou em malhas de baixa qualidade. 


\section{3 \\ Fundamentação Teórica}

\section{1}

\section{Engenharia Reversa}

A engenharia reversa de sólidos geométricos pode ser entendida como o processo de obtenção de uma representação contínua de um objeto, a partir de sua representação discreta. Essas técnicas têm servido de suporte na reconstrução da superfície de sólidos por meio de malhas triangulares e nuvens de pontos.

A utilização da engenharia reversa em nuvens de pontos é bastante utilizada no processo de aquisição de modelos geométricos de objetos já existentes no mundo real. Em geral, um sensor é utilizado para mapear a superfície desses objetos, fornecendo uma representação discreta da mesma, como nuvem de pontos (Figura 3.1). Já a utilização da engenharia reversa em malhas triangulares é de grande importância para modelos $\mathrm{CAD}$, pois é comum a presença de objetos com representação implícita sendo representados através de malhas triangulares.
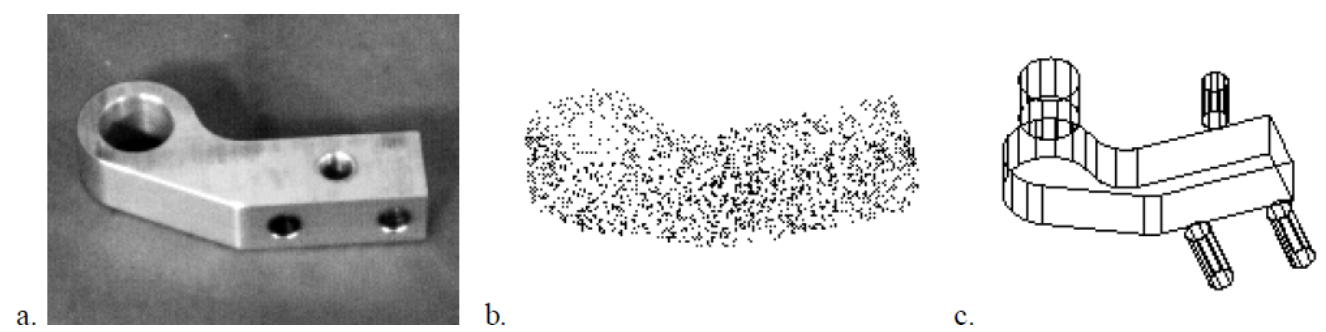

Figura 3.1: Engenharia reversa de uma peça industrial. (a) Objeto do mundo real, (b) Nuvem de pontos 3D do objeto, (c) Elementos geométricos recuperados através da engenharia reversa (Thompson et al., 1999).

Em (Varady et al., 1997) é feito um levantamento das principais técnicas e desafios no processo de engenharia reversa. Segundo o autor, o processo de engenharia reversa pode ser dividido nas seguintes fases:

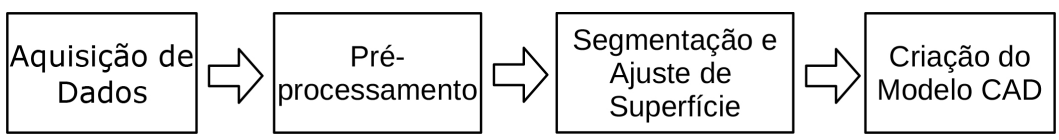

Figura 3.2: Representação esquemática das fases de engenharia reversa descritas em (Varady et al., 1997). 
As fases descritas na Figura 3.2 não são necessariamente sequenciais, podendo muitas vezes acontecerem iterativamente ou até mesmo simultaneamente. Portanto, tal representação convém mais à organização do entendimento das atividades envolvidas no processo de engenharia reversa.

\section{Aquisição de Dados}

Esta fase consiste na aquisição de dados que representem a superfície do objeto de interesse. Obtém-se assim uma representação discretizada, que será utilizada como entrada para as técnicas de engenharia reversa extraírem uma representação contínua e suave destes dados.

As técnicas de aquisição de dados de objetos do mundo real podem ser divididas em dois principais grupos: métodos sem contato e métodos tácteis. A primeira categoria corresponde às abordagens que utilizam a luz, o som ou o magnetismo, enquanto que a outra categoria caracteriza-se pelos métodos que fazem o uso de contato direto com a superfície, como sondas mecânicas na extremidade de um braço. Já para a representação de objetos ainda não existentes no mundo real, é comum a utilização de ferramentas CAGD (Computer-Aided Geometrical Design) para a elaboração desses modelos.

\section{Pré-Processamento}

Vários problemas são enfrentados na etapa de aquisição de dados, entre eles: precisão, oclusão, calibração, ruídos, acessibilidade, entre outros. Por consequência, os resultados obtidos nem sempre são satisfatórios.

Entretanto, ainda que cuidados sejam adotados na fase de aquisição de dados visando minimizar estas características, possivelmente os dados obtidos necessitarão de tratamento para que as etapas seguintes do processo de engenharia reversa atinjam seus objetivos. Esse tratamento acontece seja pela melhoria dos dados adquiridos e a consequente diminuição dos erros envolvidos no processo, seja pelo simples fato de atender a um requisito das etapas posteriores, tal como a normalização dos dados a uma determinada escala.

\section{Segmentação e Ajuste de Superfície}

A etapa de segmentação e ajuste de superfície é uma fase crítica para o sucesso da metodologia, uma vez que seu papel consiste no agrupamento de regiões de interesse, e na delimitação dessas regiões por superfícies. Estas atividades são realizadas considerando um critério de similaridade, como a curvatura por exemplo. 
Dessa forma, a presença de ruídos ou outros elementos indesejáveis no dado de entrada possivelmente resultarão em baixa qualidade dos resultados adquiridos, posto que a sensibilidade a estes elementos depende do critério utilizado para a segmentação e agrupamento dos dados. A obtenção de resultados negativos nessa etapa são garantia de péssimos resultados globais da metodologia de engenharia reversa. De modo geral, esse estágio do processo pode ser subdividido nas seguintes atividades:

- Segmentação: separação lógica dos dados originais em conjuntos disjuntos de acordo com um critério;

- Classificação: de posse dos grupos criados na fase anterior, um tipo de superfície é utilizado para representar cada um dos grupos. Exemplo: planos, cilindros, cone, torus, entre outros;

- Ajuste: etapa responsável pela configuração do tipo de superfície escolhida no estágio anterior. Tal configuração deve proporcionar o melhor ajuste da superfície aos elementos presentes no grupo em análise.

\subsection{1 \\ Engenharia Reversa em Malhas Triangulares}

Atualmente existem diversas ferramentas disponíveis no mercado para modelagem 3D. Tais ferramentas possuem uma maneira particular de representar e manipular seus dados internamente, porém muitos desses softwares exportam as informações por meio de um conjunto de malhas triangulares. A representação por malhas de triângulos apresenta algumas desvantagens, entre elas podemos citar:

- A representação por malhas triangulares sempre será uma aproximação, mesmo quando esta encontra-se muito detalhada. Por esse motivo, a discretização pode resultar em simulações imprecisas, assim como em imperfeições na fabricação de manufaturados;

- A representação por malhas triangulares requer mais dados para representar um objeto, exigindo maiores recursos computacionais para o armazenamento e a manipulação destes objetos. Por outro lado, a representação paramétrica do objeto é mais compacta: um cubo pode ser representado apenas por 2 coordenadas espaciais 3D (ponto mínimo e máximo), enquanto que em malha - sem indexação dos vértices - precisa de, no mínimo, 72 coordenadas espaciais 3D para reproduzir as posições e normais de cada vértice;

- Tarefas que envolvem cálculos numéricos tendem a ser mais eficientes com a representação paramétrica, uma vez que o resultado pode ser obtido analiticamente. Um exemplo é o cálculo da área de superfície, já discutido anteriormente; 
- Problemas de ambiguidades surgem quando uma malha pouco discretizada é utilizada para representar objeto com alto grau de detalhamento ou regiões curvas. Isso porque a baixa discretização não é suficiente para representá-los adequadamente. Esta ambiguidade pode interferir negativamente em diversas aplicações dos sistemas CAD, especificamente em engenharia mecânica, uma vez que informações de conectividade e continuidade são altamente importantes para a definição dos métodos utilizados na sua produção (Varady et al., 1997).

Tais aspectos inconvenientes motivaram a ampliação de pesquisas de engenharia reversa em malhas triangulares, devido à importância e à popularidade que esse tipo de representação tem na computação gráfica. A técnica aqui apresentada utiliza como entrada malhas triangulares já segmentadas, a fim de realizar a engenharia reversa das mesmas.

\section{2}

\section{Descritor de Forma}

Como discutido anteriormente, uma importante etapa no processo de engenharia reversa refere-se à etapa de classificação dos dados que representam o objeto sob análise. Dessa forma, o objeto antes representado por dados crus, será representado por informações de nível mais alto. A tarefa de classificação de objetos provenientes de modelos CAD está estreitamente relacionada com as atividades praticadas em técnicas de shape matching / shape retrieval, entre elas a aquisição de um descritor de forma que diferencie os objetos.

Em (Tangelder e Veltkamp, 2008) é feita uma categorização dos métodos de shape retrieval baseados em propriedades geométricas e topológicas, conforme mostra a (Figura 3.3). Tais métodos, segundo o autor, podem ser divididos em três grandes classes: baseados em características (feature based), baseados em grafo (graph based) e baseados na geometria (geometry based). 


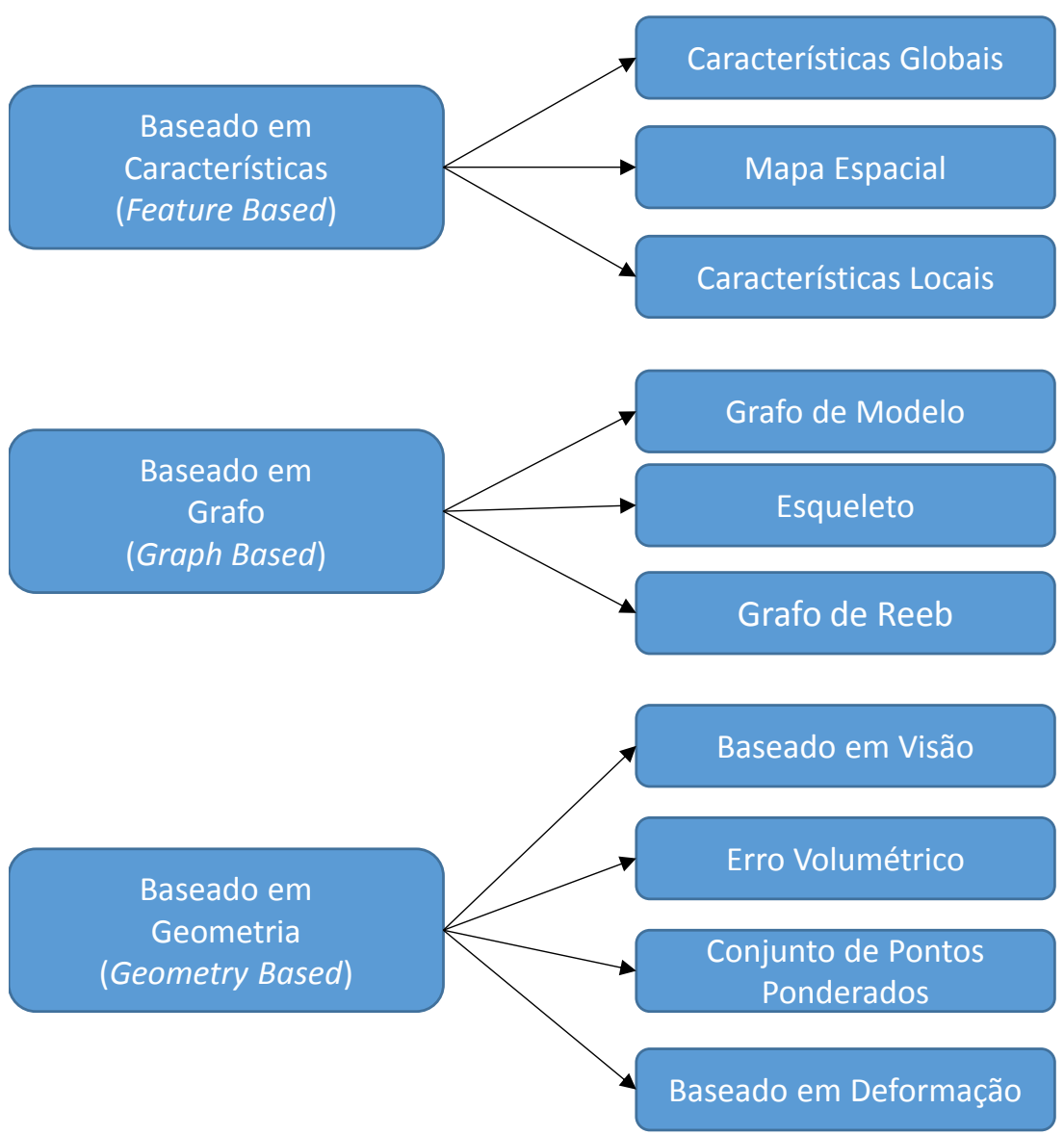

Figura 3.3: Categorização das abordagens utilizadas em técnicas de shape retrieval de acordo com o descritor utilizado.

Os métodos de shape matching baseados em características descrevem a forma do objeto através de um vetor de características, extraídas com base na topologia e geometria desse objeto. A dimensão desse vetor deve ser a mesma para todas as formas. $\mathrm{O}$ vetor de características extraído de uma determinada forma pode ser interpretado como um ponto no espaço de alta dimensão, logo, dois objetos são similares se estes pontos estão suficientemente próximos.

As técnicas baseadas em características podem ser subdivididas em técnicas que utilizam características globais (global features), locais (local features) e mapa espacial (spatial map). Os métodos que fazem uso de características globais são aqueles que produzem um único descritor capaz de descrever características do objeto como um todo, não limitando-se a regiões ou partes do objeto. Entre eles podemos citar os descritores de forma utilizados neste trabalhos e descritos em (Osada et al., 2002).

Os descritores baseados em características locais, por sua vez, levam em consideração informações da vizinhança da região sob análise (Shum et al., 1996, Zaharia e Preteux, 2001) e (Koenderink, 1990). A subcategoria de mapa espacial refere-se às técnicas que utilizam regiões espaciais para computar as características 
em cada uma dessas regiões, como pode ser visto em (Ankerst et al., 1999). Aqui, vemos que a similaridade entre superfícies moleculares é avaliada através da utilização de histogramas de forma, produzidos para cada uma das células do mapa (Figura 3.4).
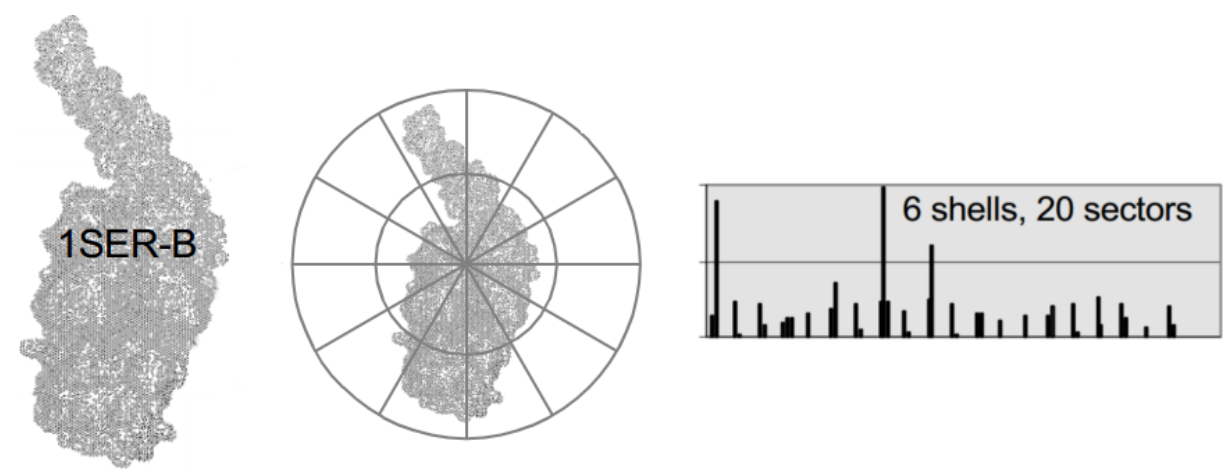

Figura 3.4: Histograma de forma de uma superfície molecular utilizando mapa espacial (Ankerst et al., 1999).

Diferentemente da categoria anterior, os métodos baseados em grafo tentam extrair da representação 3D um significado geométrico por meio da utilização de grafos. Tais grafos representam os componentes da forma e seus respectivos relacionamentos. Os métodos presentes nessa categoria podem ser subdividos nas seguintes categorias: grafo de modelo (model graph) (Hoffmann, 1989), esqueleto (skeleton) e grafo de Reeb (Reeb Graph).

Os grafos de modelo têm sido amplamente utilizados em modelos CAD, pois diversas dessas técnicas utilizam dados de engenharia dos equipamentos ou seus respectivos planos de fabricação, através do uso de grafo de dependência (Chua e Jarvis, 1997, Cicirello e Regli, 2001). Já as técnicas de similaridade baseadas em esqueleto utilizam grafos esqueléticos para modelar as informações geométricas e topológicas do objeto (Figura 3.5). Por fim, um Reeb Graph é definido como um espaço topológico quociente de uma forma $S$ e uma função quociente $f$ (Biasotti et al., 2008).
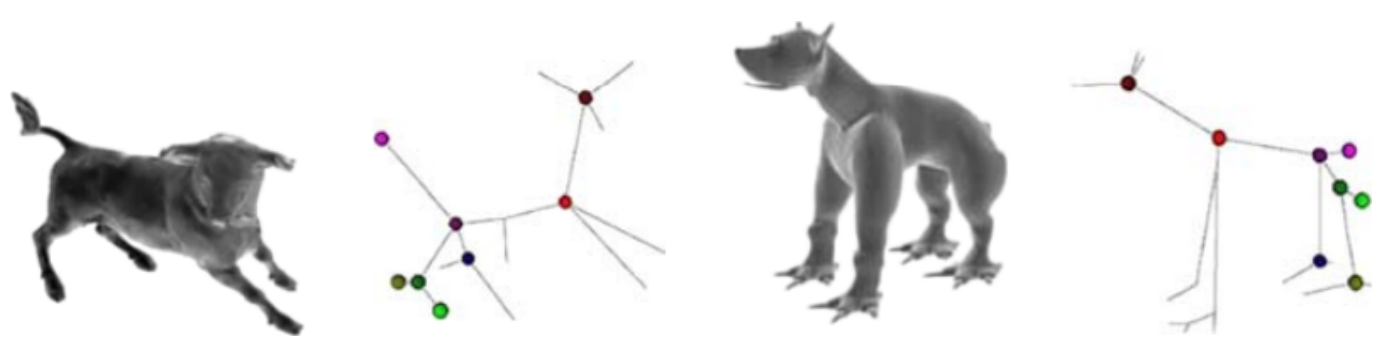

Figura 3.5: Grafo do esqueleto de dois objetos. Cores dos vértices representam a correspondência entre os nós das duas formas (Sundar et al., 2003).

A categoria das técnicas baseadas em geometria corresponde às técnicas que utilizam uma das seguintes abordagens: método baseado em visão (view based), em 
erro volumétrico (volumetric error), em conjunto de pontos ponderados (weighted point set) ou baseados em deformação (deformation based). Os métodos baseados em visão utilizam-se do fato de que dois objetos 3D são similares quando vistos em diferentes ângulos de visão, simulando assim o modelo humano de reconhecimento de objetos (Figura 3.6).

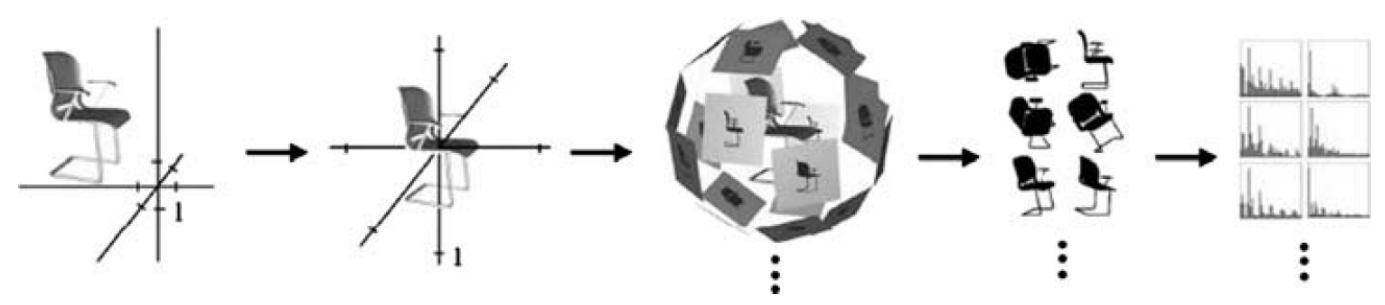

Figura 3.6: Extração do descritor de campo de luz de uma cadeira (Shen et al., 2003).

Algumas precauções devem ser adotadas no processo de escolha dos descritores para a obtenção de um bom classificador de forma. É desejável que os descritores escolhidos sejam robustos a ruídos e a diferentes níveis de detalhes. Além do mais, é importante que os mesmos sejam invariantes a transformações de translação, rotação e/ou escala.

Grande parte das técnicas de shape retrieval se baseiam na extração de descritores de características e busca exaustiva. Esta abordagem computa os descritores de forma para cada objeto da base de dados, assim como para o objeto procurado. Desse modo, a busca é feita comparando todos os descritores dos objetos da base de dados com o descritor do objeto procurado. A similaridade entre dois objetos é mensurada com o uso de uma medida de dissimilaridade. Há também trabalhos que exploram técnicas de aprendizagem estatísticas a fim de avaliar a dissimilaridade entre os vetores de características extraídos. Em (Delponte et al., 2009), um sistema de busca por formas 3D é proposto através da utilização de Máquinas de Vetores de Suporte para a classificação de histogramas de forma.

A metodologia de engenharia reversa proposta neste trabalho utiliza descritores de forma baseados em características (feature-based descriptors) para caracterizar cada uma das classes de sólidos investigadas. Os descritores adotados são provenientes dos histogramas de distribuição de forma obtidos com as medidas D1 e D2 (Osada et al., 2002); ambos são descritores globais referentes à distribuição de probabilidade de distâncias da forma. A similaridade entre os vetores de características é avaliada com o uso de Máquinas de Vetores de Suporte, que será discutido mais adiante. Por fim, a curvatura da superfície também é utilizada como descritor local, a fim de validar a classificação de algumas classes de sólidos. 


\section{3 \\ Distribuição de Forma}

Uma distribuição de forma pode ser vista como uma assinatura de um modelo 3D, onde é realizada uma amostragem estatística das propriedades da forma do objeto 3D. Essas amostras podem ser avaliadas segundo alguma medida de dissimilaridade. Em (Osada et al., 2002) é proposto utilizar a distribuição de probabilidade de métricas extraídas da forma do objeto como sendo a assinatura do mesmo. Assim, a similaridade entre duas formas é avaliada através da comparação entre as distribuições de probabilidades associadas aos dois objetos em questão.

A vantagem de se utilizar distribuição de forma para avaliar a similaridade entre dois objetos está na simplicidade da mesma, uma vez que a caracterização do objeto só depende da amostragem da superfície, da normalização dos valores obtidos e da comparação das distribuições de probabilidades adquiridas. Tarefas essas relativamente mais simples se comparadas com outras técnicas de similaridade de objetos 3D que requerem a reconstrução de um objeto sólido ou de uma superfície manifold a partir de dados 3D degenerados, ou a achar correspondência de características, entre outros. Desse modo, o autor realiza um estudo comparativo entre diferentes tipos de métricas utilizadas para a caracterização da forma de um objeto 3D. São elas:

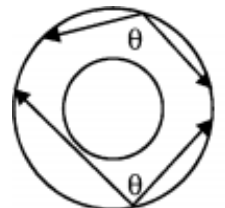

A3

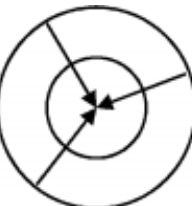

D1

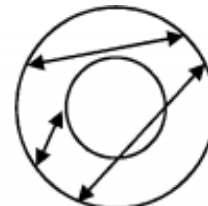

D2

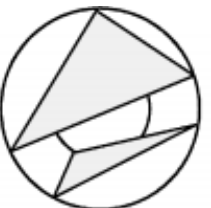

D3

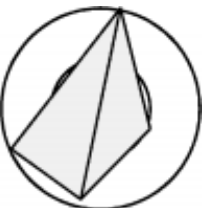

D4

Figura 3.7: Diferentes métricas para caracterização de superfície apresentadas em (Osada et al., 2002).

- A3: Medição do ângulo entre três pontos aleatórios da superfície do modelo 3D;

- D1: Medida de distância de um ponto aleatório da superfície para outro ponto fixo. Para a avaliação dessa medida, o autor usou o centroide do objeto como sendo o ponto fixo;

- D2: Medida de distância entre dois pontos aleatórios da superfície;

- D3: Medida da raiz quadrada da área do triângulo formado por três pontos aleatórios na superfície do objeto 3D;

- D4 Medida da raiz cúbica do volume do triângulo do tetraedro, formado por quatro pontos aleatórios na superfície do objeto 3D. 
Segundo o autor, tais medidas foram escolhidas devido a sua simplicidade, a não dependência da triangulação da malh, à possibilidade de computá-las rapidamente, ao fácil entendimento e à invariância a degenerações e ruídos. Ademais, a medida A3 é naturalmente invariante à escala uniforme, enquanto que as demais precisam de uma etapa de normalização para que as comparações dos histogramas sejam realizadas corretamente. Por fim, tais características demonstram-se capazes de diferenciar desde classes de objetos 3D simples, tais como cubo, cilindro e esfera (Figura 3.8); e objetos mais complexos, tais como diferentes tipos de automóveis (Figura 3.9). Para a obtenção de resultados satisfatórios é necessário gerar essas estatísticas utilizando uma grande quantidade de pontos na superfície, de tal forma que estes representem satisfatoriamente a superfície do objeto.

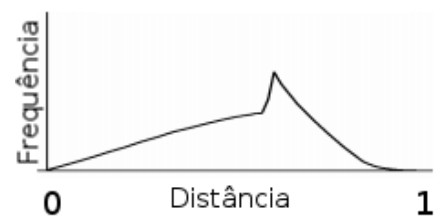

(a)

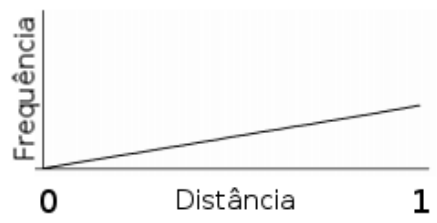

(b)

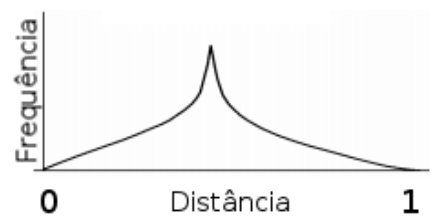

(c)

Figura 3.8: Diferenciabilidade do histograma de forma D2. (a) Cubo, (b) Esfera, (c) Cilindro.

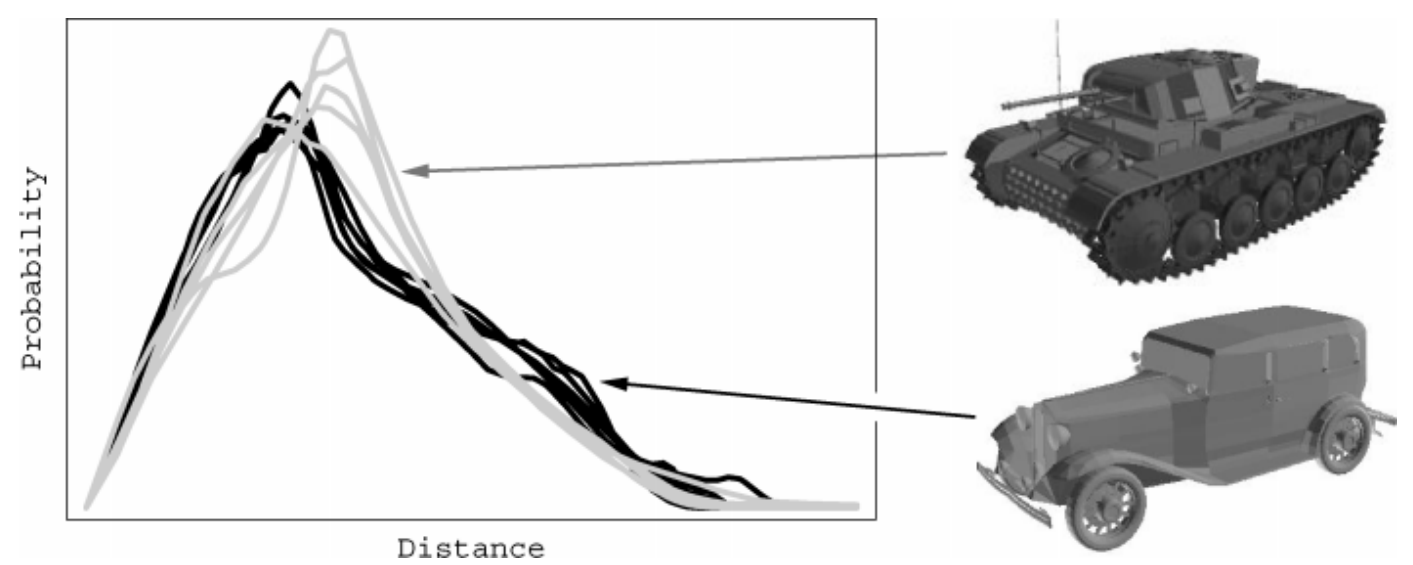

Figura 3.9: Distribuição de forma D2 de cinco tanques, em cinza, e seis carros, em preto (Osada et al., 2002).

O Algoritmo 1 refere-se ao pseudocódigo responsável pela extração do histograma D1. Nele, pontos corresponde ao conjunto de pontos da superfície, $\boldsymbol{D}$ refere-se a maior distância entre pontos na superfície, cols é o numero de colunas do histograma $\boldsymbol{H}$ e centroide é o centro geométrico 3D da forma. Já o Algoritmo 2 demonstra os passos para a obtenção do histograma de forma baseado na distribuição de forma D2. 

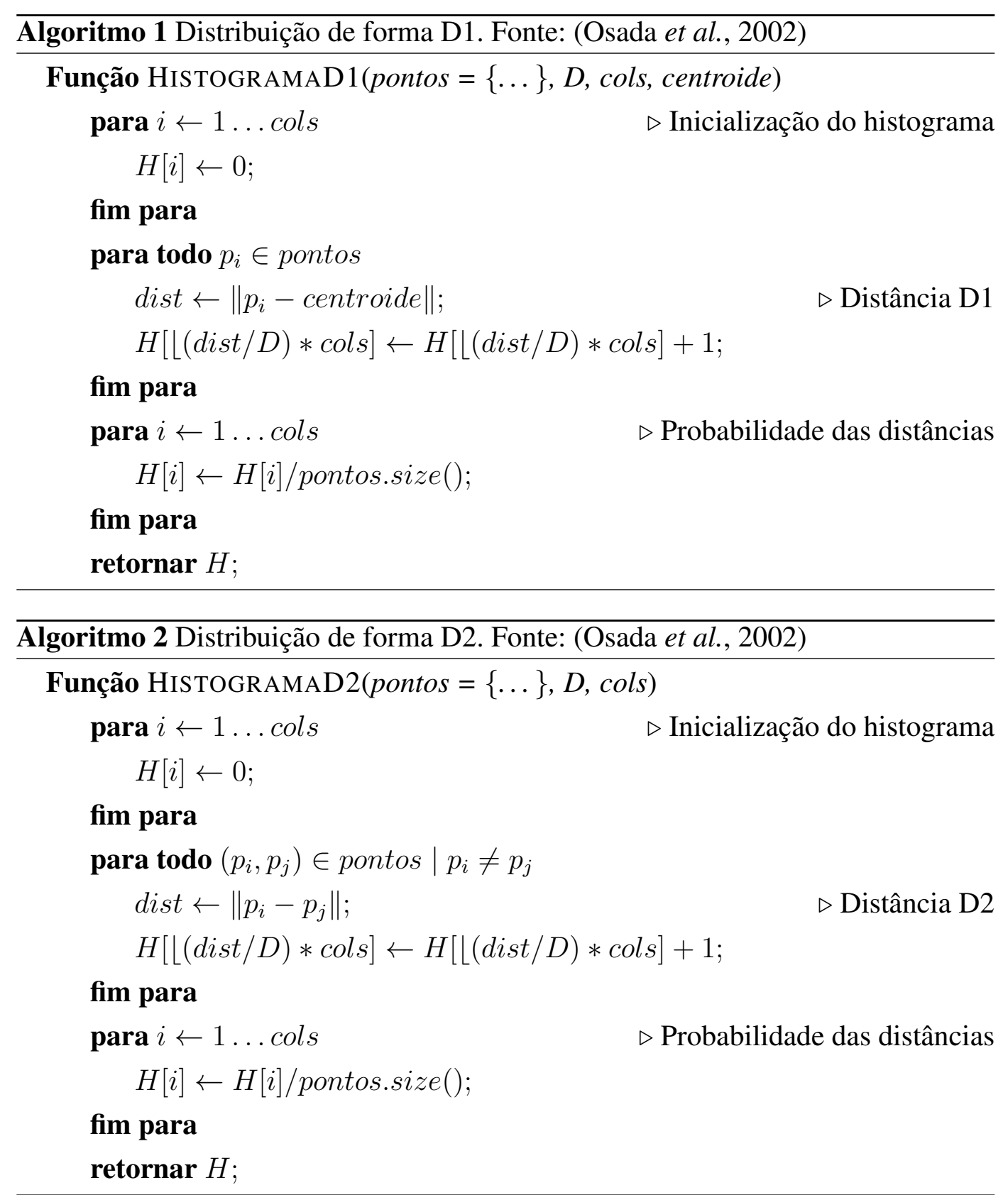

\section{4}

\section{Curvatura}

A curvatura de uma superfície tem sido utilizada de diferentes formas para descrever e extrair um vetor de características de um objeto. Utilizando a categorização dos descritores de formas apresentados anteriormente, a curvatura enquadra-se na categoria dos descritores baseados em características (características locais).

No espaço euclidiano bidimensional, a curvatura $K_{p}$ de uma curva suave $C$ em um ponto $p$ é definida pelo inverso do raio do círculo osculador neste ponto (Figura 3.10). O valor de $K_{p}$ é positivo se a normal da superfície neste ponto aponta para fora do círculo osculador, caso contrário o valor obtido será negativo. 


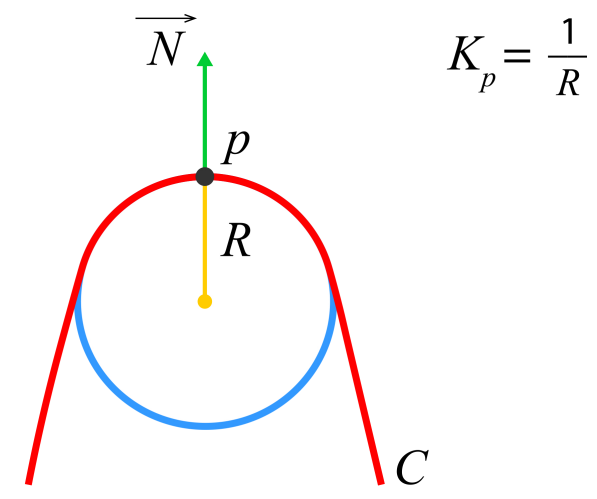

Figura 3.10: Curvatura de uma curva suave em 2D é recíproca ao raio do círculo osculador em um dado ponto.

No espaço euclidiano tridimensional, cada ponto $p$ da superfície $S$ possui um vetor normal $N$ associado. Um plano normal é um plano que contém esse vetor normal em uma dada direção tangente à superfície, onde a intersecção com a superfície $S$ forma uma curva, conhecida como seção normal $(C)$. A curvatura da seção normal é dada da mesma forma que fora demonstrado para o caso bidimensional. A curvatura principal da superfície $S$ no ponto $p$ representa os valores críticos de curvatura, sendo representados por $K_{1}$ e $K_{2}$, que correspondem ao valor da curvatura máxima e mínima de todas seções normais do ponto $p$ nas seguintes direções $\overrightarrow{D i r_{\min }}$ e $\overrightarrow{D i r_{\max }}$, conhecidas por direções principais.

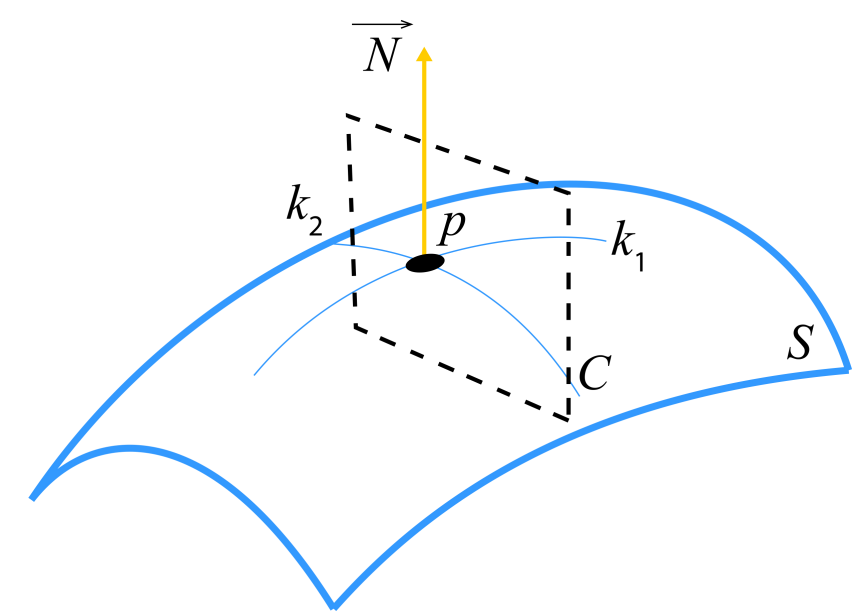

Figura 3.11: Representação da curvatura principal de uma superfície $S$ em um ponto $p$.

Como foi discutido no Capítulo 2, cada sólido apresenta um comportamento particular com relação à curvatura dos vértices da superfície. Uma esfera possui $k_{1}=k_{2}$ para todos os vértices e o raio da esfera é dado por ${ }^{1} / k_{1}$ ou ${ }^{1} / k_{2}$ pela definição apresentada anteriormente. Contudo, o valor obtido da curvatura em malhas nem sempre é confiável, uma vez que a baixa discretização da malha pode resultar em valores imprecisos. 


\section{5 \\ Aprendizagem de Máquina}

Aprendizagem de Máquina é um termo utilizado para referir-se a um conjunto de técnicas que visam criar um conhecimento sobre um determinado domínio, de tal forma que informações relevantes possam ser extraídas de um novo dado desse mesmo domínio. O processo de obtenção e aperfeiçoamento do conhecimento é realizado através da experiência adquirida ao longo das interações do algoritmo com o domínio. Essas técnicas têm sido bastante exploradas nos últimos anos devido à sua aplicação prática no cotidiano das pessoas. Algoritmos de aprendizagem de máquinas estão presentes nos serviços de reconhecimentos de fala, no reconhecimento de face das câmeras fotográficas, nas máquinas que identificam placas do carro, entre outros.

As Máquinas de Vetores de Suporte têm sido uma das técnicas de aprendizagem estatística mais utilizadas para estes fins. $O$ aumento da sua popularidade deve-se a sua simplicidade, facilidade de utilização, boa capacidade de generalização e à obtenção de resultados satisfatórios.

\subsection{1 \\ Máquinas de Vetores de Suporte}

As Máquinas de Vetores de Suporte (Vapnik, 1982) ou SVM (do inglês Support Vector Machine) têm desempenhado papel relevante em diversas áreas de pesquisas que envolvem técnicas de aprendizagem estatística. Essa abordagem baseia-se na teoria de aprendizado estatístico para a obtenção de classificadores com boa generalização, possibilitando categorizar novos dados corretamente.

As Máquinas de Vetores de Suporte enquadram-se na categoria das técnicas de aprendizagem supervisionada. As técnicas presentes nessa categoria caracterizam-se pela presença da fase denominada treinamento. Nesta fase, são fornecidas diversas entradas na forma de pares $\left(\mathbf{x}_{\mathbf{i}}, y_{i}\right)$, em que $\mathbf{x}_{\mathbf{i}}$ corresponde aos atributos de um caso do domínio (vetor de características) e $y_{i}$ denota à classe ao qual $\mathbf{x}_{\mathbf{i}}$ pertence. $\mathrm{O}$ objetivo dessa etapa consiste em produzir um classificador baseado nos exemplos fornecidos. Tal classificador consiste em um hiperplano, responsável por separar as características fornecidas de acordo com os seus respectivos rótulos. Desse modo, o espaço de características será divido em duas partes. Assim, o vetor de características $\mathbf{x}_{\mathbf{i}}$ pode ser interpretado como um ponto no hiperespaço e o resultado da classificação é obtido através da avaliação de qual lado do hiperplano que $\mathbf{x}_{\mathbf{i}}$ está contido.

É desejável que o classificador obtido na fase de treinamento seja genérico suficiente visando a classificação correta de novos vetores $\mathbf{x}_{\mathbf{i}}$ que variam ligeiramente dos dados utilizado na fase de treinamento. No caso em que o 
classificador está demasiadamente ajustado aos dados utilizados no treinamento, é provável que o mesmo tenha uma baixa taxa de acerto na predição de novos atributos. Este fato decorre do super ajustamento do classificador (overfitting). Também é possível que o classificador apresente baixa taxa de acerto nos dados de teste em virtude de um sub ajustamento aos dados de treinamento (underfitting). Em geral, o sub ajustamento é decorrente da baixa representatividade dos dados utilizados no treinamento, ou mesmo pela simplicidade do classificador obtido.

As Máquinas de Vetores de Suporte One Class trabalham com rótulos binários, isto é, $y_{i} \in\{-1,+1\}$. Esta binarização representa cada um dos lados do hiperplano. O hiperplano é obtido pela resolução da Equação 3-1:

$$
f(x)=\mathbf{w} \cdot \mathbf{x}+b=0
$$

onde w é conhecido por vetor de peso (weight vector), vetor normal ao hiperplano, e $b$ por bias, que corresponde à translação do hiperplano em relação à origem. A Equação 3-1 divide o espaço dos dados em duas regiões: $f(\mathbf{x})>0$ e $f(\mathbf{x})<0$. Portanto, todos os dados presentes em um lado do hiperplano são rotulados com -1 e os demais com +1 . Sendo assim, pode ser empregada a seguinte função $g(\mathbf{x})$ para a rotulação dos dados:

$$
g(\mathbf{x})=\operatorname{sgn}(f(\mathbf{x}))= \begin{cases}+1 & \text { se } f(\mathbf{x})>0 \\ -1 & \text { se } f(\mathbf{x})<0\end{cases}
$$

Sejam os dados utilizados no treinamento separáveis pelo hiperplano $(\mathbf{w}, b)$, estes dados também são separáveis por qualquer hiperplano que seja múltiplo de $(\mathbf{w}, b)$. Portanto, existe um número infinito de representação do mesmo hiperplano. O hiperplano canônico é definido como sendo o hiperplano que dado o $\mathbf{x}_{\mathbf{i}}$ mais próximo do hiperplano, $|f(\mathbf{x})|=1$.

A distância de um ponto $\mathbf{x}_{\mathbf{i}}$ para o hiperplano $(\mathbf{w}, b)$ é definido por:

$$
\text { distância }=\frac{|\mathbf{w} \cdot \mathbf{x}+b|}{\|\mathbf{w}\|}
$$

Levando-se em conta o hiperplano canônico, o numerador pode ser substituído por 1 , resultando em:

$$
\text { distância }{ }^{\prime}=\frac{1}{\|\mathbf{w}\|}
$$

Logo, a distância $d$ entre os dois dados mais próximos de cada classe ao hiperplano é dada por:

$$
d=\frac{2}{\|\mathbf{w}\|}
$$




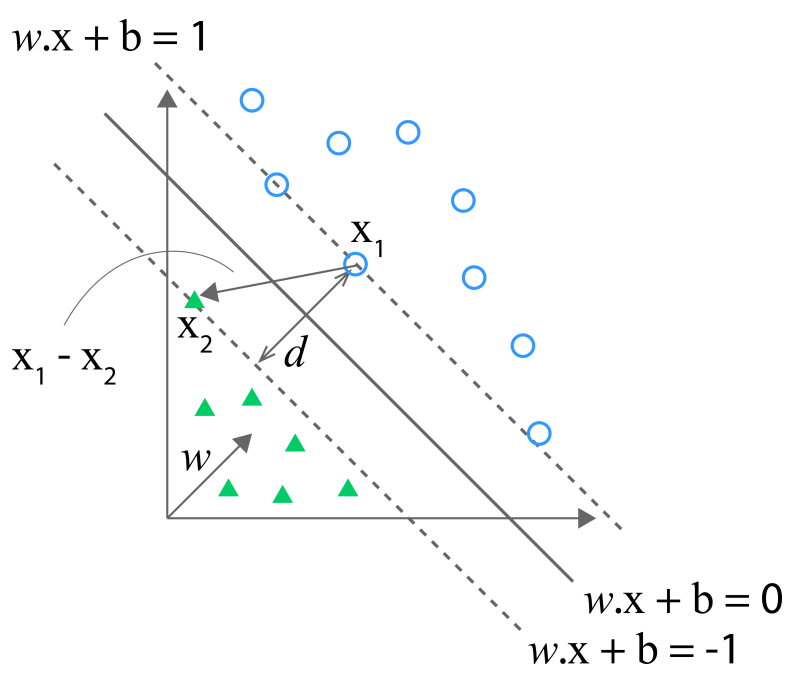

Figura 3.12: Distância $d$ entre os pontos mais próximos das duas classes (triângulos e círculos).

A distância $d$, mostrada na Figura 3.12, corresponde ao que é chamado de margem. Um bom classificador é obtido ao maximizar a margem entre as duas classes, correspondendo a tarefa de encontrar o hiperplano ótimo. Maximizar a margem $d$ é equivalente ao problema de minimizar $\|\mathbf{w}\|$ :

$$
\underset{w, b}{\operatorname{Minimizar:}}\|\mathbf{w}\|^{2}
$$

Com a seguinte restrição:

$$
y_{i}\left(\mathbf{w} \cdot \mathbf{x}_{\mathbf{i}}+b\right) \geq 1, \quad i=1, \ldots, n
$$

Este é um problema de otimização Lagrangiana que pode ser resolvido usando multiplicadores de Lagrange para obter o vetor de peso w e o bias $b$ do hiperplano ótimo.

Como visto até aqui, Máquinas de Vetores de Suporte são diretamente aplicáveis em domínios linearmente separáveis. Porém, existem diversas aplicações em que os atributos dos itens analisados não são linearmente separáveis. Neste caso, os atributos originais são mapeados por uma função $\Phi$ (kernel) para um novo espaço, conhecido como espaço de características (Vapnik, 1982). Neste espaço, os vetores de características são linearmente seperáveis, assim o hiperplano do classificador é dado pela Equação 3-8. Este espaço pode ter dimensão maior que o espaço de entrada.

$$
\mathbf{w} \cdot \Phi(\mathbf{x})+b=0
$$

$\mathrm{Na}$ Figura 3.13, o espaço de característica unidimensional não pode ser separado linearmente. Portanto, os dados originais são mapeados para um espaço bidimensional, possibilitando assim a separação linear entre círculos azuis dos quadrados laranjas. 


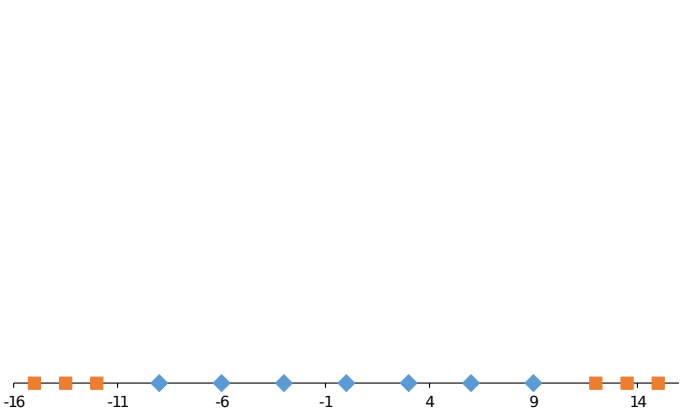

(a)

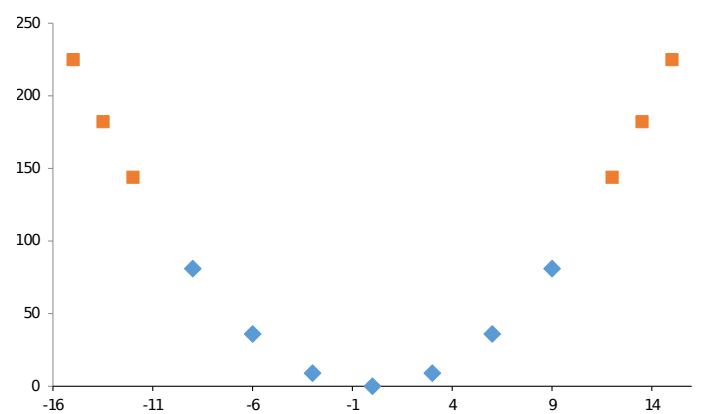

(b)

Figura 3.13: Mapeamento de dados unidimensionais não linearmente separáveis (a) para o espaço bidimensal (b).

Entre os kernels mais utilizados e difundidos, vale destacar os apresentados na Tabela 3.1.

Tabela 3.1: Kernels e suas respectivas funções.

\begin{tabular}{|c|c|}
\hline Kernel & Função $K\left(\mathbf{x}_{\mathbf{i}}, \mathbf{x}_{\mathbf{j}}\right)$ \\
\hline Gaussiano (RBF) & $\exp ^{-\gamma\left\|\mathbf{x}_{\mathbf{i}}-\mathbf{x}_{\mathbf{j}}\right\|^{2}}$ \\
\hline Polinomial & $\left(\mathbf{x}_{\mathbf{i}}^{T} \cdot \mathbf{x}_{\mathbf{j}}+1\right)^{P}$ \\
\hline Sigmoidal & $\tanh \left(\beta_{0} \mathbf{x}_{\mathbf{i}} \cdot \mathbf{x}_{\mathbf{j}}+\beta_{1}\right)$ \\
\hline
\end{tabular}

\section{5 .2}

\section{Máquinas de Vetores de Suporte com Margens Suaves}

A formulação apresentada das Máquinas de Vetores de Suporte presupõe que não há nenhum vetor de característica no hiperespaço entre as regiões delimitadas por $\mathbf{w} \cdot \mathbf{x}+b=0 \mathrm{e} \mathbf{w} \cdot \mathbf{x}+b= \pm 1$. Esta formulação é conhecida como Máquinas de Vetores de Suporte com Margens Rígidas. A grande desvantagem dessa abordagem reside no fato de que ruídos interferem diretamente no processo de aquisição do classificador, mesmo que estes ruídos estejam presentes em pequena quantidade. Em geral, os classificadores obtidos com as SVMs de margens rígidas apresentam baixa capacidade de generalização na presença de ruídos, apresentando assim baixa taxa de acerto quando submetido a novos vetores de características. Esta características deve-se ao fato de que esses ruídos podem resultar em margens estreitas, conforme a Figura 3.14. 


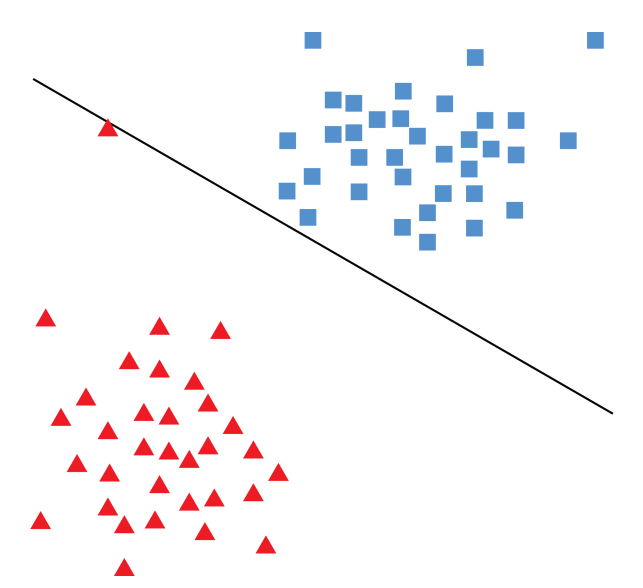

Figura 3.14: Influência de ruídos na determinação do classificador na fase de treinamento da SVM

$\mathrm{Na}$ tentativa de superar essa sensibilidade a ruídos, nasceu o conceito de Máquinas de Vetores de Suporte com Margens Suaves (Cortes e Vapnik, 1995). Neste modo, são introduzidas variáveis de relaxamento $\varsigma$ a fim de suavizar as restrições impostas na determinação do hiperplano ótimo. As variáveis de relaxamento são definidas pela Equação 3-9 e 3-10.

$$
\begin{gathered}
\text { Para } y_{i}=+1 \quad \xi_{i}=\varsigma_{i}(\mathbf{w}, b) \begin{cases}0 & \text { se } \mathbf{w} \cdot \mathbf{x}_{\mathbf{i}}+b \geq 1 \\
1-\mathbf{w} \cdot \mathbf{x}_{\mathbf{i}}+b & \text { se } \mathbf{w} \cdot \mathbf{x}_{\mathbf{i}}+b<1\end{cases} \\
\text { Para } y_{i}=-1 \quad \xi_{i}=\varsigma_{i}(\mathbf{w}, b) \begin{cases}0 & \text { se } \mathbf{w} \cdot \mathbf{x}_{\mathbf{i}}+b \leq-1 \\
1+\mathbf{w} \cdot \mathbf{x}_{\mathbf{i}}+b & \text { se } \mathbf{w} \cdot \mathbf{x}_{\mathbf{i}}+b>-1\end{cases}
\end{gathered}
$$

As variáveis de relaxamento $\varsigma_{i}$ apresentam valor 0 quando o ponto no hiperespaço está do lado correto do hiperplano e fora da região delimitada pelos por $\mathbf{w} \cdot \mathbf{x}+b= \pm 1$. Para $0<\varsigma_{i} \leq 1$, o ponto está do lado correto do hiperplano, porém contido na região delimitado pelas margens, situação conhecida como violação de margem. Quando $\varsigma_{i}$ apresenta valor superior a 1 , o vetor $\mathbf{x}_{\mathbf{i}}$ está posicionado no lado errado do hiperplano (Figura 3.15). 


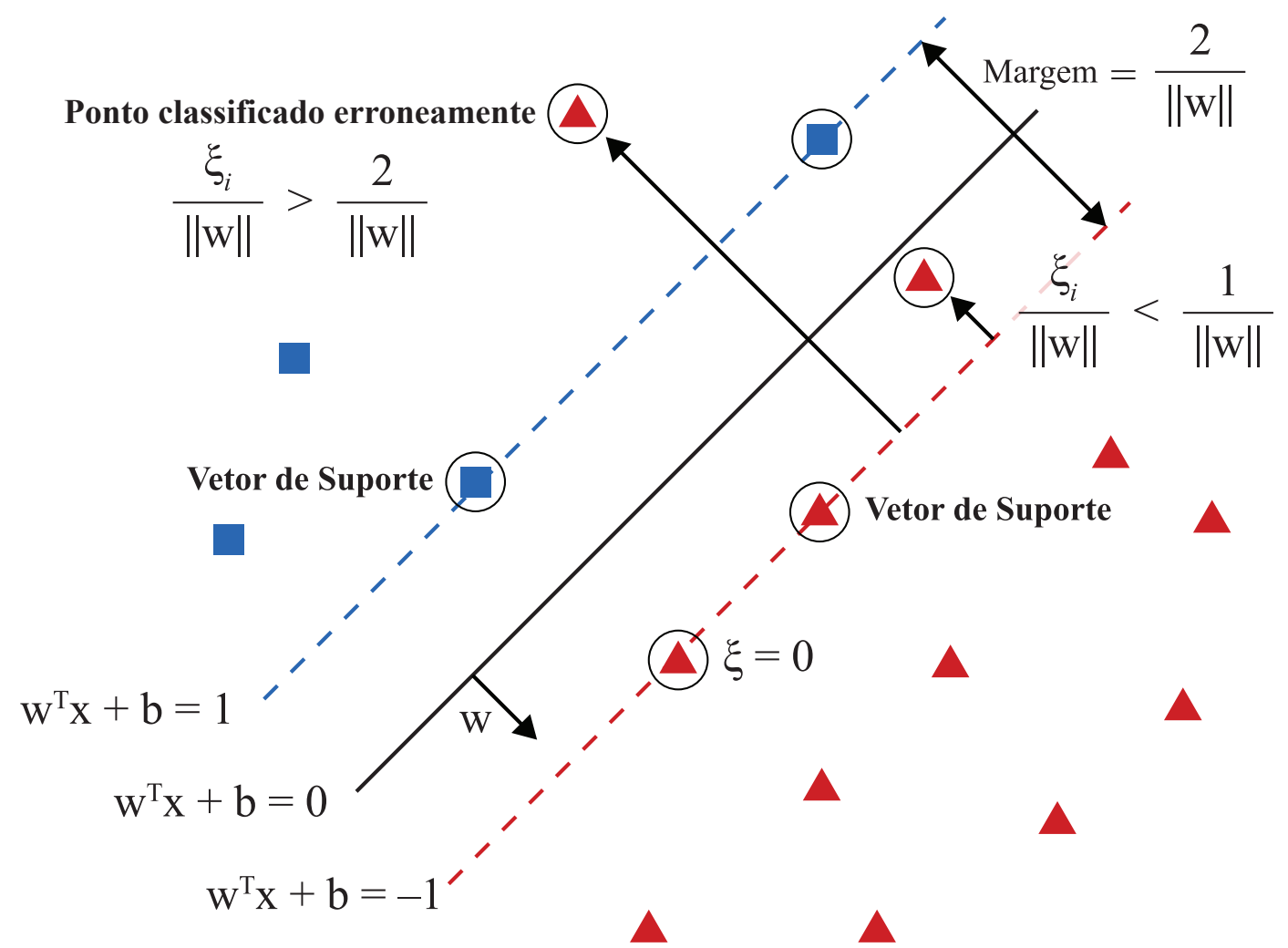

Figura 3.15: Variáveis de relaxamento na aquisição de um classificador com margens suaves.

Para a obtenção do classificador, busca-se minimizar a ocorrência de resultados errôneos ao passo que a margem de separação das classes é maximizada. Assim sendo, o classificador obtido apresentará boa capacidade de generalização. Portanto, o hiperplano ótimo pode ser obtido com a determinação do par $\left(\mathbf{w}^{*}, \mathrm{~b}\right)$ tal que minimize a Equação 3-11:

$$
\text { Minimizar: } \frac{1}{2}\|\mathbf{w}\|^{2}+C \sum_{i=1}^{n} \xi_{i}
$$

Com a seguinte restrição:

$$
y_{i}\left(\mathbf{w} \cdot \mathbf{x}_{\mathbf{i}}+b\right) \geq 1-\xi_{i}, \quad i=1, \ldots, n
$$

onde $C$ é uma constante referente a uma ponderação reponsável por regular a sensibilidade do classificador de acordo com os ruídos:

- Valores baixos de $C$ permitem que as restrições sejam facilmente ignoradas, possibilitando a aquisição de margens largas;

- Valores altos de $C$ resultam em restrições mais rígidas, dessa forma são adquiridas margens mais estreitas;

- Quando $C \rightarrow \infty$, o classificador obtido é semelhante ao de margens rígidas.

A priori, o valor de $C$ pode ser obtido empiricamente. Contudo, essa prática pode resultar um classificador super ajustado aos dados de treinamento. Um dos 
métodos bastante explorado para contornar este problema, consiste na técnica grid search. Nesse método, uma busca exaustiva é realizada a fim de adquirir uma boa configuração dos parâmetros da SVM. Essa busca é realizada guiada através de uma métrica de qualidade: por exemplo, a validação cruzada.

O $k$-fold é uma abordagem de validação cruzada que tem sido utilizada de modo expressivo na busca de uma configuração ótima para o classificador. Este método consiste na divisão do conjunto de treinamento em $k$ subconjuntos mutuamentes exclusivos. Um desses conjuntos é utilizado para a fase de teste do classificador obtido enquanto os demais $k-1$ conjuntos são utilizados para a obtenção do classificador. Esta operação é realizada $k$ vezes, onde cada um dos $k$ conjuntos será utilizado na validação do classificador obtido. A acurácia resultante é dada pela média das acurácias obtidas em cada uma das $k$ iterações. O pseudocódigo dessa busca é detalhado no Algoritmo 3, onde $C_{\text {set }}$ e $\gamma_{\text {set }}$ correspondem, respectivamente, aos valores utilizados na combinação dos parâmetros $C$ e $\gamma$. Já features é o conjunto dos vetores de características utilizados no treinamento da SVM. Por último, $k_{-}$fold é a quantidade de subconjuntos em que features será subdividido.

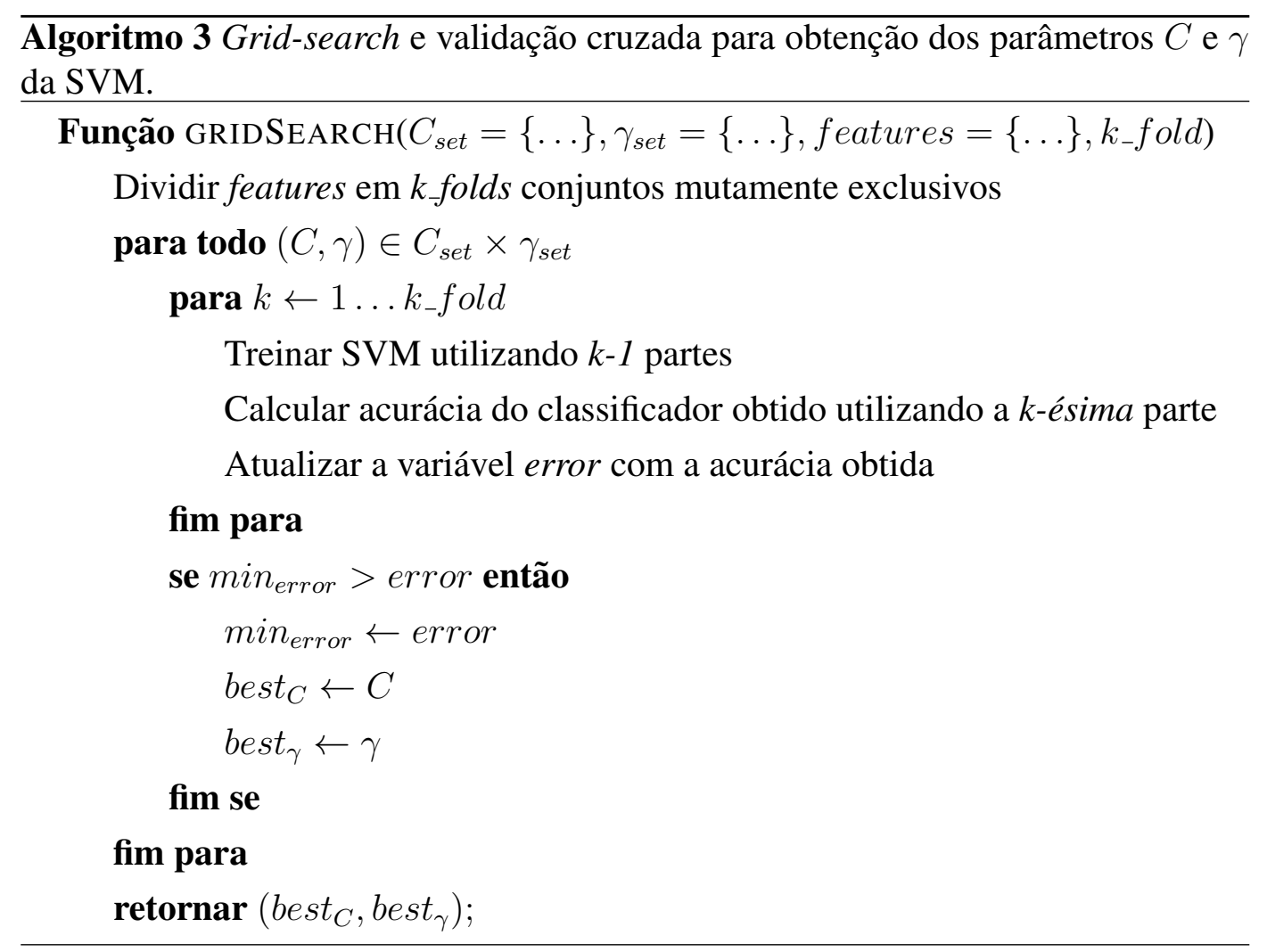

\subsection{3}




\section{Máquinas de Vetores de Suporte e Problemas Multiclasses}

As Máquinas de Vetores de Suporte foram originalmente formuladas para problemas de classificação binária. Porém, em diversas aplicações práticas é desejável trabalhar com um número maior de classes, como ocorre na etapa de classificação de engenharia reversa, onde deseja-se classificar em cilindros, cones, esferas, caixas, entre outros. Dessa forma, surgiram generalizações da abordagem inicial das Máquinas de Vetores de Suporte para trabalharem com problemas multiclasses. Essas generalizações utilizam a formulação original das Máquinas de Vetores de Suporte para a criação de vários classificadores binários, combinando-os de modo que seja possível distinguir uma entre várias classes.

\section{One Against One}

Diferentemente da abordagem anterior, na abordagem One Against One um classificador é criado para cada par de classes. Portanto, cada classificador é especialista em diferenciar o vetor de característica de uma classe com relação à outra classe. Em vista disso, para um problema com $N$ diferentes classes, os números de classificadores produzidos serão ${ }^{N(N-1)} / 2$. Logo, a quantidade de classificadores produzidos por essa abordagem é da ordem quadrática ao número de classes.

A classificação de um vetor de características $X_{i}$ é realizada através de um sistema de votação, onde cada classificador especialista em um par de classes irá votar naquela classe que é mais próxima ao vetor de característica sob análise. $\mathrm{O}$ resultado final será a classe que obteve maior votação.

\section{Grafos Dirigidos Acíclicos}

O método de classificação multiclasse por Grafos Dirigidos Acíclicos ou DAGSVM (Directed Acyclic Graph SVM) (Platt et al., 1999) é bastante similar à abordagem anterior, uma vez que nessa técnica cada classificador também é especialista em diferenciar duas classes de interesse. Logo, também são necessários $N(N-1) / 2$ classificadores. A diferença dessa abordagem decorre da combinação dos classificadores em uma estrutura hierárquica, em que cada classificador representa um nó do grafo. A hierarquia é organizada com um único nó raiz inicial e a cada nível da hierarquia, o número de nós aumenta em uma unidade até que o último nível obtenha os $N$ nós.

A classificação é realizada avaliando o vetor de características $X_{i}$ a partir do nó raiz. O caminho percorrido para o próximo nível é feito de acordo com o valor produzido pela classificação. Por exemplo, caso o resultado produzido pela 
classificação em um dado nó seja negativa, a próxima classificação será feita pelo classificador associado ao nó filho à esquerda, caso contrário será realizado pelo classificador associado ao nó filho à direita (Figura 3.16). Este processo repete-se até chegar ao último nível da hierarquia. O caminho percorrido é conhecido por caminho de avaliação (evaluation path).

Cada nó do grafo tem uma lista associada com às classes ainda válidas naquele estado. A cada nível da hierarquia, um item é removido dessa lista até que sobre apenas um no último nível, sendo esse o resultado obtido no processo de classificação.

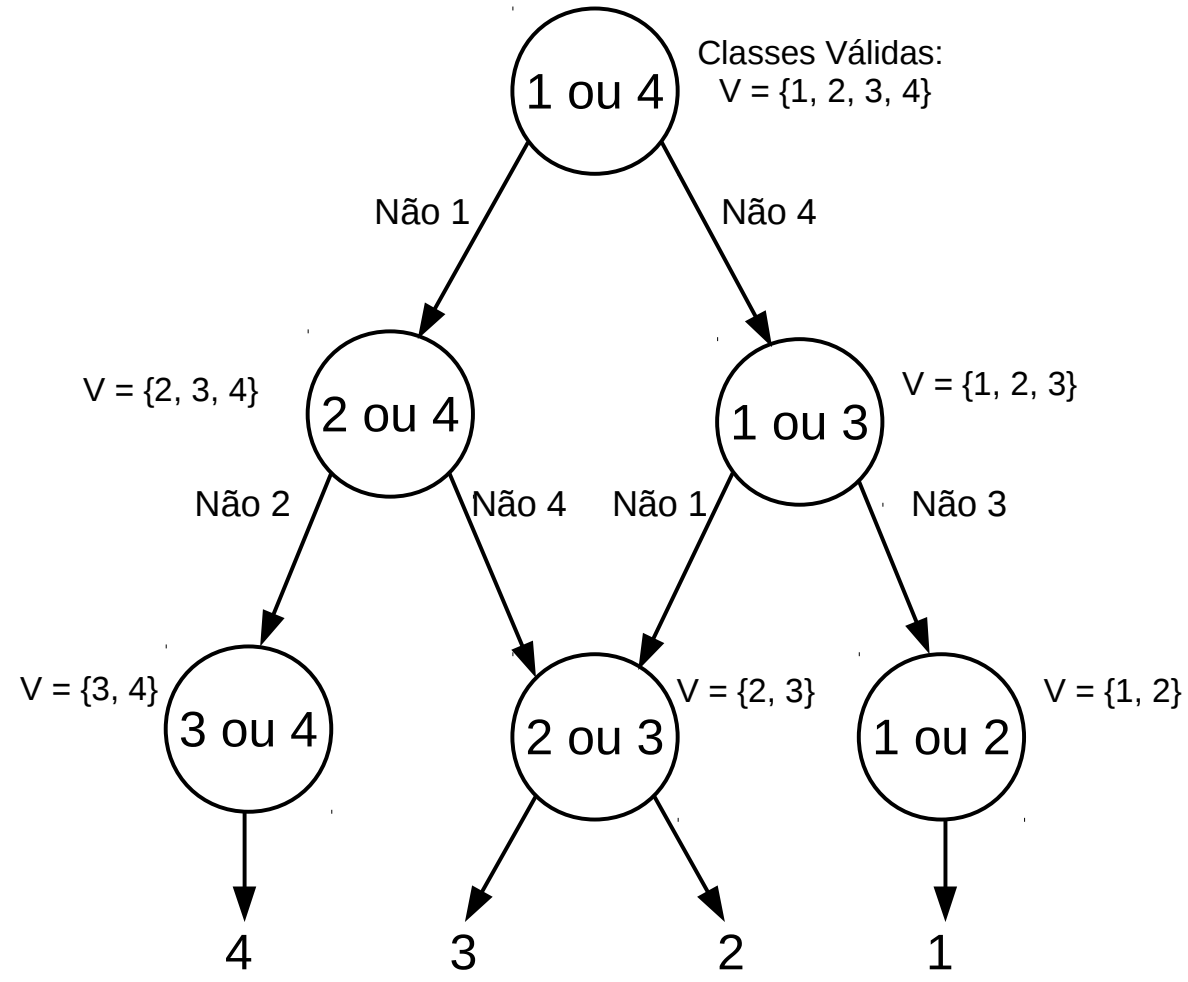

Figura 3.16: Grafo de decisão para quatro classes. O estado da lista equivalente é apresentado ao lado de cada um dos nós. (Platt et al., 1999).

Apesar do método de classificação multiclasse baseado em Grafos Dirigidos Acíclicos produzir a mesma quantidade de classificadores da abordagem One Against One, ${ }^{N(N-1)} / 2$, nele são realizadas $N-1$ classificações para a obtenção do resultado final, diferente da abordagem One Against One, em que todos os classificadores são utilizados no processo de classificação, resultando em ${ }^{N(N-1)} / 2$ classificações realizadas.

\subsection{4}




\section{Medidas de Desempenho de Aprendizagem de Máquina}

É de grande importância o uso de métricas para avaliar a qualidade dos resultados obtidos em classificações usando aprendizagem estatística. Para isso, fazse necessário que o leitor esteja familiarizado com a seguinte terminologia:

Tabela 3.2: Terminologia utilizada para os resultados obtidos na etapa de classificação.

\begin{tabular}{|c|c|c|c|}
\cline { 3 - 4 } \multicolumn{2}{|c|}{} & \multicolumn{2}{c|}{$\begin{array}{c}\text { Classificação } \\
\text { Obtida }\end{array}$} \\
\cline { 3 - 4 } \multicolumn{2}{|c|}{} & Positiva & Negativa \\
\hline $\begin{array}{c}\text { Classificação } \\
\text { Conhecida }\end{array}$ & Positiva & $\begin{array}{c}\text { Verdadeiro } \\
\text { Positivo (VP) }\end{array}$ & $\begin{array}{c}\text { Falso } \\
\text { Negativo (FN) }\end{array}$ \\
\cline { 2 - 4 } & \multirow{2}{*}{ Negativa } & Falso & Verdadeiro \\
& & Positivo (FP) & Negativo (VN) \\
\hline
\end{tabular}

Para melhor exemplificar esta terminologia, examinaremos os possíveis resultados obtidos considerando a classe de objetos do tipo cone. Se de fato a instância utilizada na classificação é do tipo cone e o resultado obtido é a classe cone, então temos um resultado verdadeiro positivo. Caso a resposta da classificação fosse uma classe que não o cone, o resultado seria um falso negativo. Por outro lado, seja a instância a ser classificada sendo de qualquer uma das outras classes paramétricas, que não seja o cone, e o resultado da classificação não sendo a classe cone, então o resultado obtido é um verdadeiro negativo. O resultado seria falso positivo caso a classe obtida fosse cone. Vale lembrar que a ocorrência de falsos positivos é mais prejudicial a abordagens de engenharia reversa de malha, quando considerada as classes de objetos paramétricos.

Indicadores importantes são utilizados a fim de avaliar um modelo de classificação, entre eles: acurácia, precisão e sensibilidade. A acurácia (Equação 3-13) reflete o acerto global da metodologia. Dada uma determinada classe, a precisão (Equação 3-14) corresponde a taxa de acerto para os objetos que foram classificados como pertencentes a esta classe, resultando assim em uma taxa de confiabilidade desta classe. Já a sensibilidade (Equação 3-15) é a medida que demonstra a capacidade de detectar instâncais de uma determinada classe.

$$
\begin{gathered}
A=\frac{V P+V N}{V P+F P+V N+F N} \\
P=\frac{V P}{V P+F P}
\end{gathered}
$$




$$
S=\frac{V P}{V P+F N}
$$

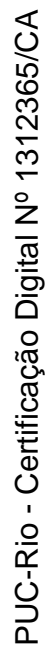




\section{4 \\ Metodologia Proposta}

Este capítulo apresenta a metodologia proposta para a engenharia reversa de caixas, cilindros, cones, esferas, pirâmides e esferoides oblatos, utilizando descritores de forma e aprendizagem de máquina. Para uma melhor organização e entendimento do trabalho, a metodologia proposta é dividida nas seguintes etapas: Segmentação da Malha, Classificação, Validação e Reconstrução, conforme o diagrama da Figura 4.1. Cada uma das etapas é apresentada a seguir, com exceção da etapa de segmentação. Isso porque essa atividade por si só já representa um vasto campo de pesquisa (Lukács et al., 1997),(Parvin e Medioni, 1982) e (Wu Leif Kobbelt, 2005). Além disso, grande parte dos modelos CAD já dispõem suas primitivas geométricas segmentadas, inclusive os modelos utilizados neste trabalho para a realização de testes.

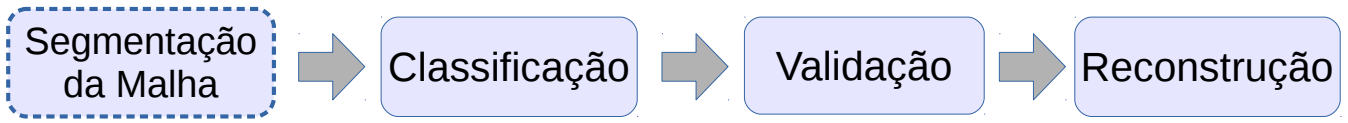

Figura 4.1: Representação esquemática das etapas presentes no processo de engenharia reversa. A etapa em pontilhado, segmentação, está fora do escopo deste trabalho.

\section{1}

\section{Classificação}

A etapa de classificação é responsável por identificar se uma determinada malha triangular pertence a alguma das classes de sólidos abordadas e, em caso afirmativo, a respectiva classe. Para atingir este objetivo, é feito uso das Máquinas de Vetores de Suporte e descritores de forma como vetores de características dos objetos. Neste trabalho são avaliados três descritores: D1, D2 (Osada et al., 2002) e um terceiro que é resultante da composição destes dois, chamado aqui de D1D2. A utilização do descritor D1D2 visa uma maior diferenciação dos objetos, uma ambas as características obtidas pelos dois descritores serão utilizadas.

Para que sejam obtidos vetores de características representativos, é preciso mensurar as distâncias de uma quantidade razoável de pontos distribuídos 
uniformemente na superfície dos sólidos. Contudo, grande parte das malhas dos objetos não possuem a quantidade de pontos apropriada para esta finalidade. Dessa forma, uma nuvem de pontos é criada a partir da malha original.

Outra problemática encontrada na classificação dos sólidos refere-se à sensibilidade dos descritores de forma à deformações. Diversos objetos de uma mesma classe sofrem deformações durante a instanciação dos mesmos. Logo, é preciso reverter as deformações aplicadas aos sólidos para que os vetores de características de objetos de uma mesma classe sejam similares.

Visando superar tais dificuldades, duas atividades são apresentadas a seguir:

\section{Geração de Nuvem de Pontos e Normalização da Escala.}

\subsection{1}

\section{Geração de Nuvem de Pontos}

A criação de uma nuvem de pontos a partir de uma malha triangular provê uma maior representação da superfície dos objetos, possibilitando a aquisição de histogramas de forma mais representativos. Ademais, é preciso que essa nuvem de pontos esteja distribuída uniformemente na superfície, evitando que determinadas regiões da superfície prevaleça na obtenção dessas métricas.

Para a obtenção de uma nuvem de pontos uniformemente distribuída, é necessário que a probabilidade de um ponto pertencer a um triângulo da malha seja proporcional à área deste triângulo. Dada uma malha com $k$ triângulos, esta relação é obtida com a divisão do intervalo $[0,1] \mathrm{em} k$ subintervalos, onde cada um dos subintervalos é proporcional à área do triângulo associado a este (Figura 4.2).

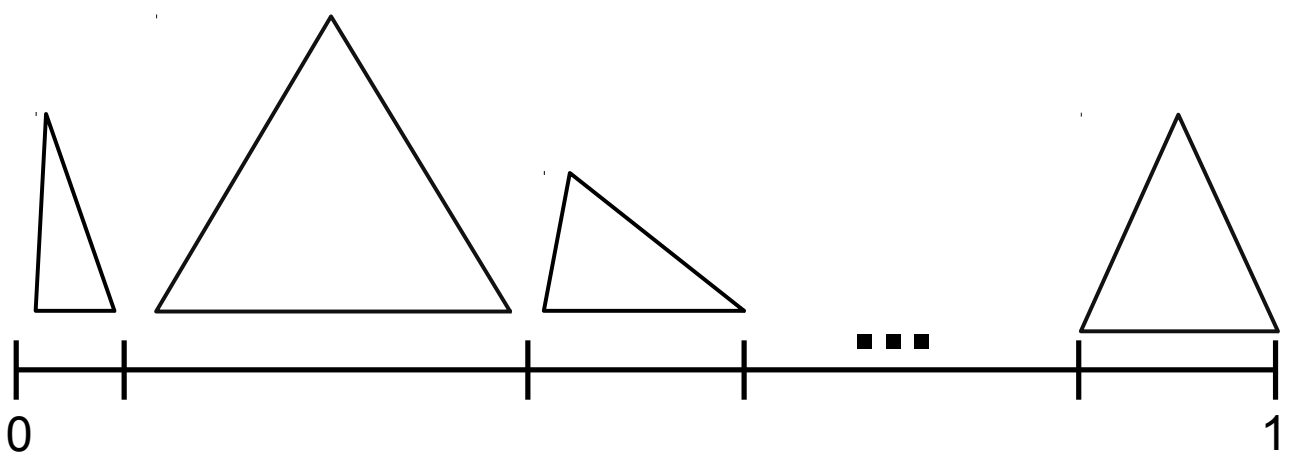

Figura 4.2: Subdivisão do intervalo $[0,1] \mathrm{em} k$ intervalos de acordo com a proporção da área do triângulo em relação à área total da superfície.

A geração de um número aleatório entre 0 e 1 indicará o subintervalo com o triângulo associado que será introduzido o novo ponto. Seja $A B C$ o triângulo sorteado, as coordenadas do novo ponto $p$ neste triângulo se dá através da geração de outros dois números aleatórios $r_{1}, r_{2} \in[0,1]$ aplicados à seguinte equação (McWherter et al., 2001): 


$$
p=\left(1-\sqrt{r_{1}}\right) A+\sqrt{r_{1}}\left(1-r_{2}\right) B+\sqrt{r_{1}} r_{2} C
$$

A Figura 4.3 demonstra o resultado alcançado pela geração da nuvem de pontos na superfície de um cilindro. A Figura 4.3(a) representa o wireframe da malha original, utilizada para a geração da nuvem de pontos. A Figura 4.3(b) exibe a nuvem de pontos obtida a partir da malha original do cilindro.

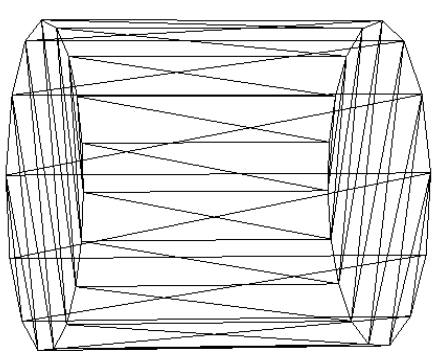

(a)

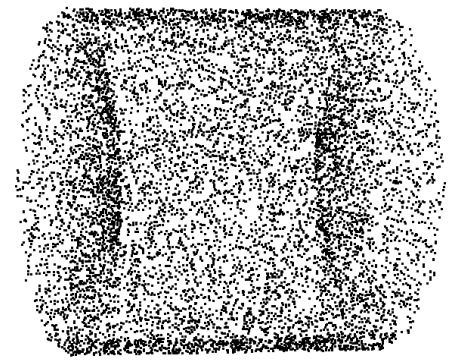

(b)

Figura 4.3: Geração de nuvem de pontos na superfície de um cilindro. Em 4.3(a), a malha original utilizada para a geração da nuvem de pontos. Em 4.3(b), a nuvem de pontos produzida na superfície do cilindro.

\section{Normalização da Escala}

Apesar dos histogramas de forma utilizados neste trabalho serem invariantes à escala uniforme, o mesmo comportamento não acontece quando há deformações nos objetos. A aplicação de escala não uniforme nos objetos produz alterações nas proporções de distância observadas em pontos da superfície do sólido, modificando o resultado obtido com os descritores de forma (Figura 4.4).

Este fato impede a utilização direta desses descritores como vetor de características dos objetos presentes em modelos CAD. Na instanciação desses objetos, são realizadas transformações de escala, rotação e translação. Em grande parte destas instanciações, são realizadas transformações de escalas não uniformes. Deste modo, os atributos característicos do sólido são modificados, conforme a Figura 4.5: um cilindro de raio 1 e altura 1 é utilizado como sólido padrão para a geração de dois outros cilindros; um com altura 10 e raio 1, outro com altura 100 e raio 1 . 


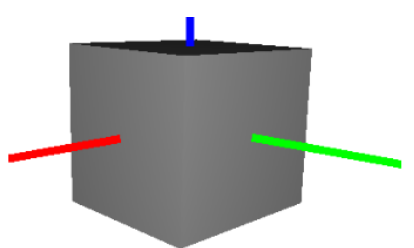

(a)

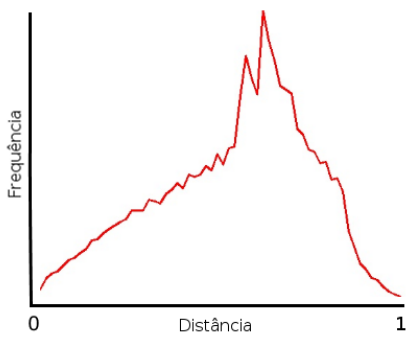

(d)

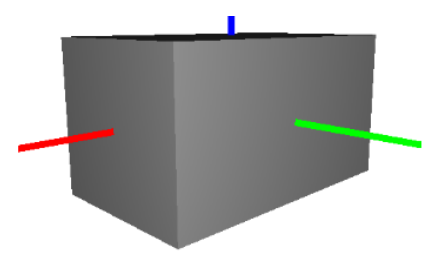

(b)

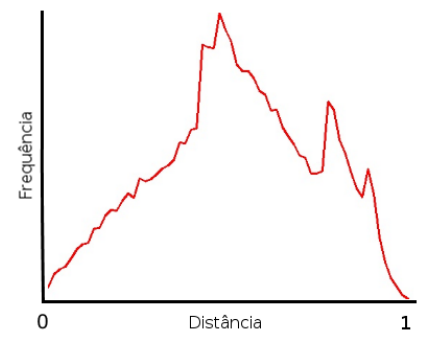

(e)

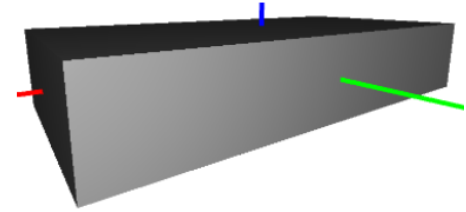

(c)

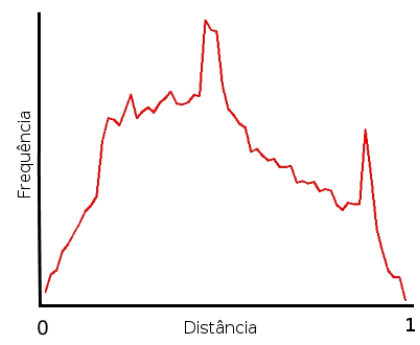

(f)

Figura 4.4: Sensibilidade do descritor D2 à deformação. 4.4(a), 4.4(b), 4.4(c) são caixas de tamanho $L 1=L 2=L 3=10 ; L 1=20, L 2=12, L 3=10$; e $L 1=80$, $L 2=20, L 3=10$, respectivamente. Seus histogramas correspondentes em $4.4(\mathrm{~d})$, 4.4(e), 4.4(f).

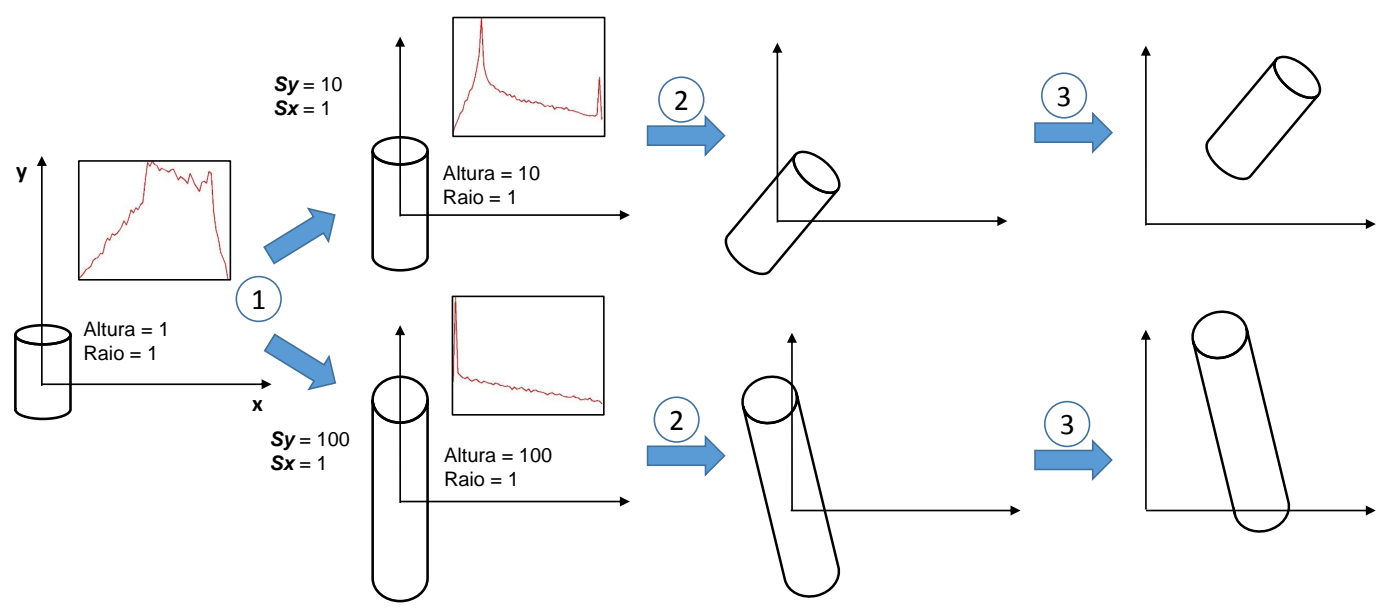

Figura 4.5: Sequência de transformações aplicadas a um objeto. (1), (2) e (3) correspondem à escala, rotação e translação, respectivamente.

A Normalização da Escala tem por finalidade a transformação de todos os objetos de uma mesma classe em uma forma padrão, sendo assim possível a comparação dos histogramas de forma de objetos deformados. Este procedimento é realizado a partir de transformações similares às empregadas nas instanciações dos objetos.

Em decorrência de uma restrição para os sólidos do tipo caixa, que será explicada adiante, a dimensão considerada do objeto inicial deve ser a mesma ao longo dos três eixos $\left(\operatorname{dim}_{x}=\operatorname{dim}_{y}=\operatorname{dim}_{z}\right)$. Assim, todos os objetos terão sua caixa envolvente transformada em um cubo. 
Uma vez que o objeto encontra-se posicionado na cena, é preciso alinhá-lo aos eixos do sistema para a normalização das dimensões do mesmo. Os procedimentos que serão adotados no alinhamento requerem que a densidade de pontos seja a mesma sobre toda a superfície. Como não é garantido que as malhas possuam esta característica, uma nuvem de pontos é gerada a partir da malha original. Portanto, as transformações necessárias para o alinhamento são obtidas com base nessa nuvem de pontos.

O primeiro passo para o alinhamento consiste em transladar o centroide do objeto para a origem. O centroide pode ser obtido através da média aritmética das coordenadas dos vértices. O alinhamento dos eixos do objeto com os eixos do sistema de coordenadas pode ser realizado por meio do método PCA (Principal Component Analysis). Com o PCA é possível obter uma base ortonormal referente às direções de dispersão de variáveis aleatórias. Em se tratando de nuvem de pontos, busca-se obter a direção de dispersão dos pontos. Tais direções são obtidas pela análise dos autovalores e autovetores da matriz de covariância dos vértices.

Seja $V$ o conjunto de pontos, a matriz de covariância $C$ é dada por:

$$
\begin{gathered}
C=\frac{1}{n}\left(V V^{T}\right) \\
=\frac{1}{n}\left[\begin{array}{ccc}
\sum_{k=0}^{n-1}\left(x_{k}-\bar{x}\right)^{2} & \sum_{k=0}^{n-1}\left(x_{k}-\bar{x}\right)\left(y_{k}-\bar{y}\right) & \sum_{k=0}^{n-1}\left(x_{k}-\bar{x}\right)\left(z_{k}-\bar{z}\right) \\
\sum_{k=0}^{n-1}\left(x_{k}-\bar{x}\right)\left(y_{k}-\bar{y}\right) & \sum_{k=0}^{n-1}\left(y_{k}-\bar{y}\right)^{2} & \sum_{k=0}^{n-1}\left(y_{k}-\bar{y}\right)\left(z_{k}-\bar{z}\right) \\
\sum_{k=0}^{n-1}\left(x_{k}-\bar{x}\right)\left(z_{k}-\bar{z}\right) & \sum_{k=0}^{n-1}\left(y_{k}-\bar{y}\right)\left(z_{k}-\bar{z}\right) & \sum_{k=0}^{n-1}\left(z_{k}-\bar{z}\right)^{2}
\end{array}\right] \\
=\left[\begin{array}{ccc}
\sigma_{x}^{2} & \sigma_{x y} & \sigma_{x z} \\
\sigma_{x y} & \sigma_{y}^{2} & \sigma_{y z} \\
\sigma_{x z} & \sigma_{y z} & \sigma_{z}^{2}
\end{array}\right]
\end{gathered}
$$

Os autovalores da matriz de covariância podem ser obtidos através das raízes da equação característica:

$$
\text { determinante }(A-\lambda I)=|A-\lambda I|=0
$$

Seja $\lambda$ um autovalor da matriz $A$, há um vetor $x$ tal que:

$$
A x=\lambda x
$$


$\mathrm{O}$ vetor $x$ que atende tal propriedade é denominado autovetor da matriz $A$. A matriz $M$, formada pelos autovetores unitários da matriz de covariância, pode ser interpretada como uma matriz de rotação dos eixos do sistema para os eixos locais do objeto. Desse modo, o alinhamento do sólido com os eixos do sistema pode ser realizado pela aplicação da matriz inversa $M^{-1}$, conforme a Figura 4.6:

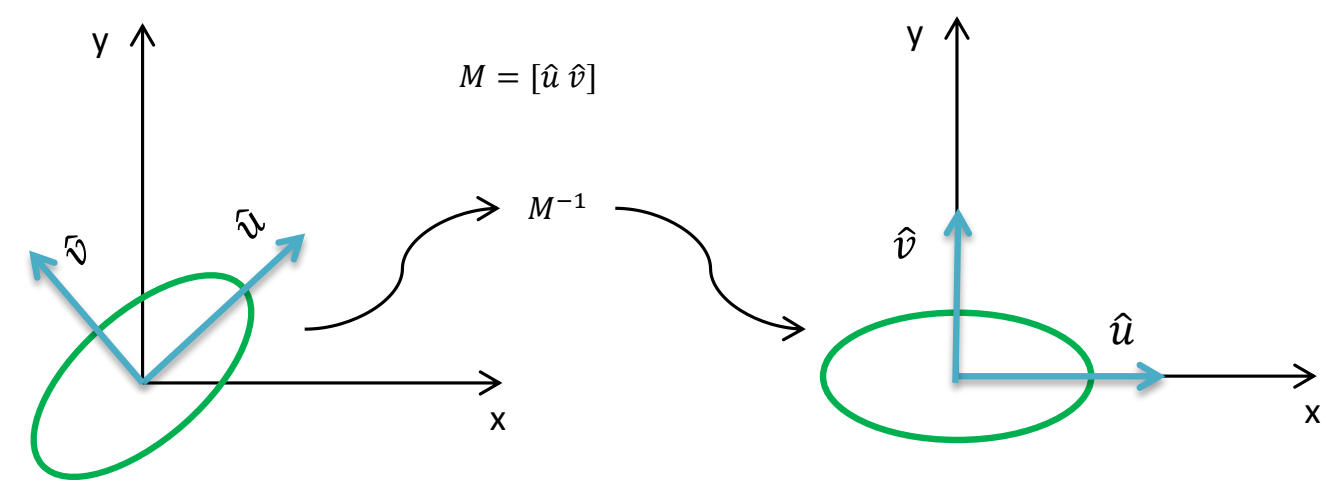

Figura 4.6: Alinhamento dos autovetores, obtidos da matriz de covariância, com os eixos do sistema através do método PCA.

Em algumas ocasiões, não é possível alinhar o sólido corretamente. A matriz de covariância reflete a dispersão dos dados em cada dimensão do espaço. Quando os pontos encontram-se distribuídos igualmente no espaço, não é possível definir uma direção de dispersão única. Quando a nuvem de pontos apresenta esta característica, os autovalores extraídos da matriz de covariância apresentam valores iguais. Neste caso, não é certificado que o alinhamento do objeto ocorrerá. Assim, a normalização das dimensões do objeto possivelmente deformará o objeto. Portanto, diferentes ações são realizadas, com base nos autovalores obtidos, para assegurar o alinhamento total do objeto:

A) $\lambda_{1} \neq \lambda_{2} \neq \lambda_{3}$ :

Neste caso não ocorre a indeterminação na direção de dispersão dos pontos. O alinhamento é realizado sem nenhum tratamento adicional.

B) $\lambda_{1}=\lambda_{2}=\lambda_{3}$ :

Das classes de sólidos abordadas neste trabalho, duas classes em particular apresentam tal comportamento: esfera e a caixa, quando esta última é um cubo. A esfera não chega a ser um problema para a metodologia, devido a sua simetria em todas as direções. Além disso, todas as esferas da cena são instanciadas por uma escala uniforme, não sofrendo assim deformações. Porém, o mesmo não acontece com o cubo (Figura 4.7). Caso a normalização 
da escala seja realizada em um cubo mal alinhado com os eixos do sistema, o objeto poderá deformar e a classificação possivelmente falhará. Logo, nenhuma escala é aplicada quando $\lambda_{1}=\lambda_{2}=\lambda_{3}$. Assim, a superfície do cubo permanecerá inalterada.

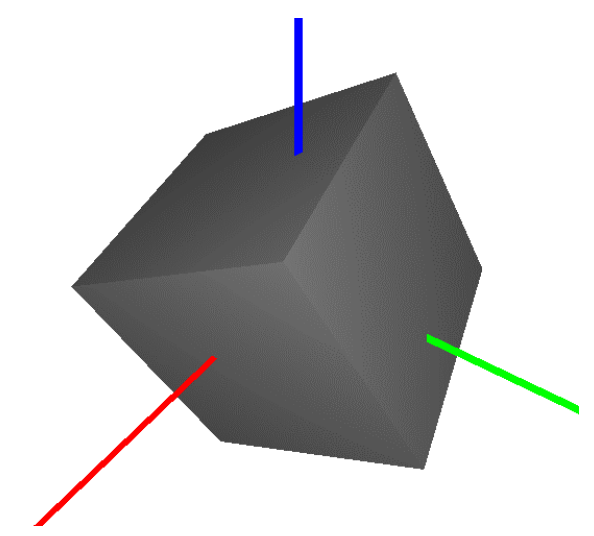

Figura 4.7: Não alinhamento do cubo aos eixos do sistema de coordenadas.

Para agregar todos os cubos e paralelepípedos retos em uma mesma classe de sólidos (tipo caixa), é necessário que a etapa de normalização da escala transforme todos esses sólidos para uma forma comum. Todavia, não é possível transformar cubos em paralelepípedos retos, devido o não alinhamento desses sólidos com os eixos do sistema. Já o contrário é possível, isto é, transformar todos os paralelepípedos retos em um cubo. Deste fato resulta a restrição de que a dimensão adotada para os objetos consiste em um valor qualquer, desde que seja o mesmo valor para todas as três dimensões.

C) $\quad \lambda_{i}=\lambda_{j} \neq \lambda_{k} \quad \mid \quad i, j, k \in\{1,2,3\}, i \neq j \neq k$

Um comportamento similar acontece quando a matriz de covariância apresenta dois autovalores iguais. Do mesmo modo, haverá uma indeterminação nos autovetores associados às dimensões com distribuições uniformes. Cilindros, cones e esferoides oblatos apresentam tal comportamento. Contudo, nestes sólidos também não há uma orientação definida no plano em que esta indeterminação ocorre, não representando assim um problema.

Por outro lado, caixas e pirâmides também apresentam indeterminação em dois autovetores, caso duas dimensões desses objetos sejam iguais. Diferentemente dos sólidos citados anteriormente, caixas e pirâmides possuem orientação definida no plano onde ocorre a indeterminação (Figura 4.8). Transformações de escalas poderão deformar estes objetos.

Quando esta configuração ocorre, o alinhamento via PCA irá deixar o sólido alinhado somente na direção do autovetor $x_{k}$ associado à $\lambda_{k}$. Para o 


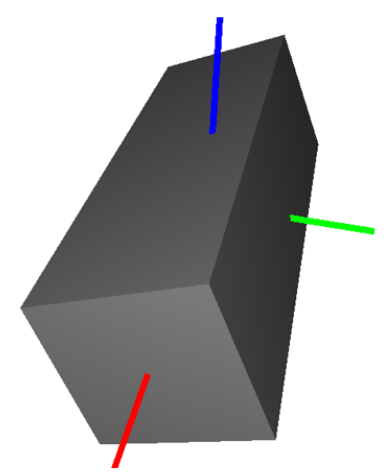

(a)

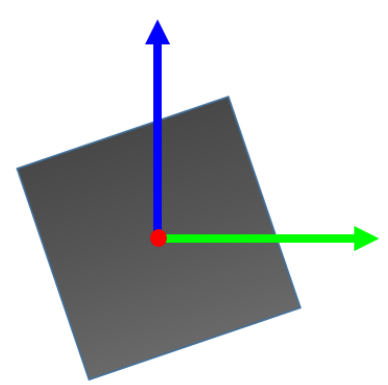

(b)

Figura 4.8: Não alinhamento de objetos em dois eixos. Em 4.8(a), uma caixa não alinhada, onde $L 1=L 2 \neq L 3$. Em 4.8(b), uma representação do objeto visto ao longo do eixo longitudinal.

alinhamento correto do sólido, é preciso realizar uma última rotação em torno do autovetor $x_{k}$. Para isso, é considerado os pontos contidos em um plano perpendicular à $x_{k}$. Destes pontos é obtido o fecho convexo. Seja $o$ o centro do fecho convexo e $p_{c}$ o ponto do fecho mais próximo de $o$, o alinhamento do vetor $p_{c}-o$ com os eixos do sistema resultará no alinhamento do sólido, conforme a Figura 4.9.

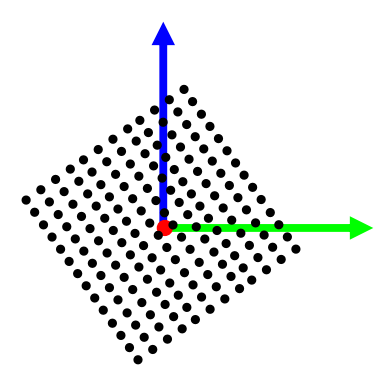

(a)

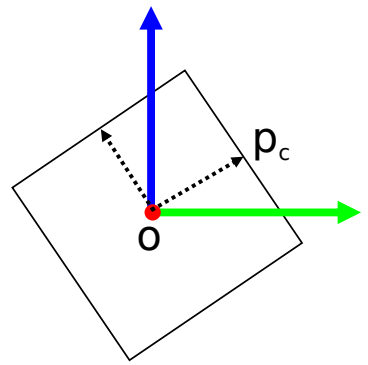

(b)

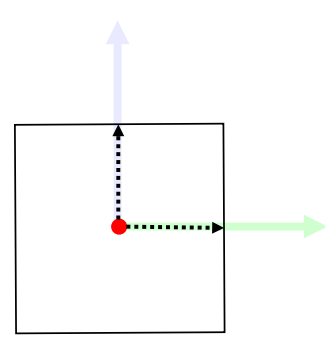

(c)

Figura 4.9: Alinhamento de um sólido com dois autovalores da matriz de covariância iguais. Em 4.9(a), a configuração inicial de não alinhamento. Em 4.9(b), o fecho convexo e vetores a serem alinhados. Em 4.9(c), o alinhamento utilizando os vetores tracejados.

Por fim, nem todos os tipos sólidos podem ser transformados em uma forma exatamente igual. A Figura 4.10 apresenta uma visão longitudinal de um cone, onde não é possível obter uma transformação de escala que altere as proporções entre o raio maior e o raio menor. A pirâmide também tem comportamento similar ao cone: a razão entre a base superior e inferior não pode ser modificada por meio das transformações descritas. A instanciação dos sólidos destas classes se dá a partir de sólidos padrões diferentes. Dessa forma, o processo de normalização da escala 
apenas aproxima essas primitivas para uma configuração comum. Tal aproximação, aliada à boa capacidade de generalização das Máquinas de Vetores de Suporte, garante a viabilidade da comparação dos histogramas de forma desses sólidos.
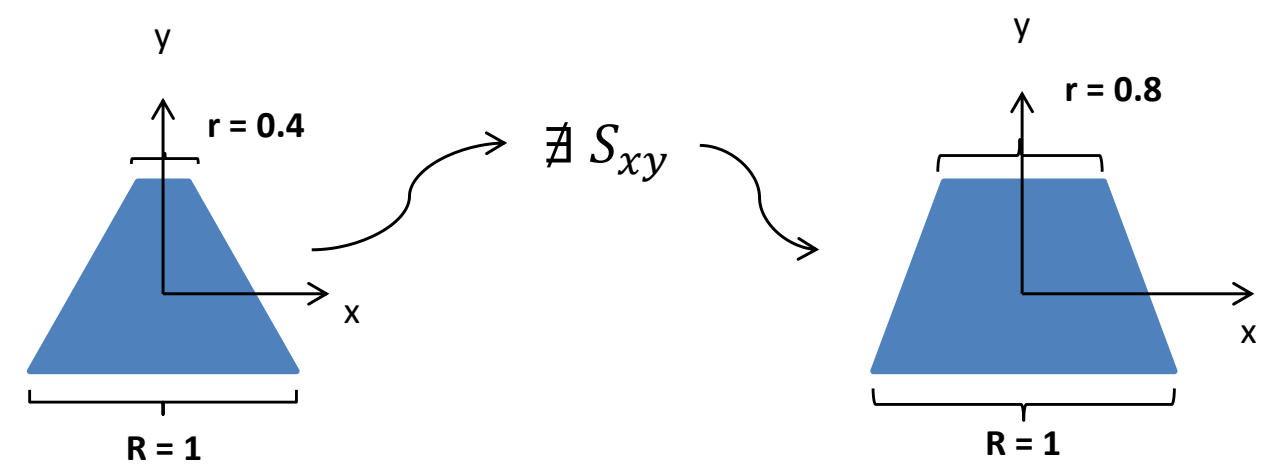

Figura 4.10: Cones com diferentes proporções entre o raio maior e o raio menor, impossibilitando a transformação de uma forma na outra.

Uma vez que todos os procedimentos descritos foram realizados, o histograma de forma pode ser extraído. No entanto, o histograma não pode ser obtido através da nuvem de pontos utilizada até então. Isto porque a normalização das dimensões da mesma pode ter sido obtida através de uma escala não uniforme, não garantindo assim que os pontos ainda estejam distribuídos uniformemente sobre superfície da malha original. Em vista disso, é necessária a criação de uma nova nuvem de pontos que os pontos estejam garantidamente distribuídos uniformementes. Para tal, as transformações obtidas para a normalização da escala são utilizadas na malha original, posteriormente a nova nuvem de pontos é obtida seguindo os procedimentos já descritos anteriormente. Uma vez que as características tenham sido extraídas a partir dessa nova nuvem de pontos, a classificação do objeto será obtida através da Máquina de Vetores de Suporte.

As próximas etapas da metodologia, Validação e Reconstrução, atuam sobre os vértices da malha original alinhados aos eixos, porém sem a normalização das dimensões dos mesmos. É necessário que os vértices estejam preservados na escala original para a extração correta dos atributos característicos do sólido.

Os procedimentos realizados na etapa de Classificação podem ser resumidos segundo o Algoritmo 4. 


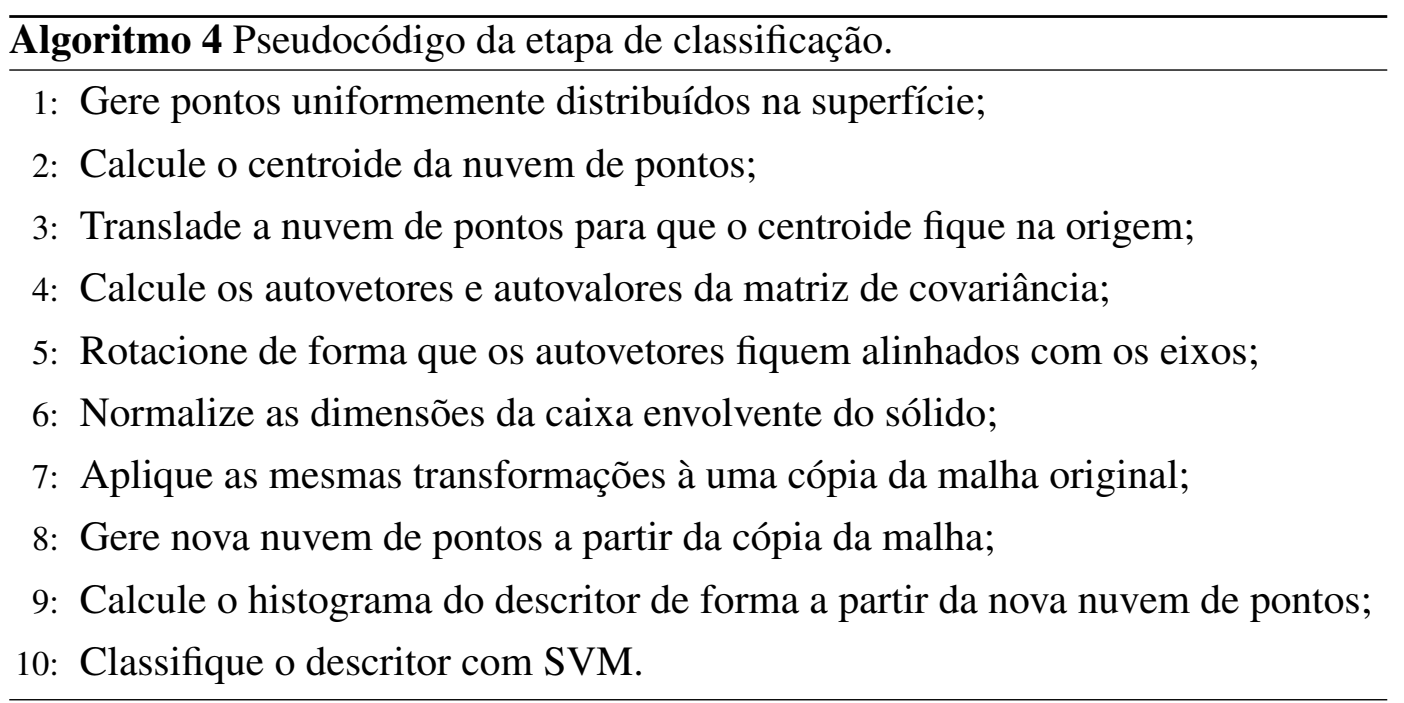

\section{2}

\section{Validação}

Metodologias que utilizam aprendizagem estatística como método de classificação de dados estão suscetíveis à produção de resultados errôneos. Estes podem ser divididos em duas categorias: falso positivo e falso negativo. $\mathrm{O}$ primeiro está relacionado aos resultados obtidos como afirmativos para uma determinada classe, quando, no entanto, o resultado correto seria a predição negativa para a mesma. Já os resultados falsos negativos acontecem quando o resultado da classificação é negativo para uma dada classe e o resultado correto seria o resultado positivo.

O grande desafio de qualquer método de classificação de dados consiste em minimizar a ocorrência de resultados falsos, ao passo que as predições corretas sejam maximizadas. Contudo, dificilmente é possível obter um classificador que não produza resultados errôneos. Nesse caso, a depender da aplicação, a ocorrência de um dos tipos de erros é mais aceitável que a ocorrência de outro. Na engenharia reversa é preferível ocorrências de falsos negativos à de falsos positivos para as classes dos sólidos paramétricos.

Quando ocorre um falso positivo, a forma do objeto é alterada, podendo resultar em ambiguidades na visualização e interpretação do modelo. Além disso, resultados numéricos obtidos através dos parâmetros do objeto não produzirão resultados confiáveis. A ocorrência de falsos negativos, por outro lado, não ocasiona grandes efeitos colaterais ao modelo, pois a forma da superfície do objeto permanece inalterada, garantindo assim que todas atividades que utilizam este objeto continuem preservadas. O lado negativo é que o objeto continuará sendo representado como malha, enquanto que o mesmo poderia tirar vantagens providenciadas pela representação paramétrica. 
A etapa de Validação visa a diminuição de falsos positivos obtidos na etapa anterior (Classificação). Os critérios adotados para validação são particulares a cada uma das classes de sólidos, uma vez que estes possuem características peculiares que são necessárias para que uma malha pertença à classe. Esta fase é realizada a partir da malha original do sólido, porém alinhada aos eixos do sistema. Apesar disso, somente os vértices e as normais da malha são utilizadas para a validação dos requisios, garantindo que não dependa da triangulação da malha. Os critérios de validação de cada uma das classes de sólidos são listados a seguir:

\section{Caixas}

- Possui apenas seis normais únicas na superfície, uma para cada plano;

- Para cada uma das seis normais, há uma normal que é paralela e em sentido oposto; as quatro demais normais são perpendiculares.

\section{Cilindros}

- Extraindo as normais únicas da superfície, existem duas que são paralelas e com sentidos opostos $\left(P_{D I R}\right)$. As demais são perpendiculares em relação a estas duas;

- Todos os vértices que possuem as normais perpendiculares ao eixo principal apresentam uma curvatura principal com valor 0 e a outra com valor não nulo;

\section{Cones}

- Entre as diferentes normais da superfície, existem no máximo duas normais $\left(P_{D I R}\right)$ que são paralelas entre si, em sentidos opostos. As restantes pertencem à lateral do cone;

- Todas as normais da lateral do cone formam o mesmo ângulo com os vetores $P_{D I R}$;

- Os vértices das laterais possuem $K_{\min }=0$ e $K_{\max } \neq 0$. 


\section{Esferoides Oblatos}

- Quando centrado na origem e alinhado com os eixos, duas dimensões apresentam tamanhos iguais. A terceira dimensão corresponde à $P_{D I R} \mathrm{e}$ apresenta tamanho menor que as outras duas;

- A clusterização dos vértices, utilizando os planos normais à $P_{D I R}$, apresenta características particulares. Todos os vértices contidos em um dos planos são equidistantes em relação ao ponto obtido pela intersecção entre $P_{D I R}$ e o plano (Figura 4.11);

- Os vértices presentes no mesmo plano possuem curvaturas principais iguais.

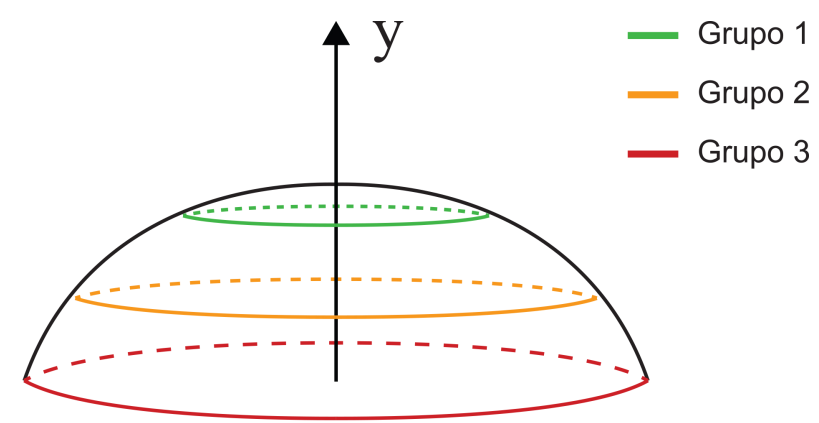

Figura 4.11: Clusterização dos vértices de um esferoide oblato segundo a curvatura. Cada um dos grupos representa pontos contidos em um plano.

\section{Esferas}

- Todos os pontos são equidistantes em relação ao centro geométrico;

- Para todos os vértices, $K_{\min }=K_{\max }=C$;

\section{Pirâmides}

- Possui 5 ou 6 normais únicas;

- Existe no máximo duas normais na direção longitudinal da pirâmide $P_{D I R}$;

- As normais das faces laterais não são perpendiculares à $P_{D I R}$;

- Existem no máximo dois valores diferentes de ângulos formados entre $P_{D I R}$ e as normais das faces laterais. 


\section{3 \\ Reconstrução}

Após as etapas de Classificação e Validação do sólido, os parâmetros característicos são adquiridos na etapa de Reconstrução. Assim como a etapa anterior, os procedimentos aqui descritos para a reconstrução do sólido consideram a malha original alinhada aos eixos do sistema. Vale salientar que somente os vértices dessa malha são utilizados na reconstrução dos parâmetros. Para maior clareza, será considerado que os vetores da direção principal dos sólidos $\left(P_{D I R}\right)$ estão alinhados com o eixo $Y$ do sistema de coordenadas.

A Figura 4.12 detalha os parâmetros associados a cada uma das formas trabalhadas.

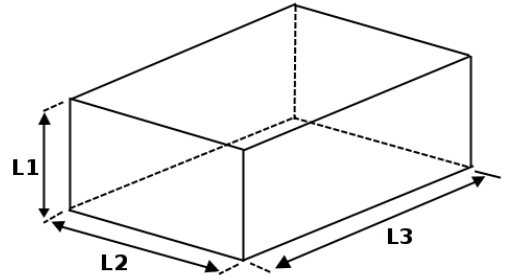

(a)Caixa

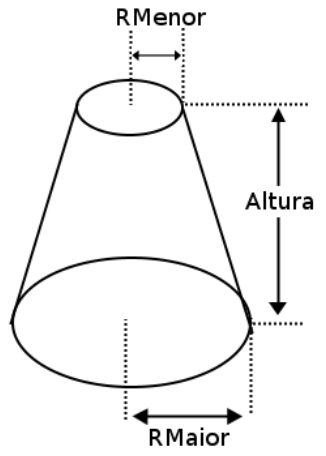

(b)Cone

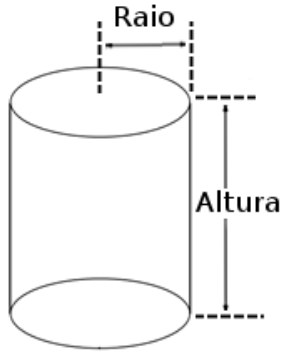

(c)Cilindro

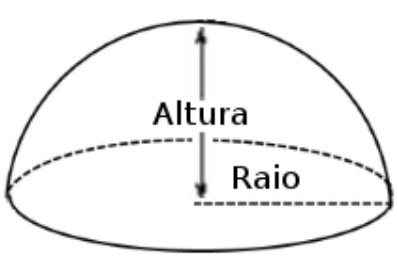

(d)Esferoide Oblato

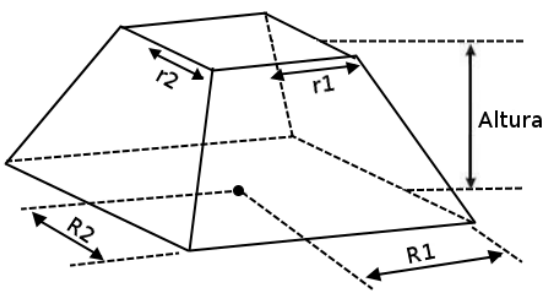

(e)Pirâmide

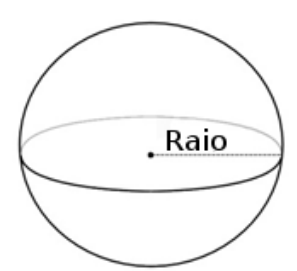

(f)Esfera

Figura 4.12: Classes de sólidos paramétricos e seus respectivos parâmetros.

A seguir, apresentamos os procedimentos adotados para a reconstrução dos parâmetros de cada uma das classes de sólidos abordadas neste trabalho:

\section{Caixas}

Como discutido anteriormente, nem sempre é possível realizar o alinhamento do cubo através do método PCA. Todavia, uma vez que na etapa de reconstrução o objeto do tipo cubo já foi classificado e validado, o alinhamento deste objeto pode ser realizado através da base ortonormal formada pelas normais das faces do 
mesmo. Desse modo, a extração dos seus atributos pode ser realizada facilmente (Figura 4.13).

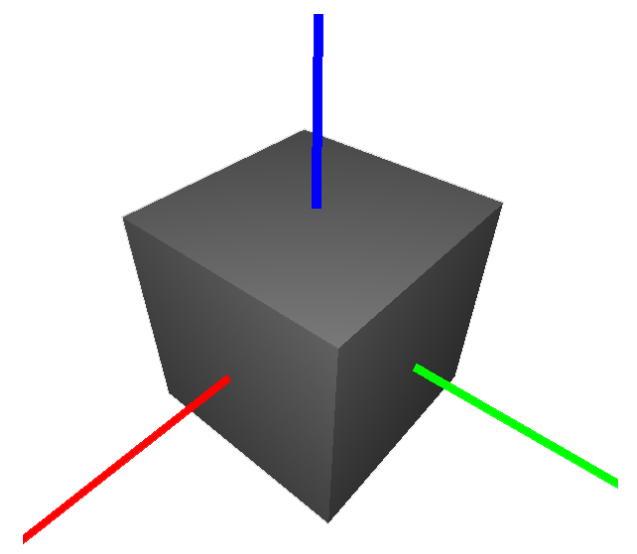

Figura 4.13: Alinhamento do cubo através da base ortonormal formada pelas normais das faces.

- Os lados da caixa são obtidos diretamente através da diferença do ponto mínimo e máximo.

\section{Cilindros}

- A altura do cilindro corresponde ao comprimento do mesmo na direção do eixo $Y$;

- O raio do cilindro corresponde à metade do comprimento na direção do eixo $X$ ou $Z$.

\section{Cones}

- A altura do cone é dada pelo tamanho do sólido na direção do eixo $Y$;

- O raio maior é dado pela metade do tamanho da na direção do eixo $X$ ou $Z$;

- A obtenção do raio menor, RMenor, é demonstrada na Figura 4.14. 


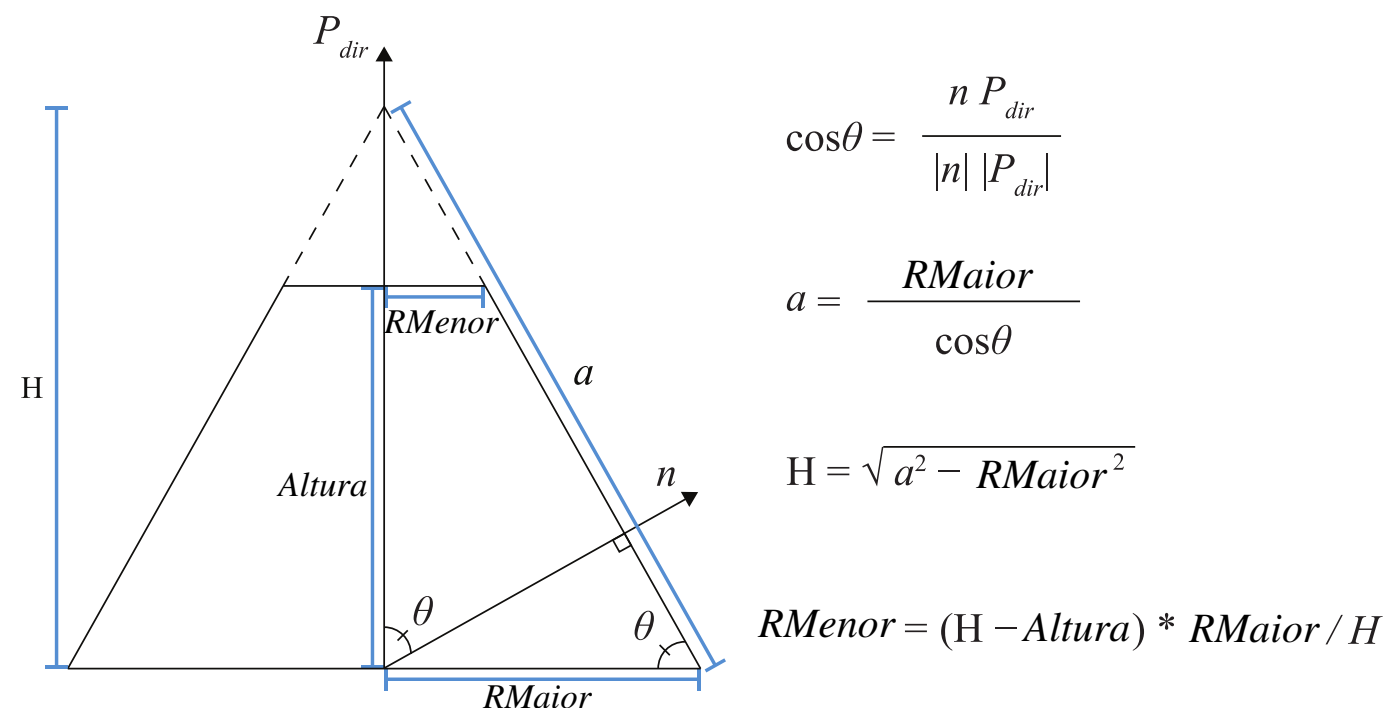

Figura 4.14: Vista longitudinal de um tronco de cone. Etapa de reconstrução do raio menor do cone.

\section{Esferoides Oblatos}

- A altura é adquirida através do tamanho do sólido na direção do eixo $Y$;

- O raio é dado pela metade do comprimento nas dimensões de tamanhos iguais, $X$ e $Z$;

\section{Esferas}

- As três dimensões apresentam o mesmo tamanho e este corresponde ao diâmetro da esfera. O raio é então obtido pela metade desse valor.

\section{Pirâmides}

- A altura da pirâmide é dada pelo tamanho na direção do eixo $Y$;

- Os lados da base inferior são dados pelo comprimento $X$ e $Z$;

- Os lados da base superior são obtidos de forma similar ao apresentado na Figura 4.14. 


\section{5 \\ Resultados Obtidos}

Para fins de testes e validação da metodologia proposta, foram utilizados modelos CAD de empreendimentos de engenharia. Também foram utilizadas malhas sintetizadas proceduralmente visando a realização de casos de testes mais controlados. O roteiro de testes seguiu detalhadamente as etapas descritas no Capítulo 4. Além disso, foram avaliados três descritores de forma: D1, D2, D1D2.

Para o alinhamento e, consequentemente, normalização das dimensões dos sólidos, foi criada uma nuvem de pontos com 100.000 elementos sobre a superfície da malha original. Após a normalização do objeto, é necessária a criação de uma nova nuvem de pontos considerando as novas dimensões do mesmo. Esta nova nuvem de pontos será utilizada para a extração dos descritores de forma.

Devido à ausência de grandes detalhes nas superfícies dos sólidos trabalhados, uma nuvem de pontos menos densa que a primeira pode ser utilizada para a obtenção dos histogramas de forma, sem prejudicar a etapa de classificação. Portanto, a quantidade de pontos utilizadas para a obtenção das métricas é bem inferior aos $1024^{2}$ pontos sugeridos em (Osada et al., 2002). Para a medida D2, o histograma foi construído a partir das medidas extraídas de 800 pontos combinados dois a dois, resultando em 319.600 aferições. Já o D1 foi obtido a partir da distância do centroide para 128.000 pontos na superfície. Ambos histogramas foram representados por 64 colunas. O histograma D1D2, por sua vez, também possui 64 colunas, a primeira metade corresponde ao descritor D1 discretizado em 32 colunas, enquanto que a outra metade corresponde ao D2 também representado por 32 colunas. As Figuras 5.4, 5.5 e 5.6 demonstram os histogramas produzidos para 10 instâncias de cada uma das classes utilizando os descritores D1, D2 e D1D2, repectivamente.

Além das seis classes de sólidos abordadas neste trabalho, também foi introduzida a classe denominada "malha" para abranger todos os objetos que não podem ser representados por nenhuma das seis classes de sólidos paramétricos. A utilização dessa categoria visa diminuir ainda mais a ocorrência de falsos positivos. Sem essa categoria, qualquer objeto seria classificado pela Máquina de Vetores de Suporte como sendo uma das seis classes de sólidos paramétricos. Dessa forma, a remoção dos resultados falsos positivos seria de responsabilidade exclusiva da 
etapa de validação. Devido ao fato da categoria "malha" corresponder ao conjunto universo dos sólidos, exceto os seis tipos paramétricos abordados, é impossível estabelecer um padrão para os vetores de características dessa categoria. Logo, os histogramas utilizados na caracterização dessa classe foram gerados aleatoriamente.

Para a generalização das SVMs em problemas multiclasses, foram testadas as abordagens One-Against-All e One-Against-One. Contudo, a última apresentou os melhores resultados e portanto consistem nos resultados aqui apresentados. Dessa forma, para as setes classes utilizadas no problema (6 classes paramétricas e 1 classe malha) foram produzidos 21 classificadores. Ademais, a SVM foi treinada utilizando o kernel RBF, pois este representa uma escolha razoável para a maioria dos classificadores lineares (Hsu et al., 2003). Além do tipo de kernel utilizado, a eficiência da SVM depende também da escolha apropriada dos parâmetros do kernel $(\gamma$ para RBF) e do parâmetro de margens suaves $(C)$. A escolha destes parâmetros foi realizada através do grid-search com validação cruzada ( $k$-fold). Os valores utilizados na busca dos parâmetros $C$ e $\gamma$ foram: $C=\left\{2^{-5}, 2^{-3}, 2^{-1}, \ldots, 2^{15}\right\}$ e $\gamma=\left\{2^{-15}, 2^{-13}, 2^{-11}, \ldots, 2^{3}\right\}$.

Tanto na validação cruzada, quanto no treinamento do classificador; foram utilizados 1.500 vetores de características de cada uma das sete classes. Os vetores de características dos sólidos paramétricos foram a partir do sintetizador de malha para estes objetos, enquanto que os vetores de características da classe malha foram obtidos através da geração aleatória do histograma de forma, conforme discutido anteriormente. No total, os 10.500 vetores de características foram divididos em 5 conjuntos disjuntos para a obtenção dos parâmetros da SVM através da abordagem grid-search. A Tabela 5.1 e a Figura 5.1 demonstram os resultados obtidos nesta etapa para cada um dos descritores.

Tabela 5.1: Resultados obtidos com grid-search e validação cruzada.

\begin{tabular}{|c|c|c|c|}
\hline Descritor & $\boldsymbol{C}$ & $\gamma$ & Acurácia \\
\hline D1 & 512,0 & 8,0 & $99,99 \%$ \\
\hline D2 & 32768,0 & 2,0 & $99,98 \%$ \\
\hline D1D2 & 512,0 & 0,5 & $99,99 \%$ \\
\hline
\end{tabular}

Analisando os valores de acurácia obtidos com a utilização da validação cruzada, é perceptível que todos os descritores utilizados apresentam bons resultados na diferenciação das classes de sólidos. Ao mesmo tempo, a Figura 5.1 corrobora esta afirmação, em consequência da presença de grandes regiões referente às configurações em que se obtiveram as melhores acurácias, indicando que, de fato, os descritores utilizados são discriminantes para as classes de sólidos trabalhadas. Pode-se constatar também que os descritores D1 e D1D2 obtiveram uma acurácia ligeiramente melhor que o descritor D2. Dessa forma, para os objetos utilizados nos 


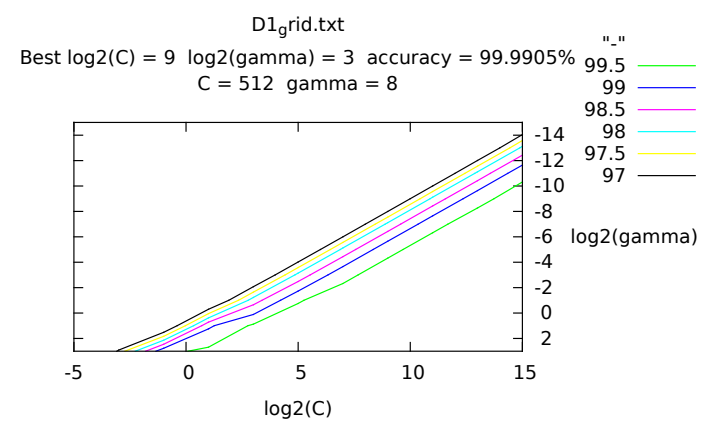

(a)Descritor de forma D1

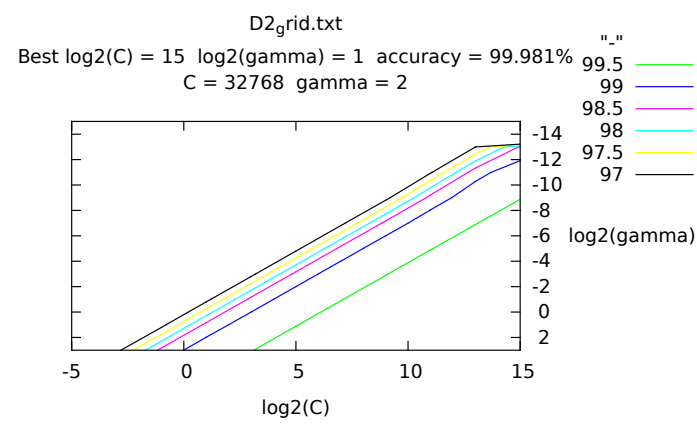

(b)Descritor de forma D2

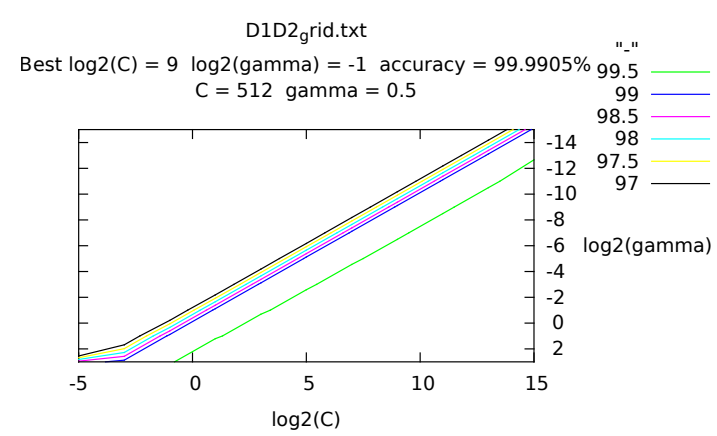

(c)Descritor de forma D1D2

Figura 5.1: Acurácias obtidas para cada um dos descritores segundo os valores de configuração da SVM obtidos através do método grid-search.

testes, o descritor D1D2 não apresentou uma capacidade maior de diferenciamento, se comparado com o descritor D1, das classes de sólidos.

Utilizando primeiramente as malhas sintéticas a fim de obter testes mais controlados, os resultados obtidos sem a etapa de validação são demonstrados nas matrizes de confusão representadas nas Tabelas 5.2, 5.3 e 5.4; para os descritores D1, D2 e D1D2, respectivamente. Vale destacar que 10\% das instâncias das caixas geradas pelo sintetizador são cubos, outros $10 \%$ são caixas com $l_{1}=l_{2} \neq l_{3}$.

Os valores predominantes nas diagonais principais das matrizes indicam que a classificação via SVM apresentou bons resultados, uma vez que estes correspondem aos casos de acerto da metodologia (verdadeiro positivo). Por isso, a taxa de precisão de todas as classes se aproximaram de $100 \%$, evidenciando que os resultados falsos positivos foram insignificantes com relação ao tamanho da amostra. Apesar disso, ainda assim, é desejável que todas as classes apresentem $100 \%$ de precisão, portanto, que não haja falsos positivos.

Outro ponto observável é que a maioria das ocorrências de falsos positivos aconteceu entre pirâmides e caixas, e também entre cilindros e cones. Isto deve-se ao fato de que pirâmides com os lados da base inferior aproximadamente iguais aos lados da base superior, em muito assemelham-se à caixas. Da mesma forma, cones com raio da base inferior próximo ao raio da base superior assemelham-se à 
cilindros. Nestes casos, os vetores de características obtidos para diferentes classes de sólidos apresentam alto grau de similaridade, conforme a Figura 5.2.

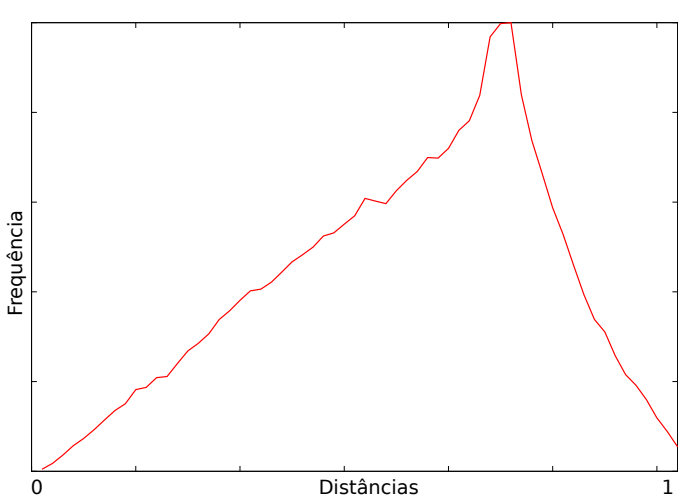

(a)

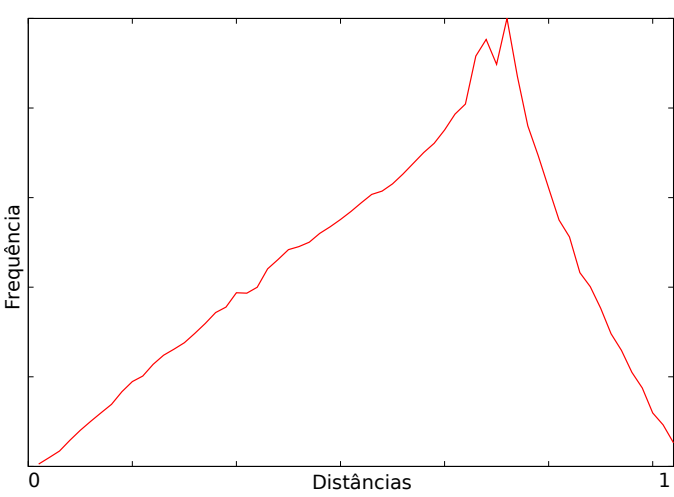

(b)

Figura 5.2: Histogramas de forma obtidos com o descritor D2. Em 5.2(a), o histograma de um cilindro de altura 1 e raio 1. Em 5.2(b), o histograma de um cone com altura 1 , raio inferior 1 e raio superior 0,95 .

Objetivando a eliminação dos resultados falsos positivos, os resultados após a etapa de validação para as mesmas instâncias das Tabelas 5.2, 5.3 e 5.4 são descritos nas Tabelas 5.5, 5.6 e 5.7, respectivamente. Diferentemente do resultado anterior, todas as classes obtiveram precisão de 100\%, logo, sem ocorrência de resultados falsos positivos. Entretanto, a sensibilidade e a acurácia diminuíram, uma vez que a etapa de validação acaba por eliminar algumas instâncias que haviam sido classificadas corretamente. Isto acontece por problemas de precisão numérica durante as atividades de validação descritas em 4.2. Apesar disso, o número de instâncias descartadas incorretamente é desprezível se comparado com o tamanho da amostra.

Avaliando somente os resultados provenientes da classificação realizada pela Máquina de Vetores de Suporte, o descritor D1 apresentou os melhores resultados. A acurácia obtida com o D1 foi de 99,97\%, levemente superior as taxas de acerto com os descritores D2 e D1D2 que foram de 99,95\% para ambos. Considerando o D1, as esferas constituem a classe de sólido com resultados mais confiáveis, obtendo-se $100 \%$ de sensibilidade e precisão, mesmo após a validação das mesmas. Dessa forma, presume-se que todas as esferas presentes em uma determinada cena serão identificadas corretamente pela metodologia.

A viabilidade da reconstrução dos sólidos visando a redução do tamanho do modelo pode ser observada na Tabela 5.8. Os resultados são referentes com base nas instâncias da Tabela 5.5. Foram considerados que os objetos representados como malha triangulares são descritos pelos seus vértices já posicionados no espaço do mundo e os triângulos são descritos pela indexação desses vértices. Já os objetos 
paramétricos são representados pelos valores necessários para a instanciação dos mesmos no mundo.

De posse das análises realizadas, o classificador D1 também foi utilizado para a identificação de sólidos paramétricos em 19 módulos de modelos CAD de refinarias e plataformas de petróleo. No total, os 19 modelos utilizados possuem 1.360.819 objetos, onde 1.140.577 foram reconstruídos, representando assim uma taxa de aproximadamente $83,81 \%$ de detecção. Os testes foram executados em uma máquina com processador Intel(R) Core(TM) i7-3632QM CPU @ 2.20GHz e com memória de 8GiB SODIMM DDR3 Synchronous 1600 MHz, nesta configuração o resultado para os 19 módulos foram obtidos em aproximadamente 3,56 horas de execução. A Tabela 5.9 exibe detalhadamente os resultados obtidos para cada uma das classes de sólidos nestes modelos. Houve ainda uma redução de aproximadamente $76,73 \%$ no total da quantidade de triângulos utilizados nas malhas dos 19 modelos. Inicialmente, as geometrias dos 19 modelos CAD somavam aproximidamente $2 \mathrm{~GB}$ de dados, enquanto que após a utilização da metodologia apresentada, este valor caiu para aproximadamente $793 \mathrm{MB}$, representando uma redução de aproximadamente $65,07 \%$ no tamanho desses modelos.

Uma dificuldade comumente enfrentada na avaliação da eficicácia de metodologias de engenharia reversa, consiste na dificuldade de verificar a corretude dos resultados obtidos. Esta dificuldade reside no fato de que pelo fato dos objetos originais estarem representados como malha, não é possível automatizar o processo de validação dos resultados. Dessa forma, alguns autores utilizam em seus testes somente casos controlados, não realizando uma bateria exaustiva de testes, como em (Bénière et al., 2011) e (Yiu IP et al., 2002). Outra abordagem baseiase na renderização e verificação visual dos resultados obtidos para a detecção de inconsistências no modelo. Uma codificação de mapa de cores é utilizada para cada uma das classes de sólidos obtidas, facilitando assim esta atividade 5.3. Utilizando esta última abordagem nos resultados descritos na Tabela 5.9, não foram encontrados objetos inconsistentes decorrentes de resultados falsos positivos.

Em se tratando de perfomance, a engenharia reversa de 6.000 sólidos (1.000 para cada classe) foi realizada em 120,421 segundos. Os testes foram realizados em uma máquina com Intel(R) Core(TM) i7 CPU 870 e memória DIMM DDR3 1333 MHz. 
Tabela 5.2: Resultados obtidos para 1.000.000 de instâncias de cada classe de sólido com o uso do descritor D1. Resultados sem a etapa de validação.

\begin{tabular}{|c|c|c|c|c|c|c|c|}
\hline & Malha & Caixa & Cone & Cilindro & $\begin{array}{c}\text { Esferoide } \\
\text { Oblato }\end{array}$ & Pirâmide & Esfera \\
\hline Caixa & 0 & 999.721 & 5 & 0 & 0 & 274 & 0 \\
\hline Cone & 0 & 0 & 998.547 & 945 & 0 & 508 & 0 \\
\hline Cilindro & 0 & 0 & 23 & 999.977 & 0 & 0 & 0 \\
\hline $\begin{array}{c}\text { Esferoide } \\
\text { Oblato }\end{array}$ & 0 & 0 & 0 & 0 & 1.000 .000 & 0 & 0 \\
\hline Pirâmide & 0 & 1 & 0 & 0 & 0 & 999.999 & 0 \\
\hline Esfera & 0 & 0 & 0 & 0 & 0 & 0 & 1.000 .000 \\
\hline \hline Precisão & - & 0,9999 & 0,9999 & 0,9990 & 1 & 0,9992 & 1 \\
\hline Sensibilidade & - & 0,9997 & 0,9985 & 0,9999 & 1 & 0,9999 & 1 \\
\hline Acurácia & & \multicolumn{7}{|l|}{$\mathbf{9 9 , 9 7 \%}$} \\
\hline
\end{tabular}

Tabela 5.3: Resultados obtidos para 1.000.000 de instâncias de cada classe de sólido com o uso do descritor D2. Resultados sem a etapa de validação.

\begin{tabular}{|c|c|c|c|c|c|c|c|}
\hline & Malha & Caixa & Cone & Cilindro & $\begin{array}{c}\text { Esferoide } \\
\text { Oblato }\end{array}$ & Pirâmide & Esfera \\
\hline Caixa & 0 & 999.696 & 0 & 0 & 0 & 304 & 0 \\
\hline Cone & 0 & 0 & 998.808 & 1.017 & 4 & 171 & 0 \\
\hline Cilindro & 0 & 0 & 4 & 999.996 & 0 & 0 & 0 \\
\hline $\begin{array}{c}\text { Esferoide } \\
\text { Oblato }\end{array}$ & 0 & 0 & 0 & 0 & 1.000 .000 & 0 & 0 \\
\hline Pirâmide & 0 & 695 & 377 & 0 & 0 & 998.928 & 0 \\
\hline Esfera & 0 & 0 & 0 & 0 & 0 & 0 & 1.000 .000 \\
\hline \hline Precisão & - & 0,9993 & 0,9996 & 0,9989 & 0,9999 & 0,9995 & 1 \\
\hline Sensibilidade & - & 0,9996 & 0,9988 & 0,9999 & 1 & 0,9989 & 1 \\
\hline Acurácia & & \multicolumn{7}{|c|}{$\mathbf{9 9 , 9 5 \%}$} \\
\hline
\end{tabular}

Tabela 5.4: Resultados obtidos para 1.000.000 de instâncias de cada classe de sólido com o uso do descritor D1D2. Resultados sem a etapa de validação.

\begin{tabular}{|c|c|c|c|c|c|c|c|}
\hline & Malha & Caixa & Cone & Cilindro & $\begin{array}{c}\text { Esferoide } \\
\text { Oblato }\end{array}$ & Pirâmide & Esfera \\
\hline Caixa & 0 & 999.976 & 23 & 0 & 0 & 1 & 0 \\
\hline Cone & 0 & 0 & 997.366 & 2.634 & 0 & 0 & 0 \\
\hline Cilindro & 0 & 0 & 36 & 999.964 & 0 & 0 & 0 \\
\hline $\begin{array}{c}\text { Esferoide } \\
\text { Oblato }\end{array}$ & 0 & 0 & 0 & 0 & 1.000 .000 & 0 & 0 \\
\hline Pirâmide & 0 & 0 & 0 & 0 & 0 & 1.000 .000 & 0 \\
\hline Esfera & 0 & 0 & 0 & 0 & 0 & 0 & 1.000 .000 \\
\hline \hline Precisão & - & 1 & 0,9999 & 0,9973 & 1 & 0,9999 & 1 \\
\hline Sensibilidade & - & 0,9999 & 0,9973 & 0,9999 & 1 & 1 & 1 \\
\hline Acurácia & & \multicolumn{7}{|c|}{$\mathbf{9 9 , 9 5 \%}$} & & \\
\hline
\end{tabular}


Tabela 5.5: Resultados obtidos para 1.000.000 de instâncias de cada classe de sólido com o uso do descritor D1. Resultados com a etapa de validação.

\begin{tabular}{|c|c|c|c|c|c|c|c|}
\hline & Malha & Caixa & Cone & Cilindro & $\begin{array}{c}\text { Esferoide } \\
\text { Oblato }\end{array}$ & Pirâmide & Esfera \\
\hline Caixa & 283 & 999.717 & 0 & 0 & 0 & 0 & 0 \\
\hline Cone & 1.453 & 0 & 998.547 & 0 & 0 & 0 & 0 \\
\hline Cilindro & 12.484 & 0 & 0 & 987.516 & 0 & 0 & 0 \\
\hline $\begin{array}{c}\text { Esferoide } \\
\text { Oblato }\end{array}$ & 80 & 0 & 0 & 0 & 999.920 & 0 & 0 \\
\hline Pirâmide & 1 & 0 & 0 & 0 & 0 & 999.999 & 0 \\
\hline Esfera & 0 & 0 & 0 & 0 & 0 & 0 & 1.000 .000 \\
\hline \hline Precisão & - & 1 & 1 & 1 & 1 & 1 & 1 \\
\hline Sensibilidade & - & 0,9997 & 0,9985 & 0,9875 & 0,9999 & 0,9999 & 1 \\
\hline Acurácia & & & \multicolumn{7}{|c|}{$\mathbf{9 9 , 7 6 \%}$} \\
\hline
\end{tabular}

Tabela 5.6: Resultados obtidos para 1.000.000 de instâncias de cada classe de sólido com o uso do descritor D2. Resultados com a etapa de validação.

\begin{tabular}{|c|c|c|c|c|c|c|c|}
\hline & Malha & Caixa & Cone & Cilindro & $\begin{array}{c}\text { Esferoide } \\
\text { Oblato }\end{array}$ & Pirâmide & Esfera \\
\hline Caixa & 307 & 999.693 & 0 & 0 & 0 & 0 & 0 \\
\hline Cone & 1.192 & 0 & 998.808 & 0 & 0 & 0 & 0 \\
\hline Cilindro & 12.328 & 0 & 0 & 987.672 & 0 & 0 & 0 \\
\hline $\begin{array}{c}\text { Esferoide } \\
\text { Oblato }\end{array}$ & 72 & 0 & 0 & 0 & 999.928 & 0 & 0 \\
\hline Pirâmide & 1.072 & 0 & 0 & 0 & 0 & 998.928 & 0 \\
\hline Esfera & 0 & 0 & 0 & 0 & 0 & 0 & 1.000 .000 \\
\hline \hline Precisão & - & 1 & 1 & 1 & 1 & 1 & 1 \\
\hline Sensibilidade & - & 0,9996 & 0,9988 & 0,9876 & 0,9999 & 0,9989 & 1 \\
\hline Acurácia & & \multicolumn{7}{|c|}{$\mathbf{9 9 , 7 5 \%}$} \\
\hline
\end{tabular}

Tabela 5.7: Resultados obtidos para 1.000.000 de instâncias de cada classe de sólido com o uso do descritor D1D2. Resultados com a etapa de validação.

\begin{tabular}{|c|c|c|c|c|c|c|c|}
\hline & Malha & Caixa & Cone & Cilindro & $\begin{array}{c}\text { Esferoide } \\
\text { Oblato }\end{array}$ & Pirâmide & Esfera \\
\hline Caixa & 25 & 999.975 & 0 & 0 & 0 & 0 & 0 \\
\hline Cone & 2.634 & 0 & 997.366 & 0 & 0 & 0 & 0 \\
\hline Cilindro & 12.418 & 0 & 0 & 987.582 & 0 & 0 & 0 \\
\hline $\begin{array}{c}\text { Esferoide } \\
\text { Oblato }\end{array}$ & 74 & 0 & 0 & 0 & 999.926 & 0 & 0 \\
\hline Pirâmide & 0 & 0 & 0 & 0 & 0 & 1.000 .000 & 0 \\
\hline Esfera & 0 & 0 & 0 & 0 & 0 & 0 & 1.000 .000 \\
\hline \hline Precisão & - & 1 & 1 & 1 & 1 & 1 & 1 \\
\hline Sensibilidade & - & 0,9999 & 0,9973 & 0,9875 & 0,9999 & 1 & 1 \\
\hline Acurácia & & \multicolumn{7}{|c|}{$\mathbf{9 9 , 7 4 \%}$} & & \\
\hline
\end{tabular}


Tabela 5.8: Comparativo da redução do tamanho dos objetos. Resultados obtidos para 1.000.000 de instâncias de cada classe de objeto utilizando o descritor D1.

\begin{tabular}{|c|c|c|c|c|c|c|}
\cline { 2 - 7 } \multicolumn{1}{c|}{} & \multicolumn{3}{c|}{ Triângulos } & \multicolumn{3}{c|}{ Tamanho (KB) } \\
\cline { 2 - 7 } \multicolumn{1}{c|}{} & Original & Resultado & $\begin{array}{c}\text { Redução } \\
(\mathbf{\%})\end{array}$ & Original & Resultado & $\begin{array}{c}\text { Redução } \\
(\%)\end{array}$ \\
\hline Caixa & 12.000 .000 & 3.396 & 99,97 & 703.125 & $35.345,29$ & 94,97 \\
\hline Cone & 60.000 .000 & 87.180 & 99,85 & 2.203 .125 & $46.107,46$ & 97,91 \\
\hline Cilindro & 60.000 .000 & 749.040 & 98,75 & 2.203 .125 & $62.221,17$ & 97,18 \\
\hline $\begin{array}{c}\text { Esferoide } \\
\text { Oblato }\end{array}$ & 240.000 .000 & 19.200 & 99,99 & $5.835 .937,50$ & $35.620,31$ & 99,39 \\
\hline Pirâmide & 12.000 .000 & 12 & 100 & 703.125 & $62.500,64$ & 91,11 \\
\hline Esfera & 480.000 .000 & 0 & 100 & 11.296 .875 & $35.156,25$ & 99,69 \\
\hline \hline Total & $\mathbf{8 6 4 . 0 0 0 . 0 0 0}$ & $\mathbf{8 5 8 . 8 2 8}$ & $\mathbf{9 9 , 9 0}$ & $\mathbf{2 2 . 9 4 5 . 3 1 2 , 5 0}$ & $\mathbf{2 7 6 . 9 5 1 , 1 2}$ & $\mathbf{9 8 , 7 9}$ \\
\hline
\end{tabular}

Tabela 5.9: Objetos recuperados em 19 módulos de modelos CAD.

\begin{tabular}{|c|c|c|c|c|c|c|c|}
\hline \#Modelo & Malha & Caixa & Cone & Cilindro & $\begin{array}{c}\text { Esferoide } \\
\text { Oblato }\end{array}$ & Pirâmide & Esfera \\
\hline $\mathbf{1}$ & 10.418 & 162.418 & 0 & 11.467 & 1.768 & 201 & 2.226 \\
\hline $\mathbf{2}$ & 912 & 30.053 & 0 & 11.920 & 230 & 75 & 0 \\
\hline $\mathbf{3}$ & 1.144 & 48.632 & 0 & 6.924 & 260 & 25 & 34 \\
\hline $\mathbf{4}$ & 1.196 & 78.384 & 3 & 11.796 & 106 & 28 & 1.020 \\
\hline $\mathbf{5}$ & 15.333 & 15.211 & 77 & 53.129 & 685 & 551 & 67 \\
\hline $\mathbf{6}$ & 3.042 & 38.010 & 0 & 10.796 & 189 & 3 & 0 \\
\hline $\mathbf{7}$ & 16.590 & 9.516 & 69 & 45.835 & 308 & 395 & 145 \\
\hline $\mathbf{8}$ & 1.936 & 1.509 & 0 & 8.794 & 223 & 30 & 25 \\
\hline $\mathbf{9}$ & 4.289 & 8.336 & 0 & 13.035 & 99 & 6 & 0 \\
\hline $\mathbf{1 0}$ & 12.502 & 37.947 & 0 & 15.299 & 0 & 170 & 4 \\
\hline $\mathbf{1 1}$ & 29.979 & 18.420 & 6 & 101.392 & 2.457 & 411 & 233 \\
\hline $\mathbf{1 2}$ & 4.242 & 14.818 & 0 & 6.344 & 1.694 & 207 & 2 \\
\hline $\mathbf{1 3}$ & 3.149 & 30.927 & 2 & 21.385 & 32 & 0 & 1.325 \\
\hline $\mathbf{1 4}$ & 4.864 & 21.484 & 0 & 11 & 0 & 15 & 0 \\
\hline $\mathbf{1 5}$ & 9.357 & 6.664 & 0 & 18.027 & 637 & 138 & 951 \\
\hline $\mathbf{1 6}$ & 14.751 & 5.038 & 0 & 9.872 & 186 & 21 & 28 \\
\hline $\mathbf{1 7}$ & 64.901 & 185.011 & 2 & 15.266 & 0 & 289 & 278 \\
\hline $\mathbf{1 8}$ & 9.381 & 15.508 & 0 & 6.905 & 0 & 407 & 0 \\
\hline $\mathbf{1 9}$ & 12.256 & 25.325 & 0 & 752 & 0 & 9 & 65 \\
\hline \hline $\mathbf{T o t a l}$ & $\mathbf{2 2 0 . 2 4 2}$ & $\mathbf{7 5 3 . 2 1 1}$ & $\mathbf{1 5 9}$ & $\mathbf{3 6 8 . 9 4 9}$ & $\mathbf{8 . 8 7 4}$ & $\mathbf{2 . 9 8 1}$ & $\mathbf{6 . 4 0 3}$ \\
\hline
\end{tabular}


Tabela 5.10: Redução na quantidade de triângulos e do tamanho de 19 módulos de modelos CAD.

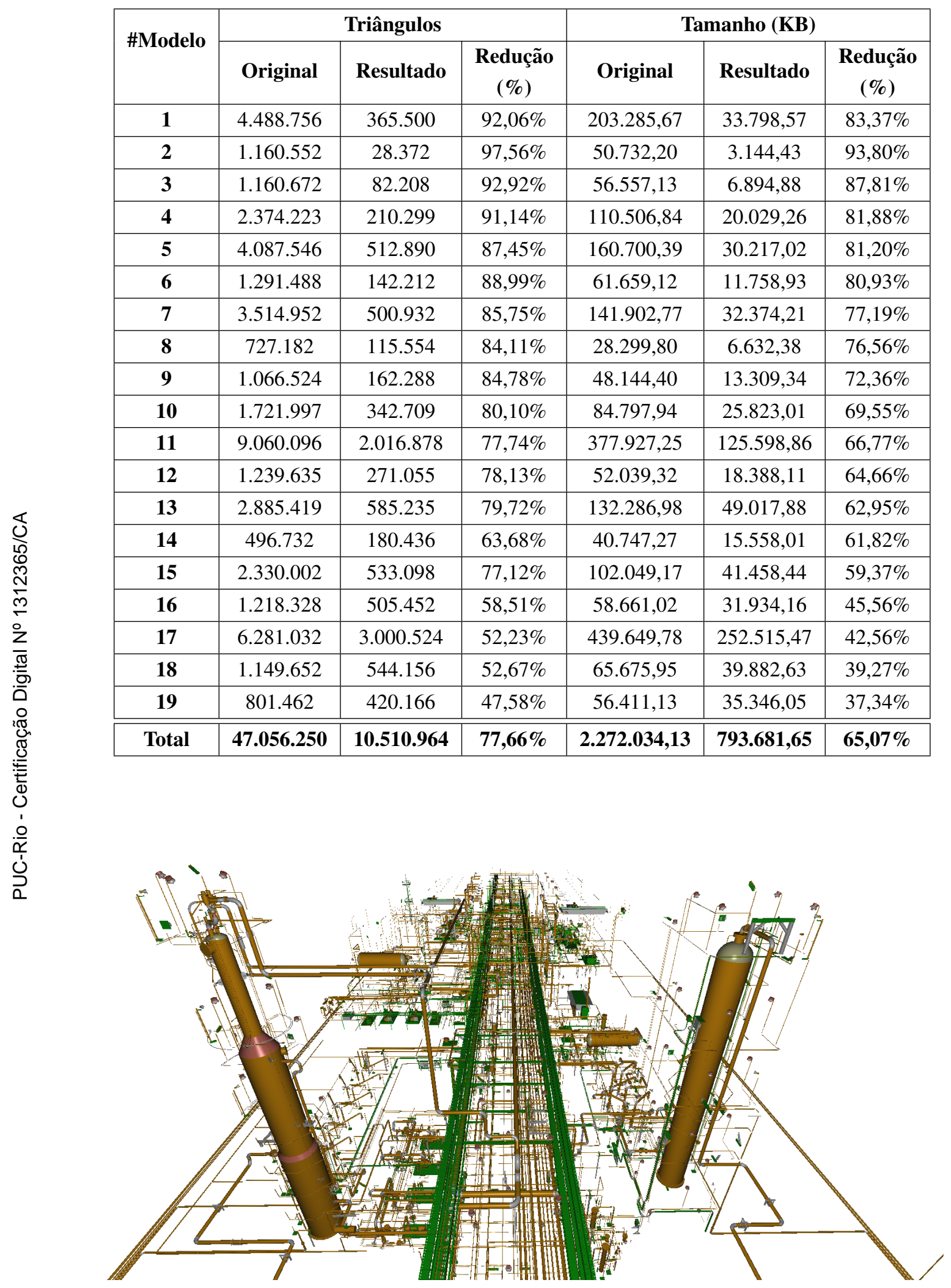

Figura 5.3: Resultado visual, através de mapa de cores, obtido com a técnica de engenharia reversa em um modelo CAD. 


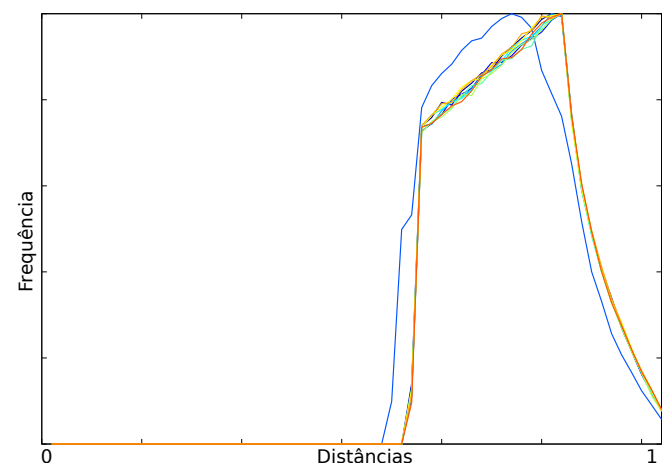

(a)Caixas

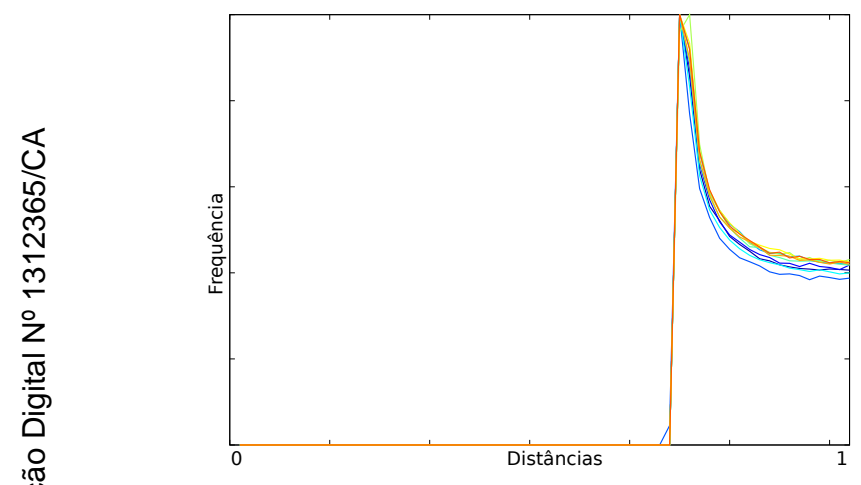

(c)Cilindros

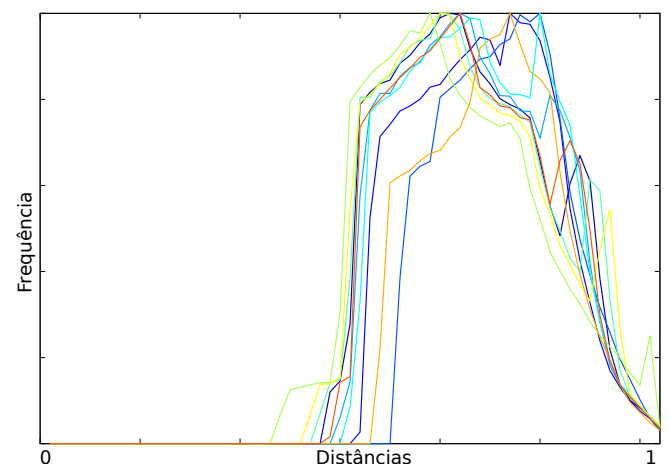

(e)Pirâmides

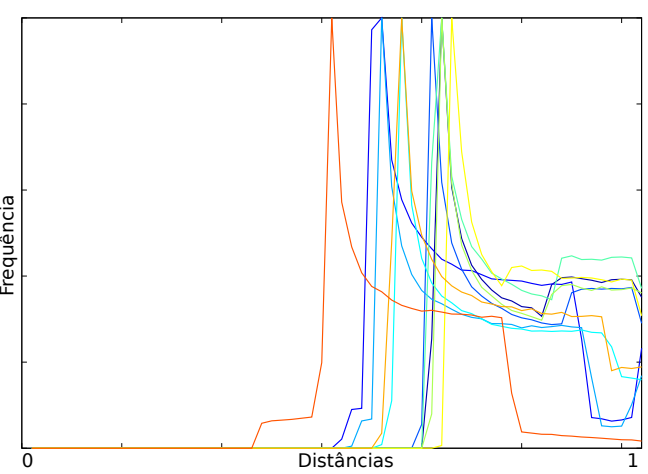

(b)Cones

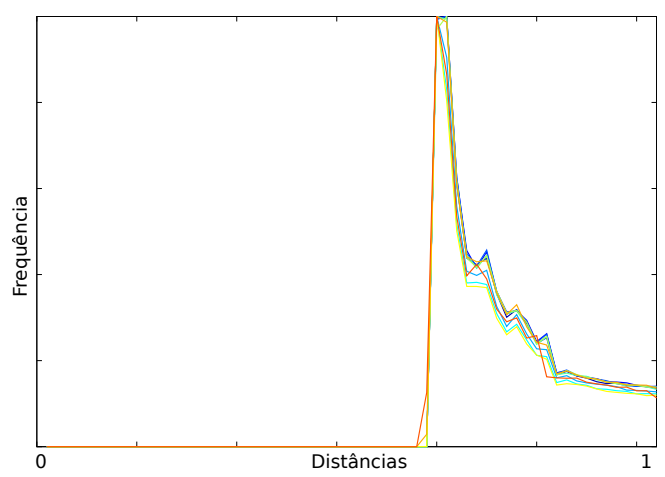

(d)Esferoides Oblatos

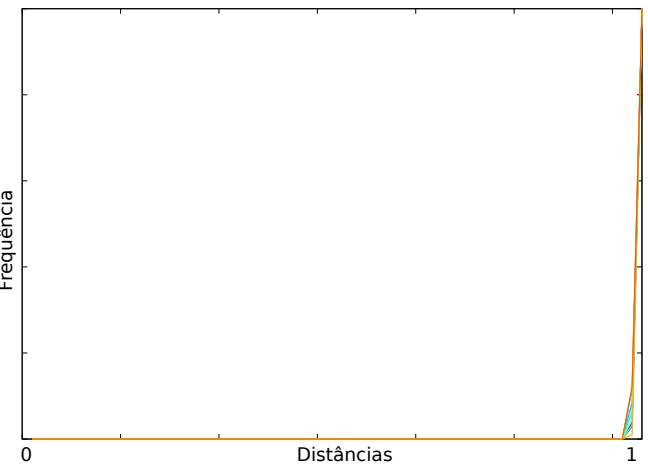

(f)Esferas

Figura 5.4: Histogramas obtidos com o descritor D1 para 10 instâncias de cada classe de sólido. 


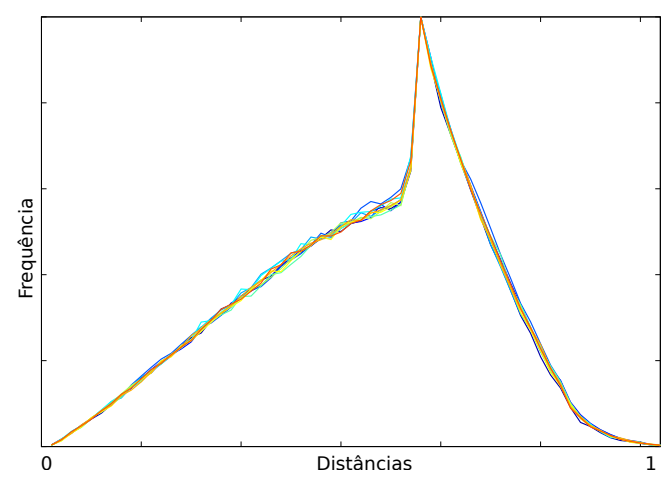

(a)Caixas

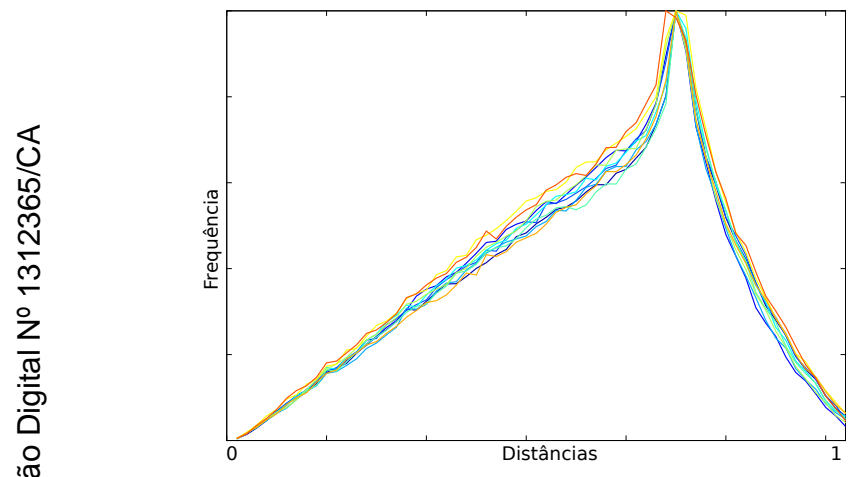

(c)Cilindros

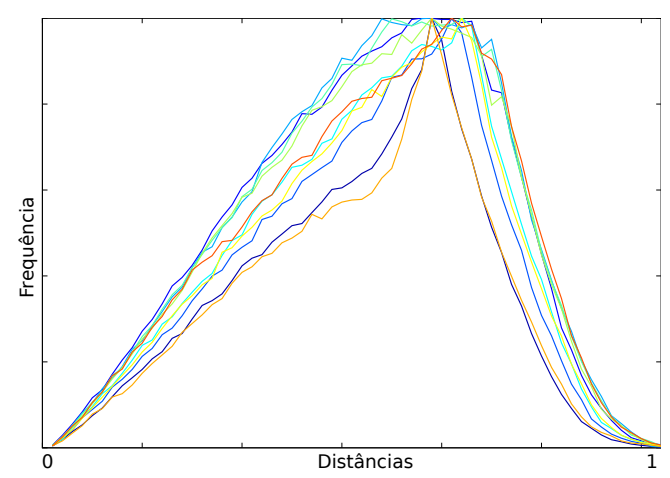

(e)Pirâmides

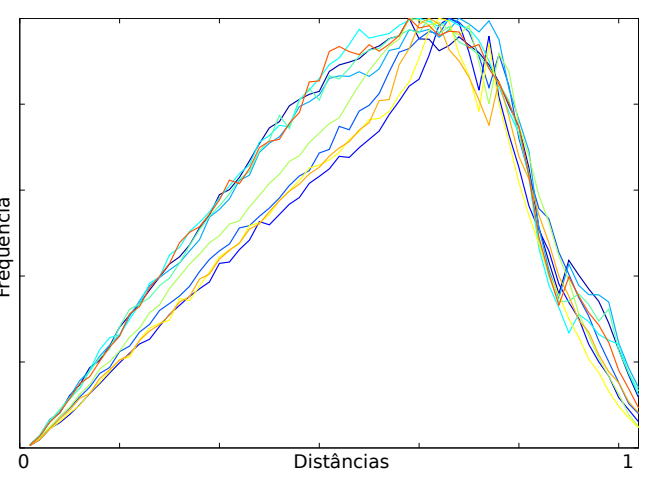

(b)Cones

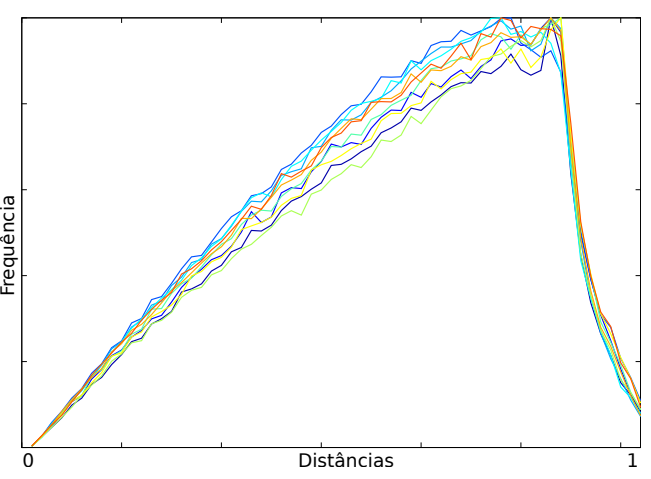

(d)Esferoides Oblatos

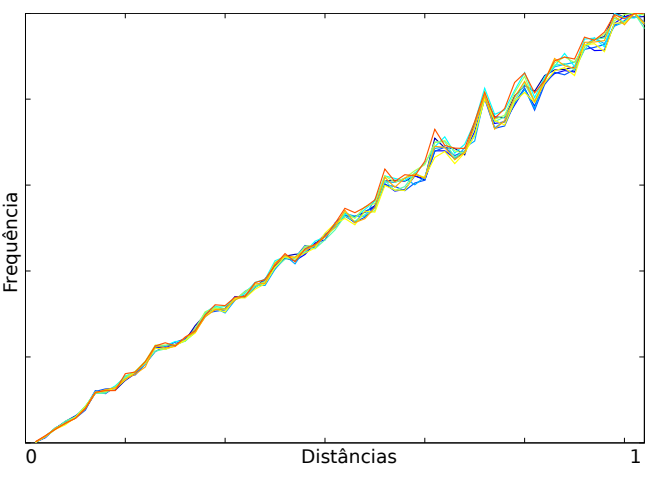

(f)Esferas

Figura 5.5: Histogramas obtidos com o descritor D2 para 10 instâncias de cada classe de sólido. 


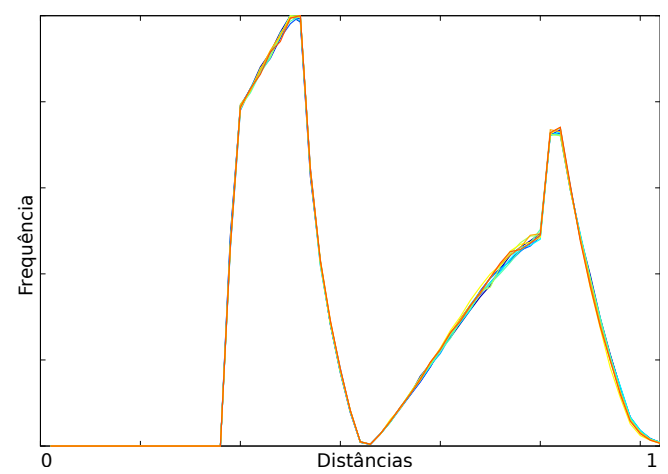

(a)Caixas

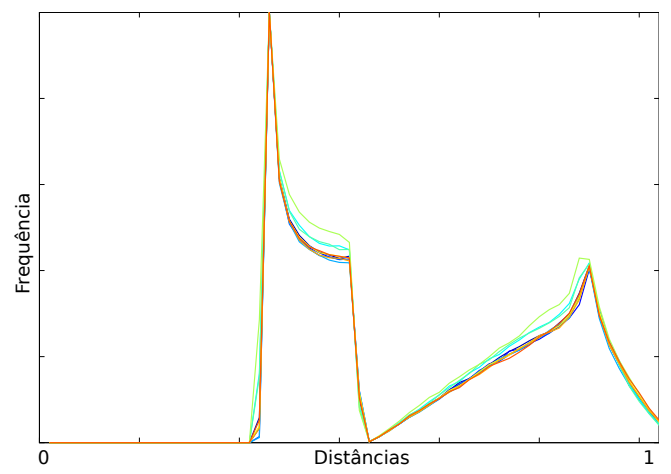

(c)Cilindros

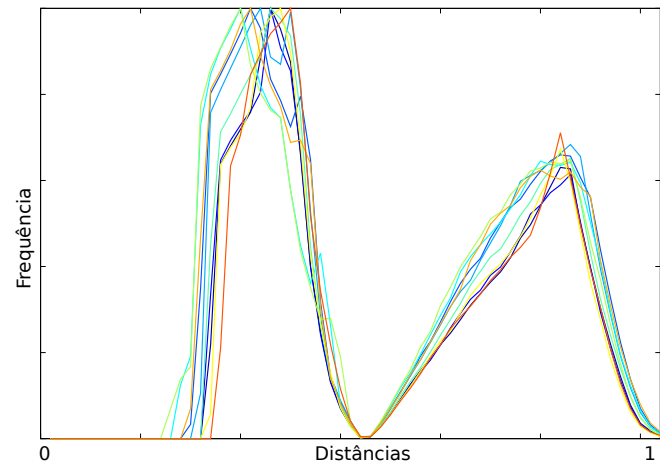

(e)Pirâmides

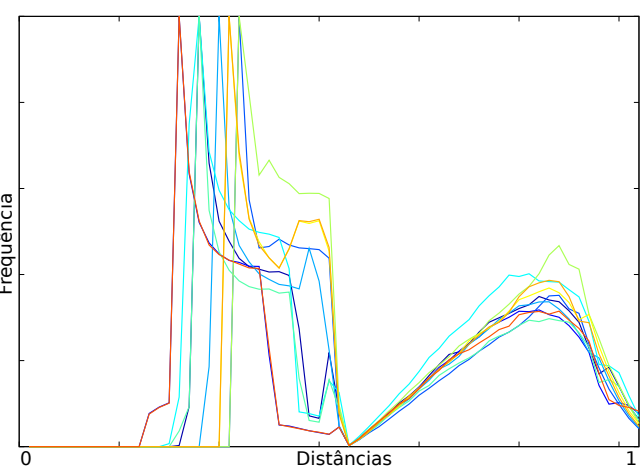

(b)Cones

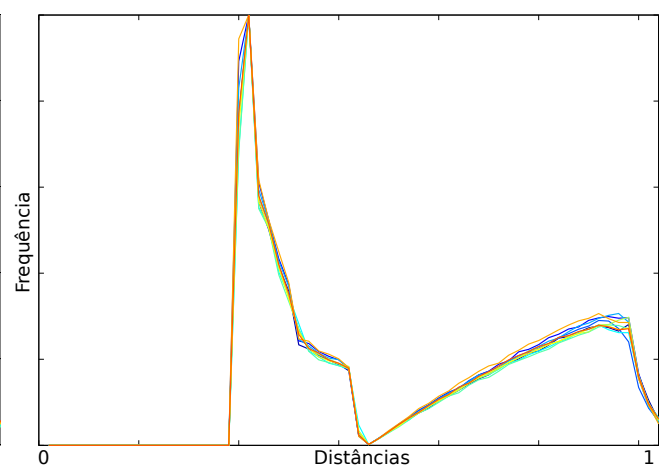

(d)Esferoides Oblatos

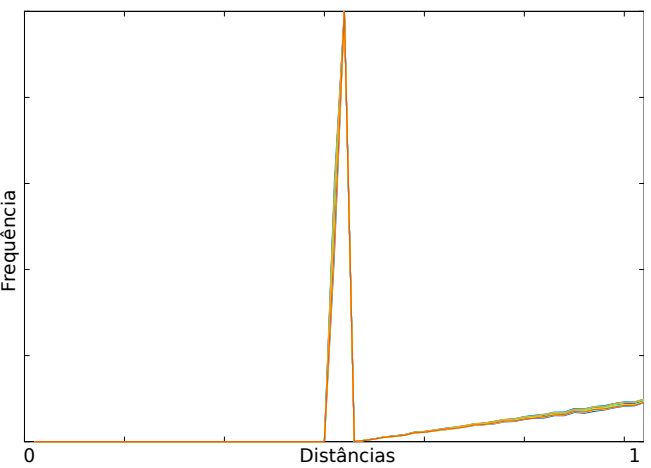

(f)Esferas

Figura 5.6: Histogramas obtidos com o descritor D1D2 para 10 instâncias de cada classe de sólido. 


\section{6 \\ Conclusões e Trabalhos Futuros}

Técnicas de engenharia reversa de objetos têm sido utilizadas em modelos CAD com diversas finalidades. Em modelos CAD, a engenharia reversa tem sido utilizada para a conversão de malhas triangulares para representações contínuas, como a paramétrica. Esta representação oferece inúmeras vantagens se comparada à malha de triângulos, entre elas: capacidade de obter resultados numéricos mais precisos, representação mais compacta da superfície, eliminação de ambiguidades.

Significativa parte das técnicas existentes são sensíveis à topologia da malha, falhando quando esta não está conforme esperado. Dessa forma, uma das contribuições da metodologia descrita neste trabalho está no fato da mesma ser invariante à triangulação da malha, triângulos degenerados e resolução da malha. Tais características foram possibilitadas pela utilização dos descritores de forma como vetores de características.

Ademais, o fato da técnica proposta não ser dependente da topologia da malha, devido à conversão desta em nuvem de pontos, conferiu à técnica a possibilidade de também ser utilizada para a reconstrução de superfícies através de uma nuvem de pontos. Tal característica é de grande utilidade em consequência do crescimento da popularidade desta representação, ao passo em que é cada vez mais comum a utilização de escâner a laser para aquisição de superfícies de empreendimentos já construídos.

Outro ponto forte da metodologia apresentada está relacionado ao número de classes abordadas. Enquanto os demais trabalhos suportam um número limitado de classes, três ou quatro classes de sólidos, neste trabalho foram abordadas seis classes de sólidos: caixa, cilindro, cone, esferoide oblato, esfera e pirâmide. De fato, quanto mais classes são introduzidas em uma técnica de engenharia reversa, maior será a dificuldade na utilização de uma abordagem capaz de diferenciar corretamente cada uma das classes. Esta limitação surge da dificuldade em extrair características que possam diferenciar cada uma das classes sem ambiguidades.

Os resultados obtidos nos testes realizados apontam a viabilidade da metodologia proposta. Os três descritores de forma (D1, D2 e D1D2) apresentaram boa taxa de acurácia, com $100 \%$ de precisão, logo, sem falsos positivos. A ausência de falsos positivos se deu, principalmente, pela utilização da etapa de validação. $\mathrm{O}$ 
bom desempenho da técnica proporcionou uma diminuição expressiva no tamanho dos modelos CAD que foram utilizados no teste, aproximadamente $63 \%$ do tamanho original. Entre os fatores determinantes para o sucesso da metodologia, vale apontar a utilização do método PCA para o alinhamento e padronização da escala, bem como a seleção dos parâmetros da SVM utilizando o grid search com validação cruzada por meio do algoritmo $k$-fold.

É comum encontrar nos modelos CAD outros tipos de sólidos paramétricos que não foram abordadas neste trabalho: torus circular, torus retangular, cilindro com deslocamento no eixo longitudinal, entre outros. Para incluir estas classes de sólidos neste trabalho, é necessário produzir um vetor de característica unívoco para cada uma das classes de sólido. Conforme descrito anteriormente, esta não é uma tarefa simples. Alguns desses sólidos, como os torus por exemplo, não apresentam vetores de características discriminantes com a utilização dos descritores de forma utilizados. Uma alternativa para a inclusão desses sólidos seria a realização da classificação de modo semelhante as SVMs baseadas em Grafos Dirigidos Acíclicos (Seção 3.5.1). Dessa forma, em cada nível do grafo seria utilizada uma característica particular para diferenciar grupos de tipos de sólidos. Outra alternativa reside na adoção de um histograma de forma baseado na curvatura dos objetos (Ip e Regli, 2005).

Para a aquisição de métricas que reflitam o desempenho da classificação em modelos CAD, é preciso que os objetos estejam rotulados. A validação dos resultados obtidos nestes modelos através da visualização dos objetos codificados em mapa de cores é uma tarefa repetitiva, que requer atenção e sujeita a erros. Logo, deseja-se utilizar futuramente os dados de engenharia do objeto como indicativo de validação.

Por fim, diferentemente das técnicas apresentadas nos trabalhos relacionados - onde a segmentação, classificação e reconstrução da forma são realizadas em fases altamente acopladas -, a metodologia apresentada é construída de forma modular. Essa modularização garante que as etapas da metodologia estejam fracamente acopladas, permitindo a realização de mudanças em cada uma dessas sem a necessidade de alterar as demais. Portanto, pouco esforço será requerido caso a curvatura seja adotada como descritor. 


\section{Referências Bibliográficas}

[Ankerst et al., 1999] ANKERST, M.; KASTENMÜLLER, G.; KRIEGEL, H.P. ; SEIDL, T.. 3d shape histograms for similarity search and classification in spatial databases. In: ADVANCES IN SPATIAL DATABASES, p. 207226. Springer, 1999. 3.2, 3.4

[Benko et al., 2002] BENKO, P.; KÓS, G.; VÁRADY, T.; ANDOR, L. ; MARTIN, R.. Constrained fitting in reverse engineering. Computer Aided Geometric Design, 19(3):173-205, 2002. 2

[Biasotti et al., 2008] BIASOTTI, S.; GIORGI, D.; SPAGNUOLO, M. ; FALCIDIENO, B.. Reeb graphs for shape analysis and applications. Theoretical Computer Science, 392(1):5-22, 2008. 3.2

[Böhm e Brenner, 2000] BÖHM, J.; BRENNER, C.. Curvature-based range image classification for object recognition. In: INTELLIGENT SYSTEMS AND SMART MANUFACTURING, p. 211-220. International Society for Optics and Photonics, 2000. 2, 2.5

[Bénière et al., 2011] BÉNIÈRE, R.; SUBSOL, G.; GESQUIÈRE, G.; LE BRETON, F. ; PUECH, W.. Recovering primitives in 3d cad meshes. In: IS\&T/SPIE ELECTRONIC IMAGING, p. 78640R-78640R. International Society for Optics and Photonics, 2011. 2, 2.4, 5

[Cai et al., 1996] CAI, Y.; NEE, A. ; LOH, H.. Geometric feature detection for reverse engineering using range imaging. Journal of visual communication and image representation, 7(3):205-216, 1996. 2

[Chua e Jarvis, 1997] CHUA, C. S.; JARVIS, R.. Point signatures: A new representation for 3d object recognition. International Journal of Computer Vision, 25(1):63-85, 1997. 3.2

[Cicirello e Regli, 2001] CICIRELLO, V.; REGLI, W. C.. Machining featurebased comparisons of mechanical parts. In: SHAPE MODELING AND APPLICATIONS, SMI 2001 INTERNATIONAL CONFERENCE ON., p. 176-185. IEEE, 2001. 3.2 
[Cortes e Vapnik, 1995] CORTES, C.; VAPNIK, V.. Support-vector networks. Machine learning, 20(3):273-297, 1995. 3.5.2

[Delponte et al., 2009] DELPONTE, E.; BASSO, C.; ODONE, F. ; PUPPO, E.. Improving 3d shape retrieval with svm. In: GRAPP, p. 46-51, 2009. 3.2

[Gao et al., 2010] GAO, S.; ZHAO, W.; LIN, H.; YANG, F. ; CHEN, X.. Feature suppression based cad mesh model simplification. ComputerAided Design, 42(12):1178-1188, 2010. 1.2

[Hakala et al., 1981] HAKALA, D.; HILLYARD, R.; MALRAISON, P. ; NOURCE, B.. Natural quadrics in mechanical design. Proc-AUTOFACT West, 1:17-20, 1981. 1.1

[Hartmann et al., 2008] HARTMANN, T.; GAO, J. ; FISCHER, M.. Areas of application for $3 \mathbf{d}$ and $4 \mathbf{d}$ models on construction projects. Journal of Construction Engineering and management, 134(10):776-785, 2008. 1.1

[Hoffmann, 1989] HOFFMANN, C. M.. Geometric and solid modeling. Morgan Kaufmann, 1989. 3.2

[Hsu et al., 2003] HSU, C.-W.; CHANG, C.-C.; LIN, C.-J. ; OTHERS. A practical guide to support vector classification, 2003. 5

[Ip e Regli, 2005] IP, C. Y.; REGLI, W. C.. Manufacturing classification of cad models using curvature and svms. In: SHAPE MODELING AND APPLICATIONS, 2005 INTERNATIONAL CONFERENCE, p. 361-365. IEEE, 2005. 6

[Koenderink, 1990] KOENDERINK, J. J.. Solid shape, volumen 2. Cambridge Univ Press, 1990. 3.2

[Koo e Fischer, 2000] KOO, B.; FISCHER, M.. Feasibility study of 4d cad in commercial construction. Journal of construction engineering and management, 126(4):251-260, 2000. 1.1

[Lavva et al., 2008] LAVVA, I.; HAMEIRI, E. ; SHIMSHONI, I.. Robust methods for geometric primitive recovery and estimation from range images. Systems, Man, and Cybernetics, Part B: Cybernetics, IEEE Transactions on, 38(3):826-845, 2008. 2 
[Lukács et al., 1997] LUKÁCS, G.; MARSHALL, A. ; MARTIN, R.. Geometric least-squares fitting of spheres, cylinders, cones and tori. RECCAD, Deliverable Document 2 and 3, COPERNICUS project, (1068), 1997. 4

[McWherter et al., 2001] MCWHERTER, D.; PEABODY, M.; SHOKOUFANDEH, A. ; REGLI, W.. Transformation invariant similarity assessment of solid models. In: ASME DESIGN ENGINEERING TECHNICAL CONFERENCES, ASME, ASME PRESS. DETC2001/DFM-21191, 2001. 4.1.1

[Osada et al., 2002] OSADA, R.; FUNKHOUSER, T.; CHAZELLE, B. ; DOBKIN, D.. Shape distributions. ACM Transactions on Graphics (TOG), 21:807-832, 2002. 3.2, 3.2, 3.3, 3.7, 3.9, 1, 2, 4.1, 5

[Parvin e Medioni, 1982] PARVIN, B.; MEDIONI, G.. Segmentation of range images into planar surfaces by split and merge. In: PROC. OF INTERNATIONAL CONFERENCE ON COMPUTER VISION AND PATTERN RECOGNITION (CVPR'86), p. 415-417, 1986. 4

[Platt et al., 1999] PLATT, J. C.; CRISTIANINI, N. ; SHAWE-TAYLOR, J.. Large margin dags for multiclass classification. In: NIPS, volumen 12, p. $547-553,1999.3 .5 .3,3.16$

[Requicha e Voelcker, 1982] REQUICHA, A. A.; VOELCKER, H. B.. Solid modeling: A historical summary and contemporary assessment. IEEE Computer Graphics and Applications, 2(2):9-24, 1982. 1.1

[Shen et al., 2003] SHEN, Y.-T.; CHEN, D.-Y.; TIAN, X.-P. ; OUHYOUNG, $M$.. 3d model search engine based on lightfield descriptors. EUROGRAPHICS Interactive Demos, Granada, Spain, p. 1-6, 2003. 3.6

[Shum et al., 1996] SHUM, HEUNG-YEUNG AON 3D SHAPE SIMILARITYND HEBERT, M.; IKEUCHI, K.. On 3d shape similarity. In: COMPUTER VISION AND PATTERN RECOGNITION, 1996. PROCEEDINGS CVPR'96, 1996 IEEE COMPUTER SOCIETY CONFERENCE ON, p. 526-531. IEEE, 1996. 3.2

[Sundar et al., 2003] SUNDAR, H.; SILVER, D.; GAGVANI, N. ; DICKINSON, S.. Skeleton based shape matching and retrieval. In: SHAPE MODELING INTERNATIONAL, 2003, p. 130-139. IEEE, 2003. 3.5 
[Tangelder e Veltkamp, 2008] TANGELDER, J. W.; VELTKAMP, R. C.. A survey of content based 3d shape retrieval methods. Multimedia tools and applications, 39(3):441-471, 2008. 3.2

[Thompson et al., 1999] THOMPSON, W. B.; OWEN, J. C.; DE ST GERMAIN, H. J.; STARK JR, S. R. ; HENDERSON, T. C.. Feature-based reverse engineering of mechanical parts. Robotics and Automation, IEEE Transactions on, 15(1):57-66, 1999. 3.1

[Toledo et al., 2008] DE TOLEDO, R.; LÉVY, B. ; PAUL, J.-C.. Reverse engineering for industrial-plant cad models. TMCE, Tools and Methods for Competitive Engineering, p. 1021-1034, 2008. 2, 2.1, 2.2, 2.3

[Vapnik, 1982] VAPNIK, V. N.; KOTZ, S.. Estimation of dependences based on empirical data, volumen 41. Springer-Verlag New York, 1982. 3.5.1, 3.5.1

[Varady et al., 1997] VARADY, T.; MARTIN, R. R. ; COX, J.. Reverse engineering of geometric models-an introduction. Computer-Aided Design, 29(4):255-268, 1997. 2, 3.1, 3.2, 3.1.1

[Wu Leif Kobbelt, 2005] WU LEIF KOBBELT, J.. Structure recovery via hybrid variational surface approximation. In: COMPUTER GRAPHICS FORUM, volumen 24, p. 277-284. Wiley Online Library, 2005. 4

[Yiu IP et al., 2002] IP, C. Y.; LAPADAT, D.; SIEGER, L. ; REGLI, W. C.. Using shape distributions to compare solid models. In: PROCEEDINGS OF THE SEVENTH ACM SYMPOSIUM ON SOLID MODELING AND APPLICATIONS, p. 273-280. ACM, 2002. 5

[Zaharia e Preteux, 2001] ZAHARIA, T.; PRETEUX, F. J.. 3d-shape-based retrieval within the mpeg-7 framework. In: PHOTONICS WEST 2001ELECTRONIC IMAGING, p. 133-145. International Society for Optics and Photonics, 2001. 3.2 